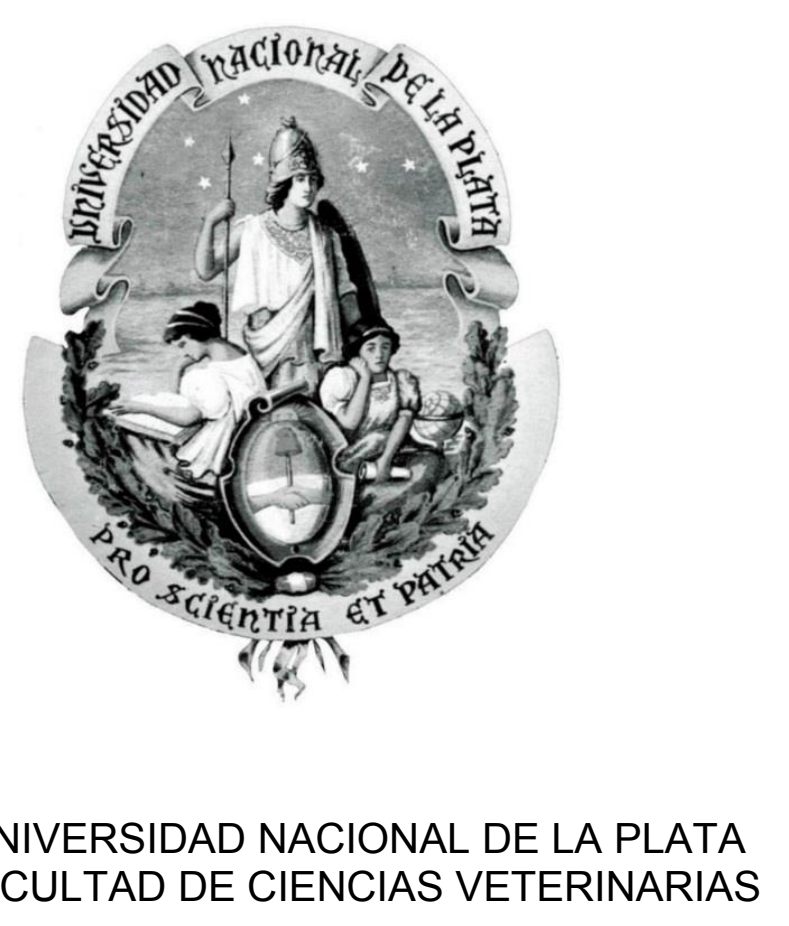

UNIVERSIDAD NACIONAL DE LA PLATA
FACULTAD DE CIENCIAS VETERINARIAS

Trabajo de tesis realizado como requisito para optar al título de DOCTOR EN CIENCIAS VETERINARIAS

\title{
"Dinámica de la infestación por Fasciola hepatica en el sur de la provincia de Entre Ríos"
}

\author{
AUTOR: Pruzzo, Cesar Iván \\ DIRECTOR: Sanabria, Rodrigo E \\ COODIRECTOR: Romero, Jorge \\ LUGAR DE TRABAJO: \\ MIEMBROS DEL JURADO: \\ Dr. Moré Gastón \\ Dra Ribicich Mabel \\ Dr. Unzaga Juan Manuel
}

Centro de Diagnóstico e Investigaciones Veterinarias (CEDIVE)

Facultad de Ciencias Veterinarias. Universidad Nacional de La Plata 
Índice de contenidos

Abreviaturas y símbolos $\quad$ IV

Trabajos presentados en congresos y reuniones científicas VII

Agradecimientos IX

$\begin{array}{ll}\text { Resumen } & 1\end{array}$

Abstract 3

\section{Capítulo 1: Introducción}

1.1 Generalidades $\quad 5$

$\begin{array}{ll}\text { 1.2 Descripción del parásito } & 7\end{array}$

$\begin{array}{ll}1.3 \text { Hospedador definitivo } & 12\end{array}$

$\begin{array}{ll}1.4 \text { Hospedador intermediario } & 15\end{array}$

$\begin{array}{ll}1.5 \text { Control } & 18\end{array}$

$\begin{array}{ll}1.6 \text { Epidemiología } & 18\end{array}$

1.7 Hipótesis 24

$\begin{array}{ll}1.8 \text { Objetivos } & 25\end{array}$

\section{Capítulo 2: Objetivo I}

Dinámica de infestación por Fasciola hepatica en el ganado

2.1 Introducción 26

$\begin{array}{ll}2.2 \text { Materiales y métodos } & 28\end{array}$

2.2.1 Lugares de estudio $\quad 28$

2.2.2 Trabajo de campo y laboratorio 32 
2.2.3 Obtención de datos climáticos, geográficos y confección

de archivos SIG

2.2.4 Determinación del estado de resistencia a drogas

2.2.5 Análisis estadístico

2.3 Resultados

2.4 Discusión

\section{Capítulo 3: Objetivo II}

Análisis de la genética poblacional de Fasciola hepatica en el sur de la provincia de Entre Ríos

3.1 Introducción

3.2 Materiales y métodos

3.3 Resultados

3.4 Discusión

\section{Capítulo 4: Objetivo III A}

Identificación de lymneidos mediante criterios moleculares

4.1 Introducción

4.2 Materiales y métodos

4.2.1 Colecta y procesamiento del hospedador intermediario

4.3 Resultados

4.4 Discusión

\section{Capítulo 5: Objetivo III B}

Abundancia y estructura poblacional de lymneidos 
$\begin{array}{ll}5.1 \text { Introducción } & 78\end{array}$

$\begin{array}{ll}\text { 5.2 Materiales y métodos } & 80\end{array}$

5.3 Resultados $\quad 82$

$\begin{array}{ll}5.4 \text { Discusión } & 84\end{array}$

\section{Capítulo 6: Objetivo IV}

Evaluación de la susceptibilidad de los lymneidos a la infestación por Fasciola hepatica

$\begin{array}{ll}6.1 \text { Introducción } & 88\end{array}$

$\begin{array}{ll}\text { 6.2 Materiales y métodos } & 89\end{array}$

$\begin{array}{ll}6.3 \text { Resultados } & 92\end{array}$

$\begin{array}{ll}6.4 \text { Discusión } & 93\end{array}$

Capítulo 7: Conclusiones $\quad 95$

$\begin{array}{ll}\text { Capítulo 8: Bibliografía } & 100\end{array}$ 


\section{Abreviaturas y símbolos.}

A: adenina

ABZ: albendazol

ADN: acido desoxirribonucleico

ADNmt: acido desoxirribonucleico mitocondrial

AHI: abundancia del hospedador intermediario

${ }^{\circ} \mathrm{C}$ : grados centígrados

cm: centímetros

COI: citocromo oxidasa 1

CSTL: closantel

dNTPs: desoxirribonucleótidos trifosfato

DS: desvió estándar

Fis: coeficiente de endogamia

Fst: índice de fijación

Grs: gramos

G: guanina

HD: hospedador definitivo 
He: heterogenicidad esperada

HI: hospedador Intermediario

Ho: heterogenicidad observada

HPG: huevos por gramo

ICNZ: código internacional de nomenclatura zoológica

kg: kilogramos

mg: miligramos

$\mathrm{MgCl}_{2}$ : cloruro de magnesio

mM: milimolar

MTC: metacercarias

n: número de animales o especímenes muestreados

NADI: nicotinamida adenina dinucleótido 1.

OMS: Organización Mundial de la Salud

pb: pares de bases

PCR: reacción en cadena de la polimerasa

RFLP: polimorfismo en la longitud de los fragmentos de restricción.

S: Tasa de autofecundación

SIG: sistemas de información geográfica 
SRT: secuencias repetidas en tándem

T: timina

$\mathbf{T}^{\circ}:$ temperatura

TCBZ: triclabendazol

TRRH: test de reducción del recuento de huevos

WHO: World Health Organization

$\mu \mathrm{l}$ : microlitros

$\mu \mathrm{m}$ : micras o micrómetros 


\section{Trabajos presentados en congresos y reuniones científicas vinculados}

\section{a esta tesis}

1. First report of Lymnaea neotropica in northeastern Argentina: morphological and molecular identification. Pujadas Julieta,Wisnivesky Cristina, Pruzzo Cesar, Sanabria Rodrigo, Farber Marisa, Prepelitchi Lucila. En: Congreso Mollusca, 2014, México.

2. Fasciola hepatica: spread of albendazole resistance in Central Eastern Argentina. Cesar Pruzzo, Rodrigo Sanabria, Daniel Medus, Giussepe Reyna, Jorge Romero. En:Congreso, Waavp, 2015, Liverpool.

3. Datos de texturas sobre tipos de suelos utilizando Sistemas de Información Geográfica y su correlación con la prevalencia de Fasciola hepatica en el sur de la provincia de Entre Ríos. Pruzzo Cesar Iván, Illanes Federico, Niño Uribe Álvaro, Raffo Fernando, Sanabria Rodrigo. En: Jornada Jóvenes Investigadores UBA, 2017, Buenos Aires.

4. Genetic diversity of Fasciola hepatica isolated from three definitive hosts in Cajamarca's valley, Perú. Giussepe Reyna, Rodrigo Sanabria, Eva Rueda, Cesar Pruzzo, Corpus Cerna, Severino Torrel, Pedro Ortíz. En: 113th International Congress of Parasitology, 2014, México.

5. Cathepsin L3 from Fasciola hepatica induces IL-1 $\beta$ and IL-18 secretion in a NLRP3 dependent manner on dendritic cells. Celias Daiana, Silvane Leonardo, Corvo lleana, Fresno Manuel, Arranz Alicia, Pruzzo César, Sanabria Rodrigo, 
Cervi Laura. En: XII Congress of the Latin American Association of Immunology \& XXIII Congress of the Mexican Society of Immunology, 2018, México.

6. A murine model to assess anthelmintic resistance in Fasciola hepatica: preliminary study. Pruzzo Cesar, Ceballos Laura, Alvarez Luis, Sanabria Rodrigo. En: Congreso Drug discovery for neglected diseases international 4th scientific meeting of resnet npnd, 2018, Buenos Aires.

7. The egg hatch test: A useful tool for albendazole resistance diagnosis in Fasciola hepatica. L Ceballosa Cantona, Cesar Pruzzo, Rodrigo Sanabria, Laura Morenoa, Jaime Sanchis, Gonzalo Suareze, Pedro Ortiz, lan Fairweatherg, Carlos Lanussea, Luis Alvareza, María Martinez Valladar. 2019. Vet Parasitol. 271:7-13. 


\section{Agradecimientos}

Al laboratorio de diagnóstico e investigaciones veterinarias (CEDIVE) de la Universidad Nacional de La Plata, por permitirme realizar este trabajo.

Al laboratorio Maladies Infectieuses et Vecteurs: Écologie, Génétique, Évolution et Contrôle (MIVEGEC) del Intitut de Recherche pour le Devélepppement (IRD) en Montpellier, Francia, por su recibimiento, y predisposición para el procesamiento de las muestras.

Al Dr. Jorge Romero, por abrirme las puertas del CEDIVE, compartir sus conocimientos de parasitología y por permitirme realizar esta investigación.

Al Dr. Rodrigo Sanabria, mi director, por elegirme e introducirme en el mundo de la investigación; por su paciencia, su tiempo, comprensión y compartir conmigo su conocimientos.

A la Dra. Pilar Alda, por haberme permitido vivir una muy grata experiencia en el exterior del país, y por su gran aporte a la distancia.

A la Dra. Marial Laura Vignau, por introducirme en el mundo de la parasitología, por dedicarle tiempo a la lectura de la tesis y brindarme sus consejos.

A Dr. Gaston Moré por sus consejos y su predisposición para resolver problemas y dudas.

A mis compañeros de trabajo, especialmente a Federico, Álvaro, Magalí Catalina, Luis, Hector y Juan Carlos, por escucharme en los momentos difíciles, por aconsejarme, ayudarme y alentarme a seguir.

A los pasantes del laboratorio: Colito, Carolina, Sabrina y Solana, por el entusiasmo y la colaboración en los trabajos relacionados a esta tesis.

A la familia Saizar, por brindar su establecimiento y colaboración, y por el siempre cálido recibimiento. 
A la familia Ferrer, por dejarme realizar el trabajo en su campo.

Al Médico Veterinario Román Allekotte, por su cooperación para conseguir los campos para el muestreo.

Al Médico Veterinario Daniel Medus del INTA Concepción del Uruguay, por su colaboración en los trabajos de campo.

Al Médico Veterinario Federico Raffo del INTA Bariloche, por resolver mis dudas e inquietudes con los sistemas de información geográfica.

A mis amigos, por acompañarme y escucharme siempre.

A mis hermanos, Miriam, Fran e Ivana, y sobrinos, Ailen, Laila, Yago, Regina y Daira. A mi tía Norma, tío Carlos y mis primas Florencia, Eli y Eve, por estar siempre, escucharme, contenerme, alentarme.

A mi mamá y papá, por trasmitirme lo importante de esforzarse, trabajar, por el apoyo y acompañamiento de siempre, muchas veces sin entender el para qué o el por qué; por aprender conmigo, por su amor incondicional.

A Luky, mi compañero de vida, por transitar conmigo está experiencia, por su paciencia, por animarme y aconsejarme cundo las cosas no iban bien, por sostenerme y superar cada inconveniente que se nos fue presentando, por hacerme crecer, por ser parte de mi vida. Por caminar a mi lado. 


\section{Dinámica de la infestación por Fasciola hepatica en el sur de la provincia de Entre Ríos}

\section{Resumen}

La fasciolosis es una enfermedad parasitaria de distribución mundial, producida en el continente americano por Fasciola hepatica; los adultos de estos trematodes se encuentran en los canalículos biliares de una amplia variedad de mamíferos, siendo los ovinos y bovinos aquellos en los que se producen las mayores pérdidas económicas y productivas. Es una afección zoonótica, considerada por la OMS como una de las enfermedades desatendidas. Argentina presenta zonas endémicas, siendo la cuarta enfermedad con mayor importancia en el ganado vacuno. La provincia de Entre Ríos se encuentra en el tercer puesto de producción ganadera a nivel nacional y esta parasitosis es diagnosticada con frecuencia. Con la finalidad de conocer la dinámica de infestación en los hospedadores definitivos (HD) e intermediarios $(\mathrm{HI})$ se realizaron muestreos trimestrales en seis establecimientos del sur de dicha provincia durante los años 2013 a 2015. Se determinó la dinámica de infestación en el ganado bovino, se identificaron mediante técnicas moleculares los diferentes aislados de adultos de F. hepatica, así como también, sus hospedadores intermediarios. Se estudió la dinámica y estructura poblacional de estos últimos, además de evaluar la susceptibilidad diferencial a las infestaciones por $F$. hepatica en las diferentes poblaciones de lymneidos. 
En el sur de la provincia de Entre Ríos, la fasciolosis se presentó de forma endémica, estando presente todos los meses del año en los bovinos, con valores de prevalencia mayores al 40\%. Se detectó además una predominancia a la heterocigosis en las poblaciones de $F$. hepatica, indicando así una mayor tasa de fecundación cruzada respecto a la autofecundación. Adicionalmente, se comprobó resistencia generalizada a albendazol en la región.

Galba cubensis fue la única especie identificada como HI. Si bien no se hallaron infestaciones a campo, las infestaciones experimentales demostraron que esta especie es un excelente $\mathrm{HI}$, ya que el $60 \%$ de las infestaciones experimentales fueron exitosas.

Al no registrar períodos de sequía durante el lapso de estudio, los excesos hídricos estuvieron disponibles en el terreno durante todo el tiempo. La retención de agua se relacionó con la tasa de infestación, ya que los establecimientos con mayor proporción de textura de suelo franca (bajo drenaje), presentaron mayor prevalencia de $F$. hepatica en el ganado.

Palabras Clave: Fasciola hepatica; Galba cubensis; infestación, epidemiologia. 


\section{Fasciola hepatica infection dynamics in southern Entre Rios}

\section{Abstract}

Fasciolosis is a worldwide spread parasitic disease. In America, it is produced by Fasciola hepatica, whose adults are found in the bile ducts of of mammals, causing production losses in cattle and sheep. As well, it is considered as a zoonotic neglected disease by WHO.

The province of Entre Rios is third in cattle stock in Argentina, and this parasitic disease is frequently diagnosed. To better understand the infection dynamics on the definitive and intermediate hosts, seasonal samplings were carried out between 2013 and 2015, on six southern farms of this province. Either flukes and their intermediate hosts were identified on molecular basis, in order to search for species, groups or clades, and their relationship with the observed phenotypes and epidemiological features.

Additionally, the population structure and susceptibility to infection were studied in the intermediate host.

According to the results, fasciolosis was regionally endemic all over the year for cattle, with a prevalence over $40 \%$. Heterozygosis predominated in the populations of $F$. hepatica, thus indicating a dominance of cross mating over self-fecundation mechanisms. Additionally, anthelmintic resistance to albendazole was detected in all the studied farms.

Galba culbensis was the only snail species identified as intermediate host. Even though snails weren't found infected out in the field, experimental infections succeed over $60 \%$. 
Without records of dry seasons during the study, water was available in the field all the time. Regarding this fact, a high prevalence of $F$. hepatica in cattle was statistically associated to poorly drained soils.

Key Words: Fasciola hepatica; Galba cubensis, infection, epidemiology. 


\section{Introducción}

\section{$1.1 \quad$ Generalidades}

La fasciolosis es una enfermedad parasitaria ampliamente distribuida en el mundo. En Argentina como en el resto del continente americano, el agente etiológico es Fasciola hepatica (Trematoda: Digenea), en países de Asia y África, además de esta especie está presente Fasciola gigantica.

Los adultos de $F$. hepatica se ubican en los canalículos biliares de una variedad de hospedadores.

La presentación de la fasciolosis difiere según la especie a la que afecta: Ios equinos y los cerdos son de baja susceptibilidad y los rumiantes de moderada a alta, por ende, se producen elevadas pérdidas productivas y económicas (Olaechea et al, 2011).

Su potencial zoonótico es un factor importante, siendo Sudamérica una de las regiones más afectadas, con amplia distribución de casos humanos en países como Perú (Marcos et al., 2007) y Bolivia (Recalde et al., 2014). En ambos países la fasciolosis se considera regionalmente endémica, y de gran importancia en salud pública. En Argentina hay pocos casos humanos registrados debido a que no es una enfermedad de denuncia obligatoria; los mismos se hallan particularmente concentrados en las regiones andinas (Rubel et al., 2005, Mera y Sierra et al., 2011).

La OMS considera a la fasciolosis entre las enfermedades desatendidas, registrándose un aumento de reportes de casos humanos (WHO, 2008). 
Se estimó que el costo por pérdidas directas e indirectas por $F$. hepatica es, a nivel mundial, de más de 3,000 millones de dólares anuales (Boray, 1997). Respecto a los rumiantes, se estima que 300 millones de bovinos y 250 millones de ovinos, habitan en lugares donde $F$. hepatica está presente (Beesley et al., 2017). Su frecuencia es elevada en zonas con lluvias moderadas a intensas, aunque también, ocurren casos en zonas más secas, valles pantanosos, arroyos, bañados e inclusive canales de riego, donde puede habitar su hospedador intermediario, un caracol dulceacuícola de hábitos anfibios de la familia Lymnaeidae.

En los ovinos, se registran pérdidas por mortandad, reducción en la producción (carne, leche, lana), deterioros en la condición corporal y disminución de las pariciones (Robles y Olaechea, 2001). En los bovinos las pérdidas son más difíciles de discernir y dependen de la categoría afectada y la carga parasitaria, observándose en menor medida disminución de la ganancia diaria de peso, menor conversión alimentaria y producción de leche. Se han reportado reducciones en la ganancia diaria de peso entre 8 y 28\% en terneros (Ross, 1970; Hope and Cawdery, 1977, Chick et al., 1980). Por otra parte, Cardozo et al. (1991), no encontraron diferencias productivas o reproductivas entre vaquillonas parasitadas por F. hepatica, en comparación con compañeras desparasitadas. No obstante, las mayores pérdidas podrían imputarse principalmente a los costos de tratamientos antihelmínticos, de los decomisos de hígados en frigoríficos y a que las reses son clasificadas de calidad inferior. En Uruguay, por ejemplo, se decomisaron un $37,5 \%$ de los hígados bovinos durante el 
período 2007-2008 por lesiones vinculadas a F. hepatica (Olaechea et al. 2011)

Otro aspecto a tener en cuenta son las enfermedades asociadas a $F$. hepatica. Son conocidas las pérdidas por mortandades asociadas a hemoglobinuria bacilar (Clostridium haemolyticum) en bovinos, y hepatitis infecciosa necrosante en ovinos (Clostridium novy tipo B); estas bacterias anaeróbicas proliferan en las áreas necróticas producidas por migración de F. hepatica, elaborando potentes exotoxinas. Se mencionó, además, que la infección por F. hepatica puede inducir reducción de la respuesta inmunológica mediada por linfocitos Th1, frente a bacterias intracelulares como Mycobacterium bovis, causante de la tuberculosis, pudiendo, entre otras cosas, alterar la prueba de diagnóstico para esta enfermedad en el ganado vacuno, e incrementar la susceptibilidad a la infección (Flynn et al., 2009).

\subsection{Descripción del parásito:}

Fasciola hepatica (Linnus, 1758)

Phylum: Platelmintos

Clase: Trematoda

Subclase: Digenea

Orden: Echinostomata

Superfamilia: Echinostomatoidea

Familia: Fasciolidae (Schmidt y Roberts, 1977) 
F. hepatica es un helminto hermafrodita, cuerpo ancho, aplanado dorso ventralmente, mide de 18 a $50 \mathrm{~mm}$ de largo por 4 a $13 \mathrm{~mm}$ de ancho. Está provisto de dos ventosas próximas entre sí, una ubicada en el proceso cónico proximal donde se encuentra la boca, denominada ventosa oral, en tanto la ventosa ventral es de mayor tamaño y se denomina acetábulo (fig. 1.1, $A$ y $B)$.

Posee un aparato digestivo incompleto con dos ramas ciegas con numerosos divertículos laterales. El aparato reproductor se constituye por dos testículos ramificados, que ocupan la parte media corporal, y el ovario y útero están ubicados anteriormente a éstos. Las glándulas vitelógenas, ocupan los márgenes laterales de los adultos, y los conductos de estas glándulas confluyen, junto con las glándulas de Mehlis en el ootipo. Aunque su condición hermafrodita permite autofecundación, por lo general éste fenómeno ocurre en forma cruzada (Adrews, 1999). El tegumento presenta espinas (Figura 1.1 C), siendo metabólicamente activo en términos de absorción de nutrientes, osmorregulación, protección contra el hospedador y otros parásitos, y digestión, entre otras funciones (Fairweather, et al. 1999).

Para completar su ciclo biológico, F. hepatica necesita que coexista su HD mamífero (reproducción sexual), y su HI (reproducción asexual), un caracol del género Galba (syn. Lymnaea) (Figura 1.2). 
Figura1. 1 Fasciola hepatica
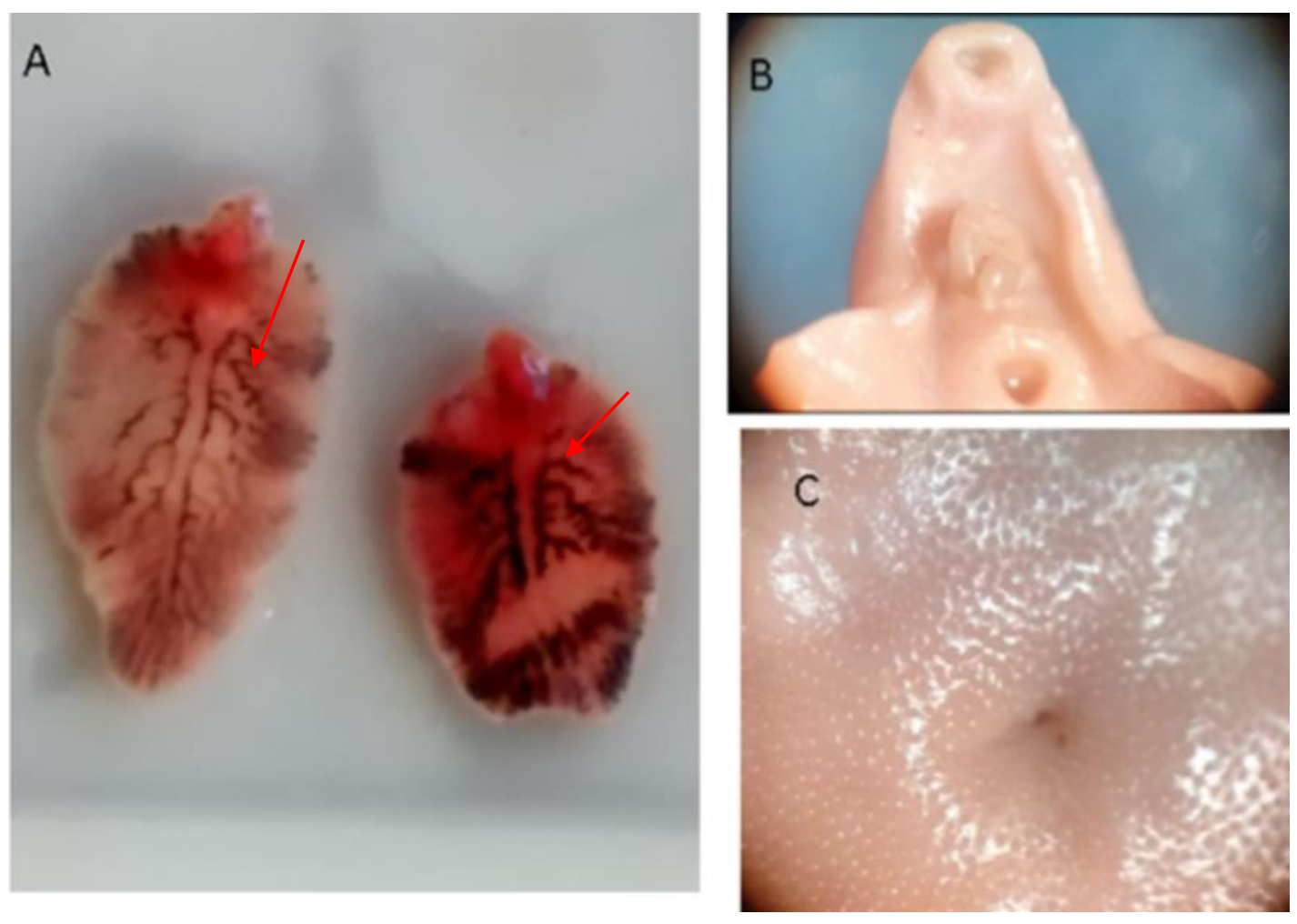

A) Adultos. Se observa el ciego ramificado en color oscuro (flechas). B) Extremo anterior. Se observan ambas ventosas y entre estas el poro genital. C) Tegumento recubiertos por espinas.

Los huevos, elipsoidales y de color amarillento, son eliminados por el HD junto con la materia fecal, y miden de 120 a $140 \mu \mathrm{m}$ de largo x 60 a $90 \mu \mathrm{m}$ de ancho (Figura 1.3.A). Un solo ejemplar de F. hepatica puede poner entre dos y cinco mil huevos al día (Rojo Vazquez y Ferre Perez, 1999). Para el desarrollo del huevo, es indispensable una cubierta de agua, y un rango de temperatura entre $10^{\circ} \mathrm{C}$ a $30^{\circ} \mathrm{C}$. A menos de $10^{\circ} \mathrm{C}$ se mantienen viables, pero no continúan su desarrollo, y por encima de $37^{\circ} \mathrm{C}$ pierden viabilidad. 
Entre los $23{ }^{\circ} \mathrm{C}$ y los $26{ }^{\circ} \mathrm{C}$ se desarrolla dentro del huevo el miracidio (Andrews, 1999) (Figura1.2. A), de forma cónica y aproximadamente $130 \mu \mathrm{m}$ de largo, rodeado por cilias. Posee en su extremo anterior, una protuberancia papiliforme y órganos fotosensibles (Figura1.2. B). El miracidio nada activamente en busca del $\mathrm{HI}$, atraído específicamente por determinadas especies de moluscos, fenómeno definido como quimiotaxis con adaptación (Thaddeus et al., 1999). Una vez infectado, el caracol puede permanecer en este estado de por vida (Torgerson y Claxton, 1999). El miracidio penetra en el tegumento del caracol activamente mediante una descarga enzimática, luego pierde rápidamente sus cilias y se transforma en el primer estadio larval dentro del molusco denominado esporocisto (Figura 1.2.C), ubicándose en la región peri esofágica del caracol. Su forma es similar a un saco, con numerosas células germinativas, que dan origen a las redias (Figura 1.2. D). Estas son de forma cilíndrica, miden de 1 a 2 $\mathrm{mm}$ de largo, y poseen un aparato digestivo consistente en faringe e intestino ciego. Se alimentan del tejido hepatopáncreático y gónadas del caracol, dado su alto contenido en lípidos, que servirán luego de reserva para las formas larvarias de vida libre. Las redias presentan células germinativas que se multiplican y darán origen a segundas o terceras generaciones de redias, o bien al siguiente estadio, las cercarias (Figura 1.2. E). Este estadio permite nuevamente el desplazamiento acuático. Las cercarías miden de 250 a $300 \mu \mathrm{m}$ y presentan un cuerpo discoidal y una larga cola. Éstas abandonan el caracol 6 a 7 semanas después de la infestación (dependiendo de la temperatura exterior), por migración a través 
de los tejidos del molusco y nadan en el agua hasta tomar contacto con una superficie plana, ya sea de la vegetación, rocas, o inclusive la superficie del agua en algunos casos (Andrews, 1999). Tras este contacto, la cercaria enquista, perdiendo su cola y rodeándose de una cubierta resistente secretada por las glándulas cimógenas. Este estadio, denominado metacercaria (MTC) (Figura.1.2. F), es la forma infectante para el HD. Son muy sensibles a las altas temperaturas y a la desecación (Andrews, 1999). Uno de los factores que contribuye a la propagación de la fasciolosis es la multiplicación asexual dentro del $\mathrm{HI}$, ya que un solo miracidio puede llegar a producir más de mil MTC (Sanabria et al., 2012).

La infestación de los rumiantes tiene lugar principalmente durante el pastoreo, o bien raramente, por la ingesta de agua contaminada con MTC. No obstante, menos del $50 \%$ de ellas tiene éxito en su implantación. La patogenicidad de $F$. hepatica depende del número de MTC ingeridas y de su capacidad de implantación, ya que se ha comprobado que su capacidad infectante también depende de las condiciones climáticas durante su enquistamiento, y del tiempo de permanencia dentro del caracol y en el exterior (Rojo Vázquez y Ferre Pérez, 1999).

Una vez que las MTC son ingeridas por el HD, se liberan las formas juveniles o fasciolómulos, los cuales atraviesan la pared intestinal, y entre los 4 y los 6 días post infestación alcanzan el hígado, atraviesan la capsula de Glisson y migran a través del parénquima hepático hasta alcanzar los conductos biliares entre la séptima y octava semana. Durante este proceso migratorio se producen lesiones que causan intensas hemorragias y fibrosis 
(Adrews, 1999). A partir de la octava semana comienza el periodo de patencia de la infección, pudiéndose recuperarse los huevos en la materia fecal del hospedador.

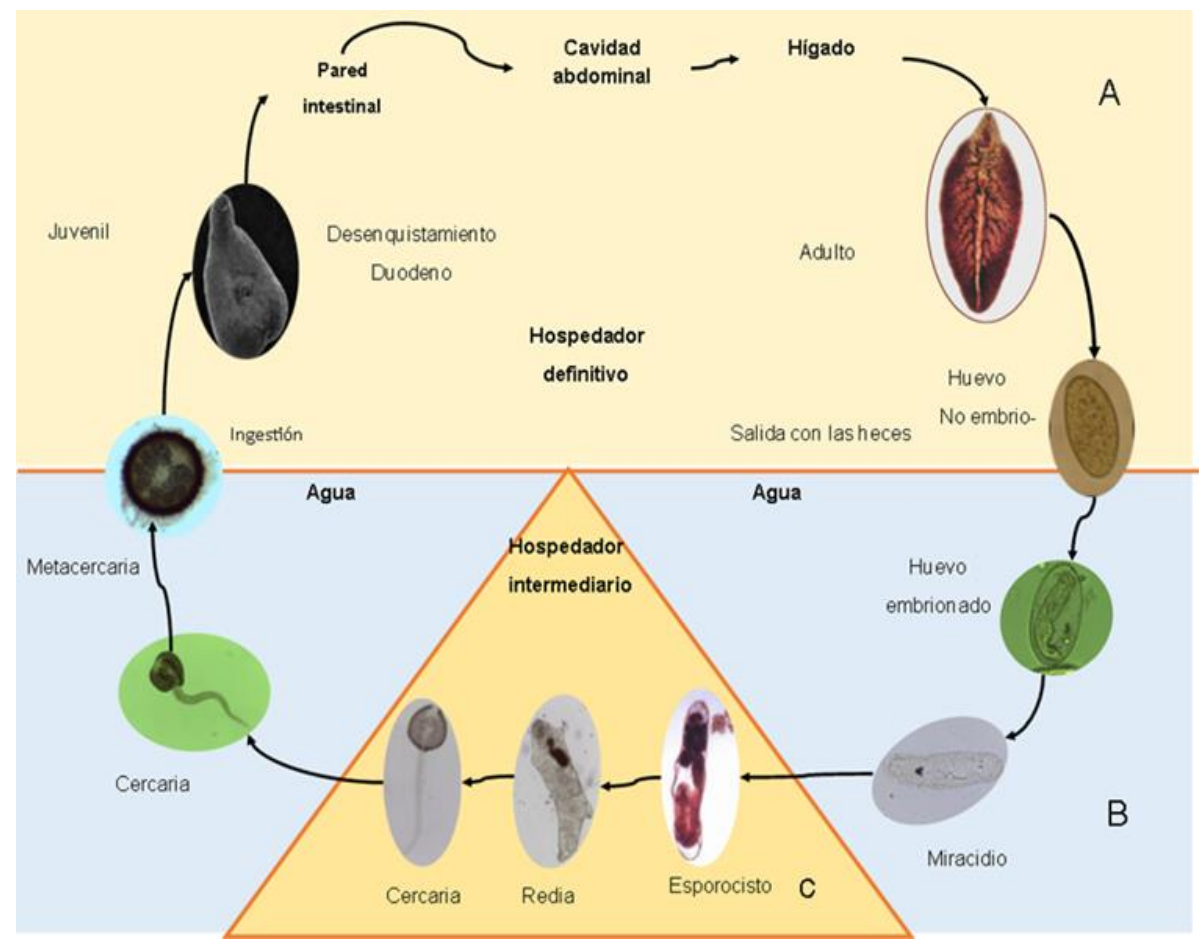

Figura 1.2. Ciclo de vida de Fasciola hepatica. A: Desarrollo en el $H D, B$ : desarrollo en el medio ambiente, C: desarrollo en el HI.

\subsection{Hospedadores definitivos}

Fasciola hepatica presenta un amplio espectro de hospedadores definitivos, siendo frecuente en ovinos, bovinos, caprinos, equinos, porcinos, varios mamíferos silvestres, y seres humanos (Hurtrez-Bousses et al., 2001). 


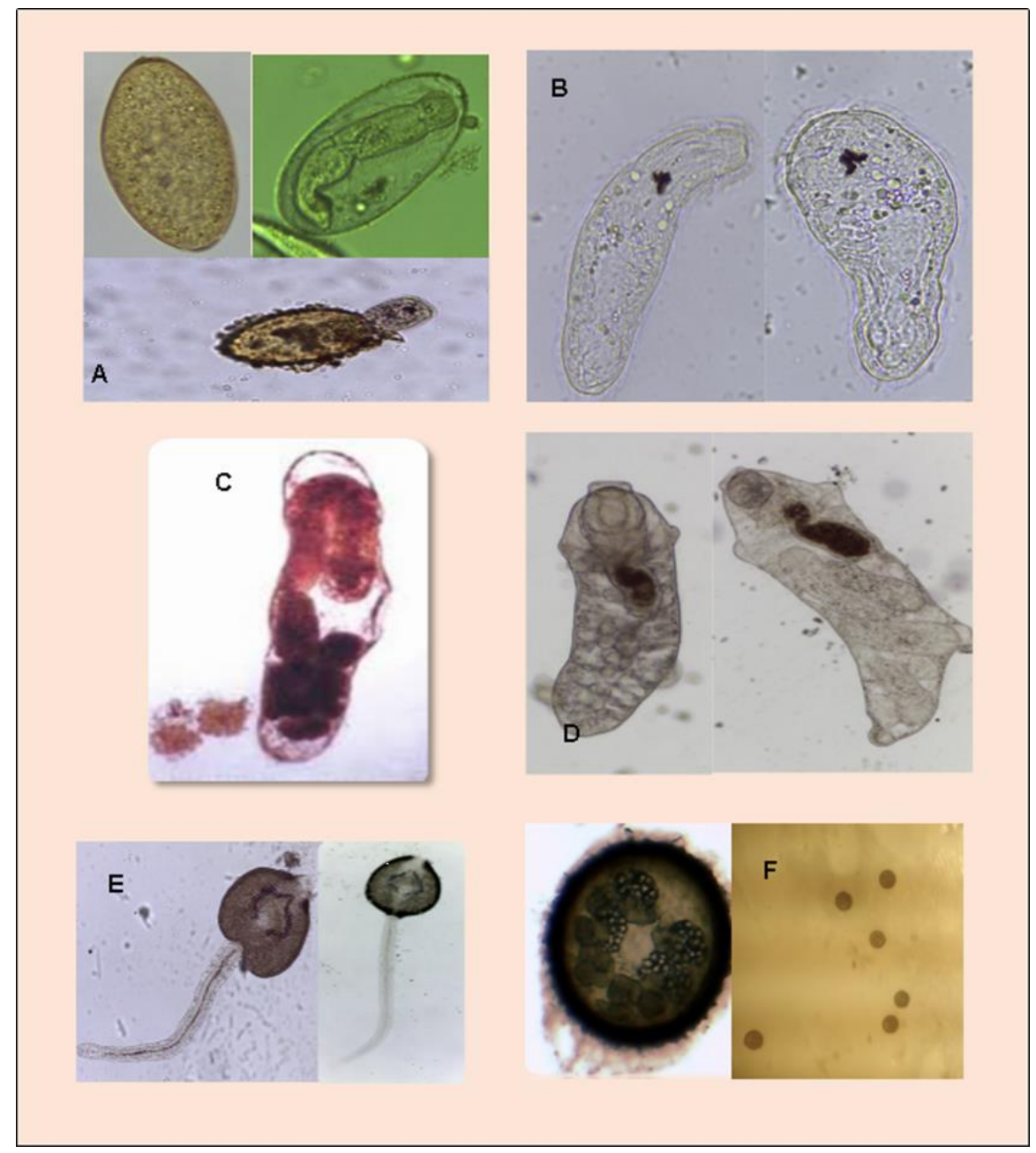

Figura 1.3. Estadios de Fasciola hepatica A) Huevo no embrionado, embrionado y eclosión de miracidio B). Miracidios. C) Esporocisto. D)Redia E) Cercarias F) Metacercarias

Los niveles de infestación varían entre sitios y especies, en humanos la variabilidad podría explicarse particularmente por las características y hábitos alimenticios, como por ejemplo el consumo de plantas acuáticas o infusiones a partir de estas (Mas-Coma et al., 1998).

El espectro de hospedadores también difiere de una región a otra, ejemplo de ello son los cerdos, los cuales son hospedadores ocasionales en la 
mayoría de los países, mientras que en el altiplano boliviano representa el segundo hospedador que actúa como reservorio (Mas - Coma et al., 1998). El Coipo o falsa nutria (Myocastor coypus), es el reservorio silvestre más estudiado en Sudamérica, presentando prevalencias que rondan el 55\% (Hurtrez-Bousses et al., 2001). No obstante, los ovinos y los bovinos son hospedadores definitivos más importantes desde el punto de vista epidemiológico y productivo.

Se ha demostrado que incluso, dentro de una misma especie, hay diferencias de susceptibilidad entre razas. Por ejemplo, ovinos raza St. Croix produjeron significativamente menor cantidad de adultos en hígado que otras tres razas ante el mismo desafío experimental (Boyce et al., 1987). La raza Indonesian Thin Tail fue estudiada por su resistencia a $F$. gigantica, pero no a F. hepatica, proceso que parece estar mediado por la expresión de determinado perfil de citoquinas de tipo 1 (Pleasance et al., 2011).

La fasciolosis puede presentarse en su forma aguda, subaguda o crónica, de acuerdo con los signos clínicos y a los hallazgos de necropsias, dependiendo del número de parásitos que se encuentren en el hígado (Rojo Vázquez y Ferré Pérez, 1999).

La forma aguda se produce por una masiva migración de formas inmaduras a través del parénquima hepático, y se caracteriza por ascitis, hemorragia abdominal, anemia y letargia, llevando rápidamente a la muerte antes del período prepatente. Las infestaciones masivas en un corto período son 
especialmente graves para bovinos jóvenes, y ovinos y caprinos de todas las edades (Malone, 2010).

En la forma subaguda, la ingesta de MTC es continua en el tiempo, por lo cual rara vez se produce la muerte del animal. En el hígado se pueden observar tanto formas inmaduras como maduras de F. hepatica. Los animales pueden exhibir letargo, anemia, edema palpebral y ascitis, entre otros signos.

Finalmente, la forma crónica se desarrolla cuando la ingesta es menor a 10 MTC/ día (Rojo Vázquez y Ferré Pérez, 1999), por un tiempo prolongado, y los signos se presentan por la existencia de los parásitos adultos en los conductos biliares, siendo los más evidentes, pérdida de peso, anemia, ascitis y edema submandibular. Los bovinos son susceptibles a temprana edad, pero pueden desarrollar elevada resistencia por lo cual raramente ocurre la muerte por F. hepatica en animales adultos (Olaechea et al., 2007). Sin embargo, la migración de las formas juveniles produce un ambiente anaerobio propicio para la proliferación de Clostridium haemolyticum y C. novyi tipo D, predisponiendo al desarrollo de "hemoglobinuria bacilar" y "hepatitis infecciosa necrosante", respectivamente.

\subsection{Hospedador intermediario}

Fasciola hepatica depende para su transmisión de la presencia de caracoles pertenecientes a la familia Lymnaeidae. 
Dentro de esta familia se encuentran un gran número de especies de caracoles de agua dulce cuya sistemática, aun, continúa sujeta a controversias (Kleiman et al., 2004; Prepelitchi, 2009; Correa et al., 2010; Lounnas et al., 2016; Alda et al., 2018). Antes de la masificación de las técnicas de biología molecular, la identificación de las especies se basaba en la morfología de la conchilla y del aparato reproductor masculino (Pontier et al., 2008). En base a estos criterios, Baker (1908) reconoció a 113 especies de lymneidos, y las dividió en 7 géneros: Acella, Bulimnea, Lymnaea, Pleurolymneaea, Pseudosuccinea, Radix y Galba. Más tarde, Hubendick (1951), realizo una comparación morfológica a nivel mundial planteando que era injustificable la división en tantas especies y subespecies debido a su gran uniformidad anatómica dejando a Lymnaea como único género valido.

Ambas maneras de clasificación hoy siguen estando vigentes, generando confusión al referirse a las distintas especies, ya que estas se pueden nombrar de dos o incluso tres maneras diferentes (Prepelitchi, 2009). Luego, se comenzaron a utilizar diferentes marcadores moleculares, como los segmentos codificantes para subunidades ribosomales $18 \mathrm{~S}$ y $16 \mathrm{~S}$ (Bargues y Mas Coma, 1997; Remigio y Blair, 1997), espacios internos transcriptos (ITS) 1 y 2 del ADN ribosómico (Carvallo et al., 2004; Vidigal et al., 2004) y otros genes como citocromo oxidasa I mitocondrial (Mera y Sierra et al., 2009; Pujadas et al., 2014), permitiendo la diferenciación y agrupación de especies. El empleo de marcadores microsatelites, permitió, 
gracias a un mayor polimorfismo que los anteriores, una clara diferenciación en especies (Lounnas et al., 2016; Alda et al., 2018).

La presencia, abundancia y estructura poblacional de estos lymneidos depende de la interrelación de factores intrínsecos y extrínsecos de su hábitat, tanto abióticos como bióticos (Prepelitchi, 2009).

Dentro de los factores bióticos, la predación y la competencia interespecífica, juegan un rol fundamental (Dillon, 2000). Por otra parte, la temperatura es uno de los principales factores abióticos que influye en la presencia, crecimiento y desarrollo de los lymneidos, siendo óptima entre los 10 y $30^{\circ} \mathrm{C}$ (Torgerson y Claxton, 1999). La humedad también es condicionante, ya que los lymneidos solo pueden crecer y desarrollarse en ambientes saturados de agua.

Cuando las condiciones son desfavorables, estos moluscos sobreviven enterrados en suelos secos (estivación), y a bajas temperaturas hibernan retraídos en su conchilla (Boray, 1964). La supervivencia a su vez dependerá del tiempo durante el cual son sometidos a dichos factores adversos. No todas las especies de lymneidos pueden estivar, ejemplo de ello es Pseudosuccinea columella que necesita constantemente de la presencia de humedad (Prepelitchi et al., 2004).

La especie más ampliamente descripta a nivel mundial como HI es Galba (Lymnaea) truncatula (Odening y Amnaliev,1977; Bargues y MasComa,1997). Esta presenta alta adaptabilidad a diferentes ambientes, desde llanuras a altitudes mayores a 4000 metros (Thaddeus et al., 1999). 
En argentina la primera especie reconocida por Bacigalupo (1934), como HI fue Lymnaea (Galba) viatrix (Venturini, 1990), desde entonces se ha descripto ampliamente en países de América del sur, constituyendo junto a G. truncatula y G. cubensis los principales HI de F. hepatica (Venturini., 1990; Kleiman et al., 2007; Pointier et al., 2006).

\subsection{Control}

El control la fasciolosis debe estar orientado a prevenir o limitar el contacto del hospedador definitivo con el parásito. Los fármacos fasciolicidas más utilizados en nuestro país y en otras partes del mundo son el albendazol (10mg/kg), closantel, y clorsulón, entre otros, los cuales solo son eficaces frente a $F$. hepatica de más de 6 semanas (Malone, 2010).

El triclabendazol, es un bencimidazol halogenado ampliamente utilizado, y es eficaz contra estadios en migración por el parénquima hepático (90\% de eficacia) y sobre ejemplares maduros (99\%). La existencia de fasciolicidas eficaces, seguros y fácilmente aplicables, hizo del tratamiento farmacológico la forma más habitual utilizada por productores para su control, muchas veces de forma sistemática y sin el asesoramiento profesional, conllevando a la aparición de resistencia a los antiparasitarios más comúnmente utilizados en nuestro país, fundamentalmente triclabendazol (Olaechea et al., 2011) y albendazol (Sanabria et al., 2013).

\subsection{Epidemiología}

Respecto a Argentina, F. hepatica ha sido descripta en casi todas las áreas geográficas y provincias, a excepción de Tierra del Fuego. Aunque el frio 
es una barrera para su desarrollo, se la ha descripto hasta el paralelo $49^{\circ}$, en la meseta Patagónica de Santa Cruz (Aguilar, 2010). Además, se reportaron hallazgos en Corrientes (Prepelitchi et al., 2005), Mendoza (Mera y Sierra et al., 2005), Salta (Aguirre et al., 2005), Entre Ríos (Sanabria et al., 2013), Catamarca (Canevari et al., 2014), y Buenos Aires (Entrocasso, 2004).

Las características climáticas, condicionan el riesgo y la estacionalidad de presentación de fasciolosis. Los veranos cálidos y húmedos representan condiciones óptimas para el desarrollo y crecimiento tanto de los estadios larvarios como de los caracoles. Por el contrario, en épocas con escasas precipitaciones y elevada evapotranspiración la supervivencia de los moluscos es limitada. Las MTC, forma infectante de $F$. hepatica, son muy susceptibles a la desecación, las radiaciones solares e incluso a temperaturas elevadas.

En aquellas regiones donde los inviernos presentan temperaturas medias por debajo de los $10^{\circ} \mathrm{C}$, se inhibe el crecimiento y desarrollo de los moluscos, y estadios larvarios de $F$. hepatica. Las bajas temperaturas invernales mantienen viables las metacercarias y los huevos en el medio ambiente, siendo estos, y los caracoles sobrevivientes, el principal pie de infestación en la primavera siguiente (Olaechea, 2001).

La cercana relación entre las condiciones climáticas y la fasciolosis, hicieron necesario el desarrollo de modelos para la estimación de riesgo de esta enfermedad (Fox et al., 2011). De hecho, el efecto del cambio climático, la expansión de la resistencia a drogas, y el desplazamiento del 
ganado a zonas no aptas para la agricultura, entre otros factores, representaron un avance esta parasitosis (Mas-Coma et al., 2009).

Se han generado modelos de dinámica de fasciolosis mediante la utilización de sistemas de información geográfica (SIG), facilitando así el manejo de la información epidemiológica, y eventualmente la toma de decisiones e implementación de estrategias para disminuir el riesgo de esta parasitosis (Dutra et al., 2010; Charlier et al., 2011; Martins et al., 2012). Los SIG también pueden ser utilizados para la estimación de áreas endémicas o libre de una enfermedad y evaluar su posible dispersión, factores importantes, teniendo en cuenta que esta parasitosis no tiene la misma dinámica en todas las áreas geográficas. Ejemplo de ello son áreas endémicas opuestas, como la región sur de Chubut donde el ciclo de $F$. hepatica solo es activo durante los meses de noviembre a marzo (Olaechea, 2007), mientras que el Noreste, (Berón de Astrada, Corrientes), las temperaturas medias anuales son superiores a $10^{\circ} \mathrm{C}$ y el ciclo puede desarrollarse durante todo el año (Prepelitchi et al., 2009). Conocer las características ambientales regionales permite comprender la dinámica de esta parasitosis, y así poder aplicar adecuadamente las medidas de control. En la Argentina la dinámica de la fasciolosis se ha descripto, como se mencionó anteriormente, en la región norte, en la provincia de Corrientes (Prepelitchi, 2009) y en la región patagónica (Olaechea, 2007). Sin embargo, no se ha estudiado en profundidad en la región Pampeana.

El sur de la provincia de Entre Ríos pertenece a esta región y debido a sus características, esta parasitosis se presenta con elevada frecuencia 
(Sanabria et al., 2012). Esta provincia se ubica entre los paralelos de $30^{\circ}$ y $34^{\circ}$ sur y meridianos $58^{\circ}$ y $61^{\circ}$ oeste, y se divide en 17 departamentos (Fig.

1.4). Posee una superficie de $78.781 \mathrm{~km}^{2}$ e integra la región Mesopotámica, junto con Corrientes y Misiones. Se encuentra rodeada por el río Paraná al sur, al este por el rio Uruguay y al norte por los ríos Guayquiraró y Mocoretá. La región sur presenta el Delta del Paraná con terrenos bajos y formación de islas. En total la provincia posee 41.790 kilómetros de ríos y arroyos.

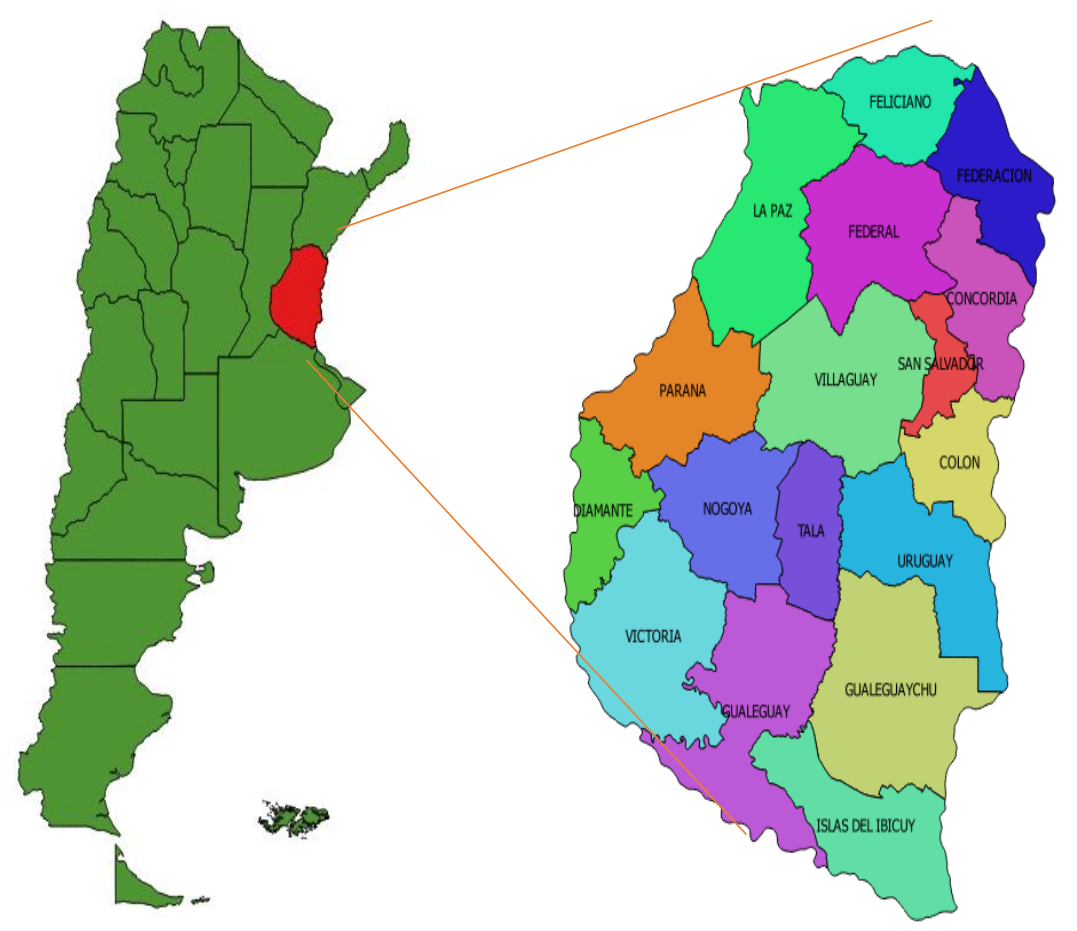

Figura 1.4. Departamentos de la provincia de Entre Ríos (QGis 2.18).

El territorio entrerriano presenta ondulaciones suaves, con una pendiente que paulatinamente sube hacia el oeste y el norte. Se caracteriza por una marcada heterogeneidad en su topografía, suelos y vegetación. Se encuentra conformado por $77 \%$ de tierra firme, $20 \%$ de islas, delta, predelta y anegadizos, y $3 \%$ de agua. 
La temperatura disminuye de norte a sur. En el noreste el clima es subtropical sin estación seca, los inviernos son suaves y en verano la temperatura supera los $26^{\circ} \mathrm{C}$, siendo la media anual de $20^{\circ} \mathrm{C}$. Las precipitaciones superan los $1.000 \mathrm{~mm}$ anuales y predominan los vientos norte, este y noreste. El centro y sur de la provincia presentan inviernos con temperaturas medias entre $7^{\circ} \mathrm{C}$ y los $10^{\circ} \mathrm{C}$, y entre los $19^{\circ} \mathrm{C}$ y $23^{\circ} \mathrm{C}$ en verano. Prevalecen vientos del sur, sureste y noreste. Las precipitaciones, en promedio, son inferiores a los $1.000 \mathrm{~mm}$ anuales (Anuario Estadístico de la Provincia de Entre Ríos, 2014).

Entre Ríos se ubica en el tercer puesto a nivel nacional de producción ganadera. El stock de ganado vacuno se estimó en 4,48 millones de cabezas en el año 2015, representando el $8,71 \%$ del total nacional, y conforme datos del Ministerio de Agricultura, Ganadería y Pesca de la Nación, en 2015 se faenaron aproximadamente 419.680 cabezas. En lo referente a las razas, se crían principalmente europeas (Hereford, Aberdeen Angus y Shorthon) productoras de carne, con menor proporción de tambos (alguna cita de datos productivos o link a datos ministerio).

Además, se ha registrado en la provincia un incremento notable en la actividad relacionada con el sector ovino, particularmente en la región norte, en el límite con Corrientes (Engler et al., 2008).

El sistema productivo predominantemente ganadero, fue cambiando en las últimas décadas a agrícola-ganadero, destinando los suelos más aptos para agricultura, con el consiguiente desplazamiento de la ganadería a campos más marginales (suelos anegadizos, próximos a arroyos, ríos o 
bañados), aptos para el desarrollo de esta parasitosis. Como en otras partes del mundo, la prevalencia de $F$. hepatica se ha incrementado posiblemente ligada a este tipo de desplazamiento de la ganadería (Olaechea et al., 2007), y en la región mencionada la fasciolosis no ha sido estudiada con profundidad.

Por lo expuesto, este trabajo busca estudiar la dinámica de infestación por F. hepatica en el ganado en esta región y sus hospedadores intermediarios. 


\subsection{HIPOTESIS:}

I. La fasciolosis se presenta en el ganado de la región sur de Entre Ríos en forma enzoótica, con variaciones estacionales e incluso interanuales. La relación entre las características climáticas y la infestación en el ganado permite establecer un índice de riesgo que puede actuar como predictivo en condiciones similares.

II. Diferentes poblaciones de $F$. hepatica pueden ser caracterizadas mediante diferencias genotípicas.

III. En la región existen diferentes especies, subespecies o poblaciones de lymneidos, que actúan como $\mathrm{HI}$ de $F$. hepatica. A su vez estas presentan diferente susceptibilidad a la infestación.

IV. La susceptibilidad del HI a la infestación por F. hepatica incide en la tasa de infestación en los HD y por ende en la endemicidad regional. 


\subsection{Objetivos}

I. Estudiar la dinámica de la infestación por $F$. hepatica en el ganado vacuno en la región con el fin de definir un patrón o tendencia de infestación si se presentase, y la incidencia de variables ambientales en el ciclo, y el impacto de la resistencia antihelmíntica.

II. Identificar mediante técnicas moleculares los aislamientos de $F$. hepatica presentes en cada uno de los establecimientos.

III. A. Relevar e identificar las especies de lymneidos que actúan como HI en la región endémica comprendida al sur de la provincia de Entre Ríos mediante criterios de análisis de biología molecular.

B. Determinar la abundancia y estructura poblacional de los lymneidos en los diferentes orígenes de la zona de estudio.

IV. Evaluar si existe susceptibilidad diferencial de las especies o poblaciones de lymneidos estudiadas por establecimiento a las infecciones por miracidios, expresado a través de los porcentajes de infestación hallados a campo y ante el desafío experimental con aislamientos de F. hepatica del mismo origen. 


\section{Objetivo I.}

\section{Dinámica de infestación por Fasciola hepatica en el ganado.}

\subsection{Introducción}

El estudio de una enfermedad en una población requiere del conocimiento de las relaciones entre los organismos (hospedadores y agentes) (Thursfield, 1990), y su medio ambiente. Estas relaciones determinan la aparición de la enfermedad en el espacio y en el tiempo. Los hospedadores y los agentes forman comunidades donde también intervienen otros organismos, determinando un ecosistema. La ecología (ciencia que estudia los ecosistemas), es parte de la epidemiología, siendo esta última definida como el estudio de una enfermedad en una población y los factores que determinan su ocurrencia.

Por ello, algunos estudios epidemiológicos se sustentan en información ecológica. Hoy en día una herramienta de fácil acceso para la obtención de datos geográficos y ambientales son los sistemas de información geográfica (SIG). Los SIG permiten obtener datos ambientales, crear con

ellos bases de datos, y generar interacciones para obtener nueva información (Shaw y McGuire, 2017). De esta forma, se puede asociar bases de datos temáticas a la descripción espacial precisa del objeto georreferenciado y relacionarlas entre sí. Los datos obtenidos se representan en forma vectorial (cada dato es representado por puntos, líneas o polígonos), o raster (la información está dispuesta en pequeñas celdas), y la estructura en la que son almacenados se denomina "capa". Una capa está compuesta por una base de datos (archivo.dbf), un archivo 
que contiene datos espaciales georreferenciados (vectorial o raster) y finalmente un archivo que vincula a ambos (shapefile) (Rytkönen, 2017).

Estas herramientas se han aplicado en diferentes disciplinas en las últimas décadas, como el estudio de la distribución y predicción de enfermedades como malaria (Rodríguez-Morales et al, 2015) o infecciones como el HIV (Khademi et al., 2016), entre otros ejemplos. En el caso de la fasciolosis, se ha utilizado para obtener modelos de dinámica en diferentes regiones en varios países, siendo útil para la toma de decisiones en estrategias de manejo y tratamiento (Martins et al., 2011). Mediante esta metodología, se han mencionado incrementos en la tasa de infestación por $F$. hepatica en países del este de Europa (Lounnas et al., 2016), posiblemente debido al cambio climático, cambios en las prácticas agrícolas y ganaderas, tanto por el uso del suelo como en movimientos de los animales (Fox et al., 2011). Incluso factores de riesgo y dispersión fueron asociados mediante este recurso respecto al creciente problema de resistencia antihelmíntica en Europa (Rose et al., 2015). Respecto a este problema, en F. hepatica se han documentado fallas post tratamiento con rafoxanide y closantel (Fairwhather y Boray, 1999). Se reportó además resistencia a triclabendazol en ovejas de Australia (Overend y Bownd, 1995), y desde entonces se ha expandido por diferentes regiones de Europa y Sudamérica (Alvarez-Sánchez et al., 2006; Mooney et al., 2009; Ortiz et al., 2013; Kelley et al., 2016). En nuestro país se ha detectado resistencia al triclabendazol (Olaechea et al 2011), y albendazol (ABZ) (Sanabria et al., 2013). Es por 
ello necesario entender cómo se desarrolla la resistencia y su alcance territorial.

La epizootiología de la fasciolosis en el ganado involucra los factores que afectan la prevalencia y la intensidad de la infestación (Bessley et al., 2017). Además, depende de la susceptibilidad del HD y también de la oferta de formas infectantes en el ambiente (Prepelitchi, 2009), y de factores abióticos como temperatura y humedad, que modulan la presencia y el desarrollo de los $\mathrm{HI}$ y del parásito. Finalmente, influyen una gran variedad de factores topográficos, biológicos y de manejo ganadero (Boray, 1985). Siendo la provincia de Entre Ríos una importante productora de carne bovina, y con un incremento sostenido en el número de ovinos, se considera pertinente estudiar la forma y dispersión espacial de esta parasitosis. Por ello, el objetivo de este capítulo es evaluar la asociación entre parámetros ambientales e indicadores de infestación animal, a fin de identificar condiciones de mayor o menor susceptibilidad para la infestación, con asistencia de SIG. Asociado a esto, se realiza una aproximación a la dispersión de la resistencia de $F$. hepatica a los antiparasitarios en la región estudiada.

\subsection{Materiales y métodos}

2.2.1. Lugares de estudio

El presente trabajo se realizó en establecimientos pertenecientes a las cuencas de los ríos Gualeguaychú (departamentos Uruguay y 
Gualeguaychú), y Gualeguay (departamentos Tala y Gualeguay) (Figura 2.1).

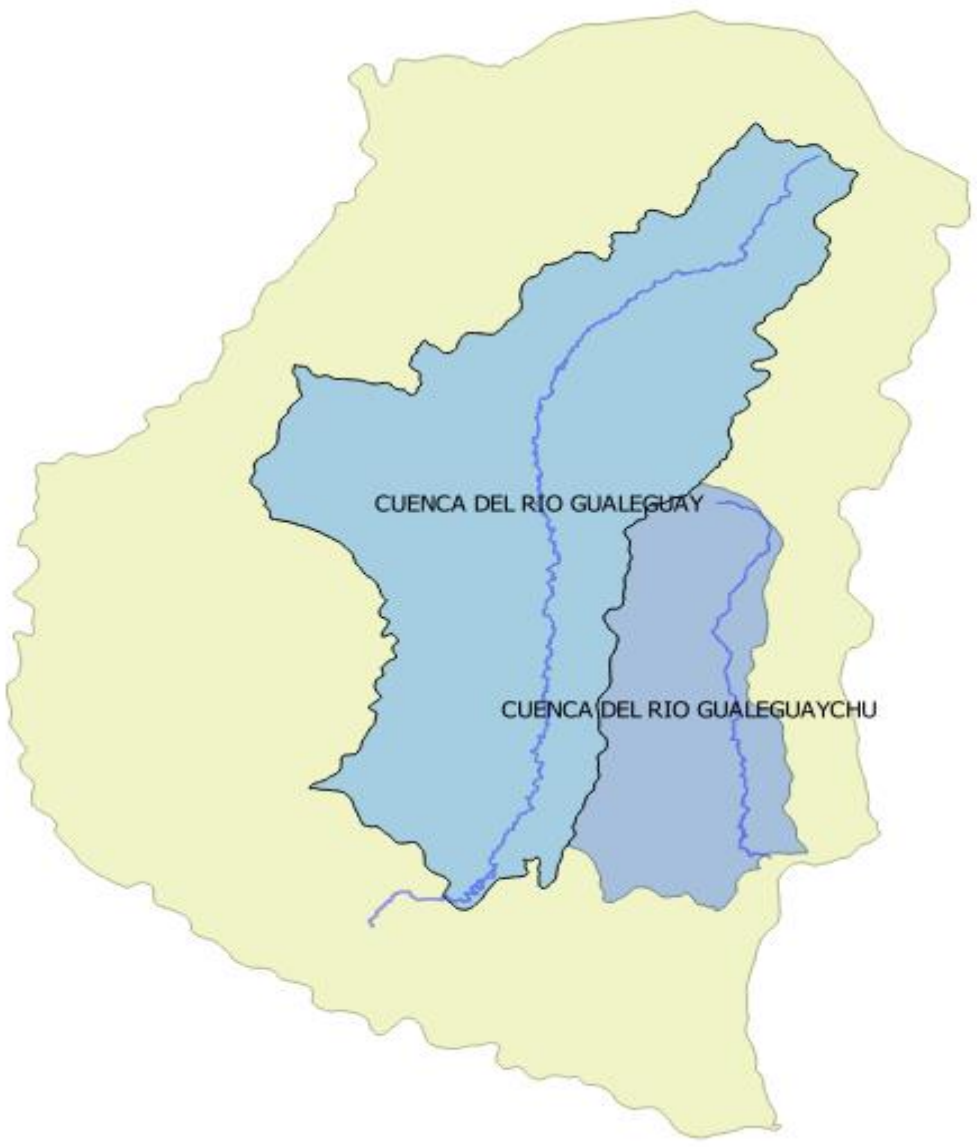

Figura 2.1 Provincia de Entre Ríos.Se destacan el Rio Gualeguay y Gualeguaychú, y cuencas homónimas.

La cuenca del rio Gualeguay ocupa el $30 \%$ del territorio entrerriano, compuesta por una gran variedad de suelos fértiles. El río homónimo tiene un régimen regular de crecientes desde marzo hasta julio, produciendo inundaciones. El principal componente edafológico son las arcillas, lo que favorece el escurrimiento. Se divide en dos ecorregiones: mesopotamia 
hacia el norte $(90 \%)$, con relieves bajos, ondulaciones, drenaje pobre e indefinido, y de pastizales húmedos (10\%) (Daniele y Natenzon, 1994).

La cuenca del rio Gualeguaychú se encuentra al sudeste de la provincia ocupando una superficie de $6690 \mathrm{~km}^{2}$, sus suelos son arcillosos, y se encuentra dentro de la ecorregión de pastizales húmedos. Su relieve es suavemente ondulado.

Los seis establecimientos donde se realizaron los muestreos se ubican en los siguientes departamentos (Figura 1.4): A) Departamento Tala, que contiene 158.132 cabezas de ganado (FUCOFA, 2015). Dentro de éste se encontraron los establecimientos "Los Castores" y "Las Casuarinas". B) Departamento de Gualeguay, con 285.935 animales (FUCOFA, 2015). Se trabajó en el establecimiento "San Julián". C) Departamento de Uruguay, con 251.144 cabezas, donde se muestrearon los establecimientos "El Cerro" y "La Yanera". D) Departamento de Gualeguaychú, que cuenta con 423.353 cabezas, siendo este el más alto de la provincia. Allí se trabajó en el establecimiento "La Torcaza". La ubicación de los establecimientos se grafica en la figura 2.2.

Los establecimientos presentaron heterogeneidad de razas, carga animal y sistemas de manejo, siendo un denominador común la categoría representada (vacas), y el pastoreo extensivo sobre praderas naturales.

A continuación, se detallan las particularidades de cada establecimiento:

a. Establecimiento “Los Castores" (32²3'1.40" S; 59 6'21.40” O): se ubica a $7 \mathrm{~km}$ de la ciudad de Rosario del Tala, pose 1200 Ha y gran parte del 
mismo son bañados destinados a la ganadería. Está limitado hacia el sur por el arroyo "La Ollita" y atravesado por arroyos temporarios. El predio contiene 200 bovinos de raza Hereford y sus cruzas, y realizan cría bovina. (Figura 2.2)

b. Establecimiento "Las Casuarinas" ( $32^{\circ} 28^{\prime} 21.38^{\prime \prime}$ S; $59^{\circ} 6^{\prime} 47.86^{\prime \prime}$ O): se sitúa a 22 km de Rosario del Tala, cercano al paraje "Las Guachas". Posee $298 \mathrm{Ha}$, de las cuales $60 \mathrm{Ha}$ son ocupadas por una laguna. Contiene además arroyos temporarios, y en parte es recorrido por el río Gualeguay, por lo que, en épocas de crecida, gran proporción del campo se inunda. Cuenta con 198 cabezas de cría bovina extensiva, principalmente de la raza Hereford y cruzas. Carece de instalaciones (mangas, corrales, aguadas), y asesoramiento profesional (Figura 2.2).

c. Establecimiento "San Julián" (3251'59.11" S; 59²6’51.46" O): está situado en el departamento Gualeguay, al norte de la ciudad homónima, próximo al paraje Lazo (Figura 2.2). Posee 1200 hectáreas, y se encuentra limitado hacia el noroeste por el arroyo Clé, el cual tributa al río Gualeguay, y en épocas de lluvia abundante, desborda inundando en buena parte los potreros donde se encuentran los animales. Desarrolla producción bovina (aproximadamente 500 cabezas de raza Hereford, Aberdeen Angus y cruzas) y ovina.

d. Establecimiento "El Cerro" (32 $35^{\prime} 0.70^{\prime \prime}$ S; $58^{\circ} 29^{\prime} 53.00^{\prime \prime}$ O): contiene $1255 \mathrm{Ha}$, de las cuales $300 \mathrm{Ha}$ son destinadas al ganado y el resto se destina a agricultura. Limita hacia el suroeste por el rio Gualeguaychú, por lo que las zonas cercanas a este son bajas e inundables, estando, además, 
circunscripto por numerosos bañados y acúmulos de agua temporarios. Cuenta con 120 bovinos, de los cuales 70 pertenecen a un plantel Aberdeen Angus.

e. Establecimiento "La Yanera" (32²4'29.20" S; 58¹6’34.80” O): presenta una superficie de $160 \mathrm{Ha}$, es atravesado por el arroyo Colman y gran parte del establecimiento está constituido por bañados. Solo se dedica a la producción bovina (cría e invernada), con un total de 105 animales británicos cruza. No se realizan de rutina controles sanitarios ni mejoramiento productivo.

f. Establecimiento "La Torcaza" (33²1'25.90" S; 58³9'57.14" O): cuenta con una superficie de $400 \mathrm{Ha}$, siendo la mayor parte bajos destinados a cría bovina. Limita hacia el sur con el arroyo "Ñancay". Cuentan con 300 animales de raza Hereford, asesoramiento sanitario, y se desparasita regularmente con albendazol e ivermectina. Además, se realizan tratamientos para $F$. hepatica, utilizando triclabendazol dos veces por año, en otoño y primavera. Anualmente se vacuna contra hemoglobinuria bacilar y carbunclo, más la aplicación de cobre inyectable 3 veces al año.

\subsubsection{Trabajos de campo y laboratorio}

Los muestreos se realizaron entre marzo de 2013 y septiembre de 2015 , en forma trimestral. No obstante, las inundaciones registradas en 2014 dificultaron el acceso y modificaron los intervalos de muestreo en algunos establecimientos. 
En cada muestreo, se colectó, al azar, materia fecal de forma individual a 20 vacas adultas. Las muestras se identificaron individualmente y se trasladaron refrigeradas hasta el laboratorio (CEDIVE, Facultad de Cs. Veterinarias, UNLP). Se procesaron 2 gramos de materia fecal de cada animal, mediante la técnica de filtración por tamices y sedimentación (Ueno y Concalves, 1988). El sedimento fue coloreado con azul de metileno al $1 \%$ y se observó bajo lupa estereoscópica a 30 aumentos. De esta forma, los huevos de $F$. hepatica se diferencian por su color ámbar de los de Paramphistomum spp., que son transparentes. De cada muestra se calculó el número de huevos por gramo de materia fecal (HPG). En base a estos resultados se determinaron el promedio de HPG para cada muestreo y la prevalencia (positivos a F. hepatica/total x 100).

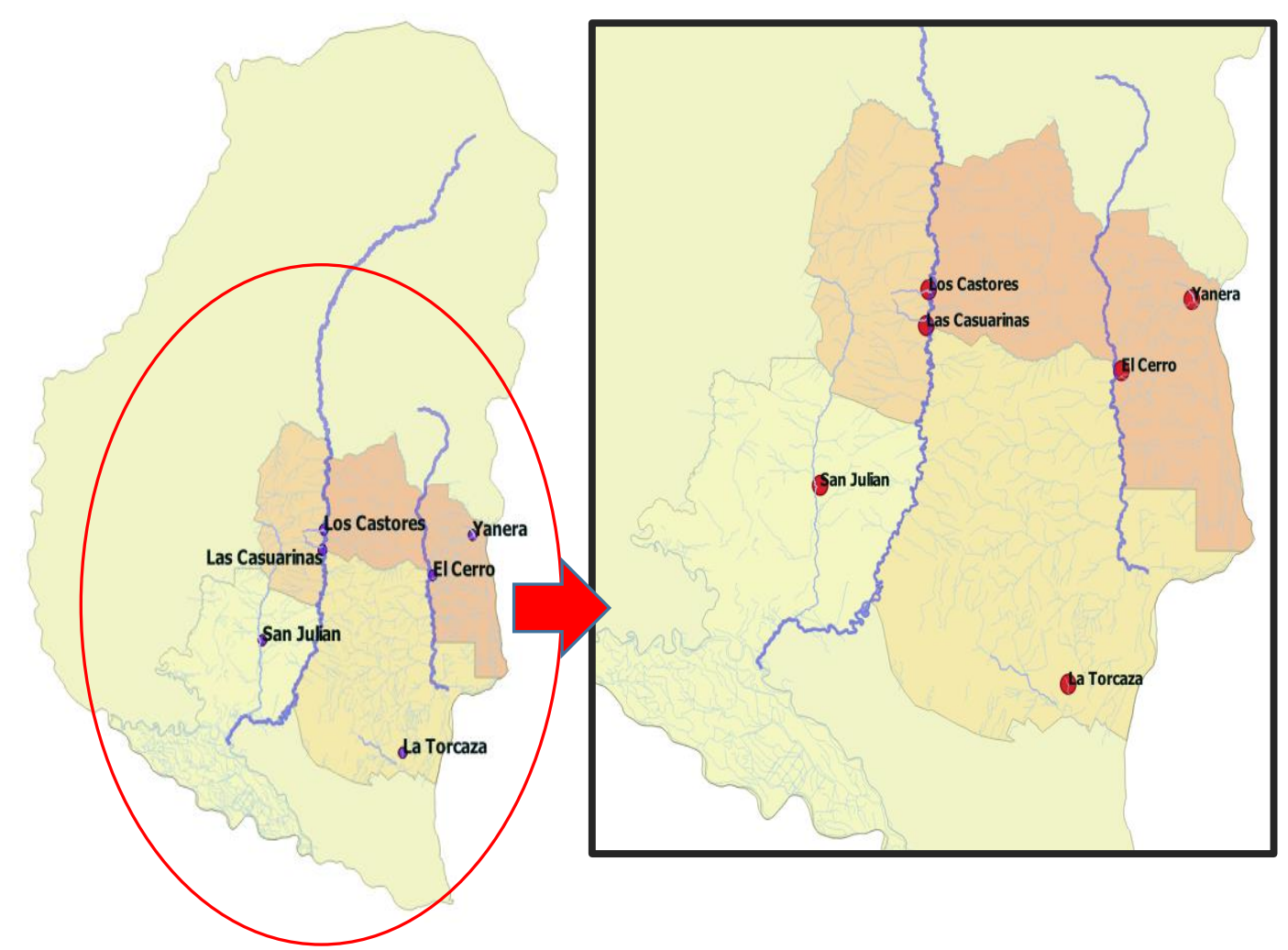

Figura 2.2. Ubicación de los establecimientos estudiados dentro de la provincia de Entre Ríos. 
2.2.3. Obtención de datos climáticos, geográficos y confección de archivos SIG

Los establecimientos se georreferenciaron in situ utilizando GPS (Garmin ${ }^{\odot}$ eTREx 20). Los datos climáticos fueron recopilados de los centros meteorológicos más cercanos a los establecimientos, los cuales fueron cedidos por la Dirección de Hidráulica de la Provincia de Entre Ríos (http://www.hidraulica.gob.ar). De esta forma se compilaron valores mensuales de temperaturas mínimas, medias y máximas, precipitaciones, déficit y exceso hídrico, tanto para el mes en curso, como para dos meses y cuatro meses antes de la fecha de muestreo de los años 2013 al 2015. La comparación de datos climáticos y ambientales anteriores con cada evento de muestreo se realizó para verificar la incidencia del período prepatente en la prevalencia. También se obtuvieron datos de tipo de suelo mediante acceso a bases de datos abiertas (http://geointa.inta.gov.ar).

Para la confección de SIG se empleó el programa Qgis versión 2.18, de acceso libre (https://www.qgis.org). En este programa se cargó la capa "suelos de Argentina" (shapefile de la página de GEOINTA http://geointa.inta.gov.ar), y una capa de la provincia de Entre Ríos (provincia_ER). A partir de estas dos se generó la capa "tipo de suelos de Entre Ríos" (tipo_sueloER). Sobre esta se creó una capa de puntos con las coordenadas de los establecimientos (puntos_campos). El sistema de referencia de coordenadas fue EPSG 4357-POSGAR 2007/Argentina 5. A partir de la capa puntos_campos se definieron zonas de influencia (buffers), proporcionales a las hectáreas de cada establecimiento, originando así otra 
capa denominada "buffer_campos". Finalmente, se confeccionó una nueva capa con los tipos de suelos de los establecimientos que se relacionó con la anterior, y se denominó "tipo_suelos_campos".

De la capa "tipo_suelo_campos" se obtuvieron los datos del área de cada clase de textura de suelo (Figura 2.3). Conociendo el área total de cada establecimiento, obtenidos a partir del radio, se obtuvo la proporción de cada textura de suelo por establecimiento.

Para evaluar la incidencia de la temperatura $\left(\mathrm{T}^{\circ}\right)$, se generó la variable dicotómica denominada "periodo del año", con dos resultados posibles: baja temperatura o alta temperatura. Se consideró "periodo de temperatura baja" a aquellos meses cuya diferencia de temperatura máxima menos temperatura máxima de 4 meses antes resultó menor a cero, indicando un descenso de la temperatura. Resultaron entonces meses de baja temperatura: abril (4), mayo (5), junio (6), julio (7) y agosto (8). Por otra parte, se consideró "periodo de temperatura alta" a aquellos meses cuya diferencia de temperatura máxima actual menos temperatura máxima 4 meses antes resultó mayor a cero, lo cual manifiesta un ascenso de la temperatura. Resultaron entonces meses de alta temperatura: septiembre (9), octubre (10), noviembre (11), diciembre (12), enero (1), febrero (2) y marzo (3). De esta forma se recategorizaron a los meses del año en los cuales se realizaron muestreos, lo cual permite agrupar las mediciones, y compararlas entre grupos de alta o baja temperatura. 
Figura 2.3 Imágenes obtenidas por sistemas de información geográfica (programa Qgis), para la región sur de Entre Ríos.
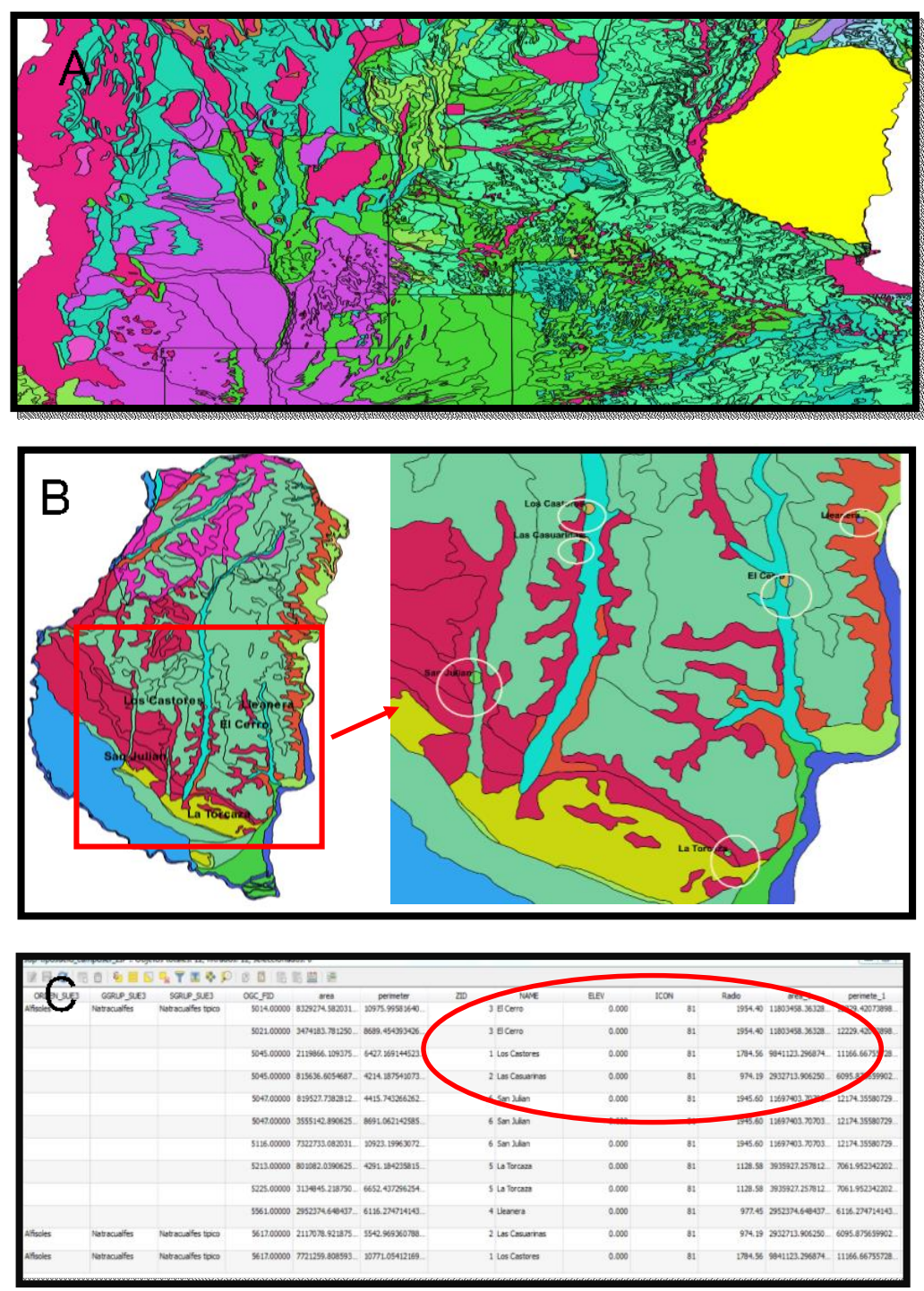

A) Capa de tipo de suelos de Argentina, con selección de la provincia de Entre Ríos (fondo amarillo), B) capa "Buffer_campos" de los establecimientos, conteniendo el tipo de suelos que estos presentan C) Captura de pantalla de tabla de atributos de tipo de suelo de los establecimientos.

Variables Epidemiológicas: se calculó la prevalencia (número de animales parasitados respecto al total de animales muestreados), y huevos por gramo (HPG) promedio, para cada fecha de muestreo. 


\subsubsection{Evaluación del estado de resistencia a drogas}

Para determinar cuál es el estado de resistencia regional a los fasciolicidas se realizó inicialmente un test de reducción del recuento de huevos (TRRH) en los establecimientos San Julián, Los Castores, El Cerro y La Torcaza. No fue posible su realización en los establecimientos La Yanera (Depto. de Uruguay), y Las Casuarinas (Depto. de Tala), por no contar con personal para el encierro de la hacienda en las fechas necesarias.

Para realizar el TRRH, se tomaron muestras individuales de materia fecal de sesenta bovinos de cada uno de los establecimietos, categoría vaca adulta, bajo la condición de presentar más de cinco HPG de $F$. hepatica. Los ensayos de resistencia se realizaron entre marzo y julio de 2013 , dependiendo de las fechas coordinadas para muestreos y disponibilidad de cada campo para encerrar los animales. Los animales elegidos fueron agrupados de forma homogénea en base a sus conteos de huevos de $F$. hepatica, y dependiendo del tratamiento que recibieron (día 0), se asignaron a los siguientes grupos:

G1: tratamiento con albendazol (ABZ), a $10 \mathrm{mg} / \mathrm{kg}$, por vía oral $(\mathrm{n}=15)$; $\mathrm{G} 2$ : tratamiento con triclabendazol (TCBZ), a $10 \mathrm{mg} / \mathrm{kg}$, por vía oral ( $\mathrm{n=15);} \mathrm{G3:}$ tratamiento con closantel (CSTL), a $15 \mathrm{mg} / \mathrm{kg}$, vía subcutanea ( $\mathrm{n=15}$ ); G4: grupo sin tratamiento $(n=15)$ todos los tratamientos se realizaron a dosis única. Posteriormente se tomaron muestras fecales el día +7 y +21 (postratamiento). Las muestras fueron analizadas en laboratorio (CEDIVEFCV-UNLP), por la técnica descripta por Ueno y Goncalves (1998). 


\subsubsection{Análisis estadístico}

Para la comparación de proporciones poblacionales, se utilizó prueba de Z. Para la comparación de medianas poblacionales para variables que no siguen una distribución normal perteneciente a muestras independientes, se emplearon las pruebas no paramétricas de Mann-Whitney (2 grupos) y Kruskal-Wallis (más de dos grupos), seguido por test de Dunn (post-hoc). La inclusión en uno u otro análisis se realizó de acuerdo al resultado del test de normalidad de Shapiro-Wilks. En el caso de variables categóricas, los datos fueron comparados por Chi2, con posterior estimación del odds ratio. Las correlaciones entre las variables textura de suelo y prevalencia, fueron determinadas mediante correlación de Pearson, o análisis no paramétrico de Spearman, de acuerdo a su distribución. En todos los casos, se consideraron diferencias significativas cuando el valor de $p$ fue menor o igual a 0,05, y tendencia entre 0,1 y 0,05 .

Para determinar la eficacia de cada una de las drogas evaluadas, se utilizó la siguiente formula:

$$
\text { \% de eficacia: } \frac{\text { HPG G4 - HPG G1/2/3 (día +21) }}{\text { HPG G4 }} \times 100
$$

Los grupos se compararon estadísticamente mediante prueba de $\mathrm{T}$, luego de una transformación logarítmica (Olaechea et al., 2011).

Los análisis estadísticos se realizaron con los programas IBM SPSS Statistics ver. 23 (IBM Corp.), InfoStat ver. 2017 (UNC, Argentina) y GraphPad Prism 6.0 (GraphPad software, USA). 


\subsection{Resultados}

El promedio de $\mathrm{T}^{\circ}$ (desvío estándar), máxima, mínima y media, respectivamente, fue de $26^{\circ} \mathrm{C}(2,7) 14^{\circ} \mathrm{C}(2,3)$, y $19,7^{\circ} \mathrm{C}(2,3)$ para el periodo de alta temperatura (figura 2.4$)$ y $21^{\circ} \mathrm{C}(2,9), 10,5^{\circ} \mathrm{C}(2,3), 15.5^{\circ} \mathrm{C}$ $(2,5)$ para el de baja temperatura (figura 2.5). El promedio de las precipitaciones (desvío estándar), fueron de 120,5 mm (68), y 122,7 mm (221), para los períodos de alta y baja temperatura, respectivamente (figura 2.6).

El promedio de la prevalencia de los establecimientos de cada cuenca, así como la comparación de prevalencias entre cuencas, departamentos y establecimientos dentro de una misma cuenca, se detallan en la figura 2.7. Al comparar las prevalencias promedio, no se hallaron diferencias entre las cuencas Gualeguay y Gualeguaychú $(p=0,24)$, sin embargo, se encontraron diferencias significativas entre los establecimientos de Gualeguay y Tala $(p=0,001)$ (pertenecientes a la cuenca río Gualeguay), y entre establecimientos de las localidades C. del Uruguay y Gualeguaychú. $(p=0,001)$ (pertenecientes a la cuenca del río Gualeguaychú) (Tabla 2.1, Figura 2.7).

Se halló asociación positiva entre las variables prevalencia y temperatura, ( $p<0,001)$, (Tabla 2.2), indicando que en períodos de alta temperatura se incrementa en promedio 3 veces la probabilidad de hallar animales positivos, respecto a la probabilidad de hallarlos en período de baja temperatura (OR 2,86; IC95\% 1,87-3,85). 
Para los valores de HPG, solo se halló una tendencia en la diferenciación entre establecimientos, $(p=0.056)$.

Figura 2.4. Distribución de temperaturas máximas en períodos de baja y alta temperatura

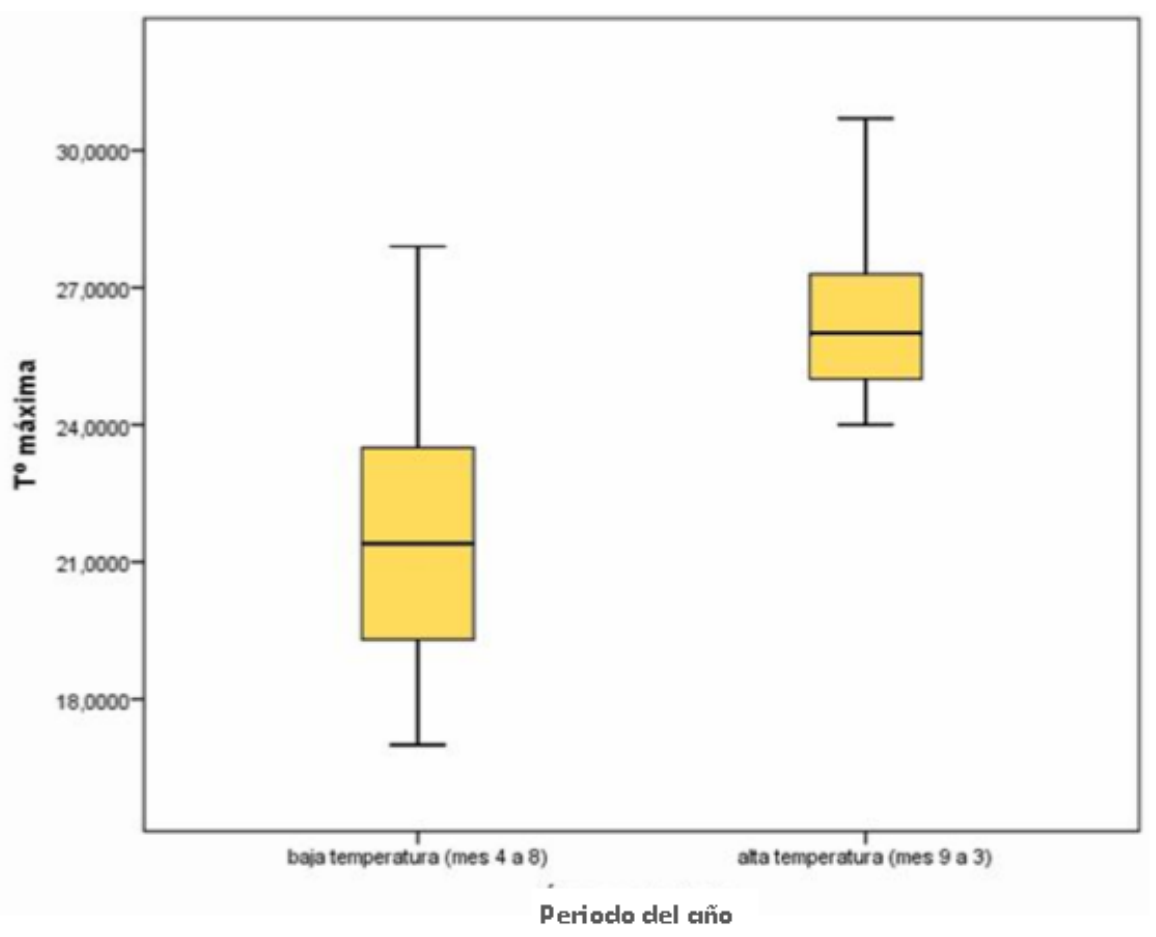


Figura 2.5. Distribución de temperaturas mínimas en períodos de baja y alta temperatura

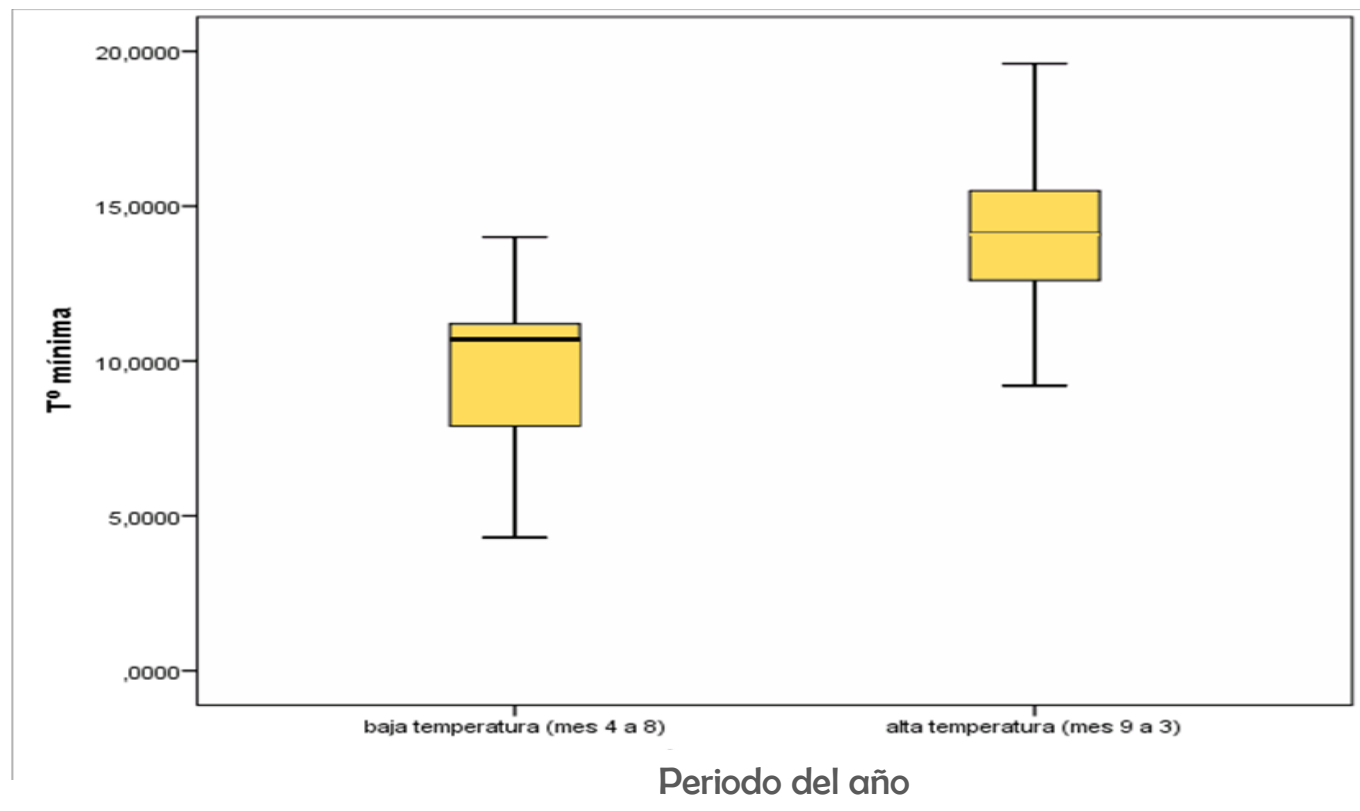

Figura 2.6.Distribución de precipitaciones en períodos de baja y alta temperatura.

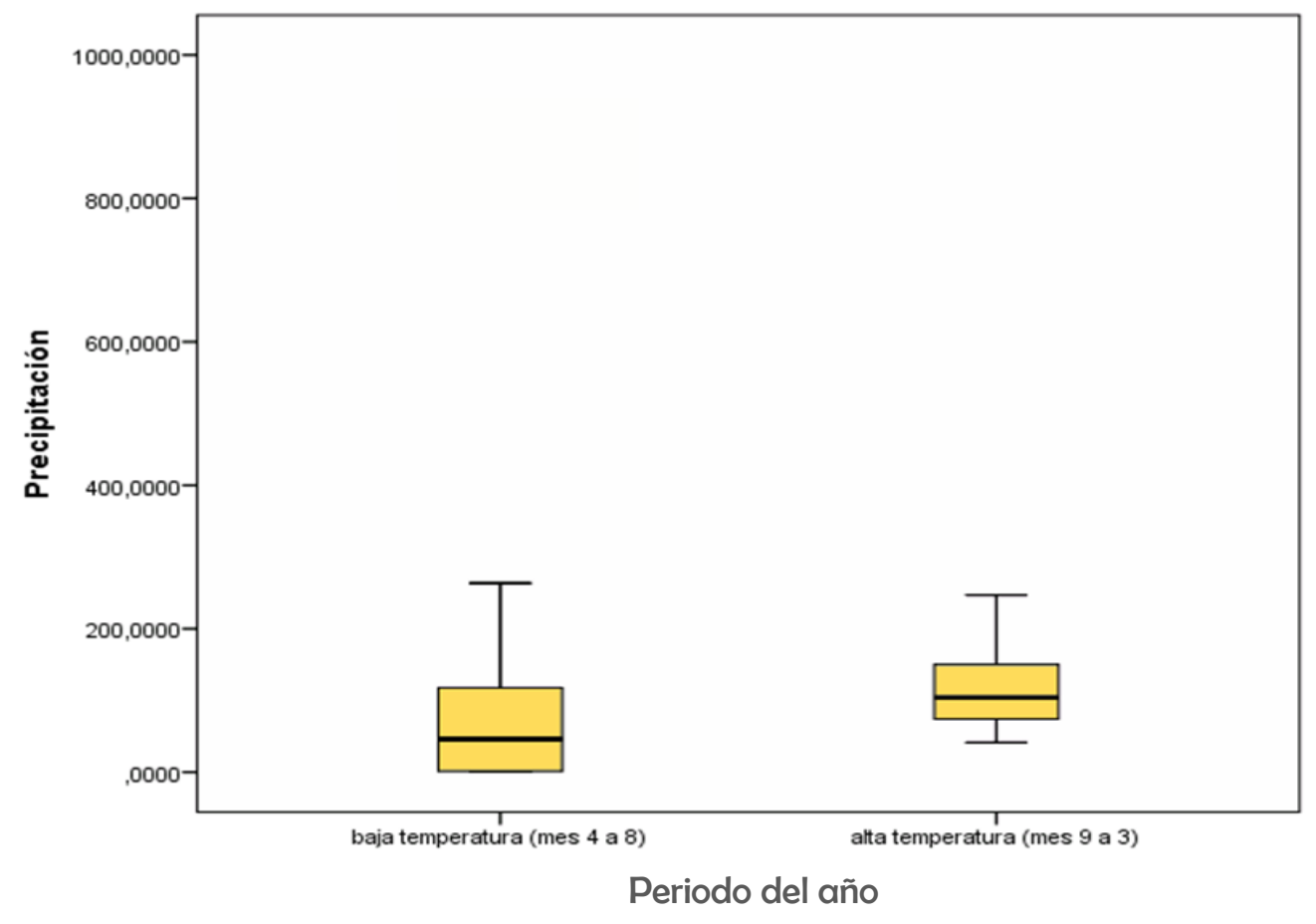

Página | 41 
Figura 2.7. Comparación de prevalencias generales (promedio de todos los muestreos), a nivel de cuencas, localidades y establecimientos de cada localidad.

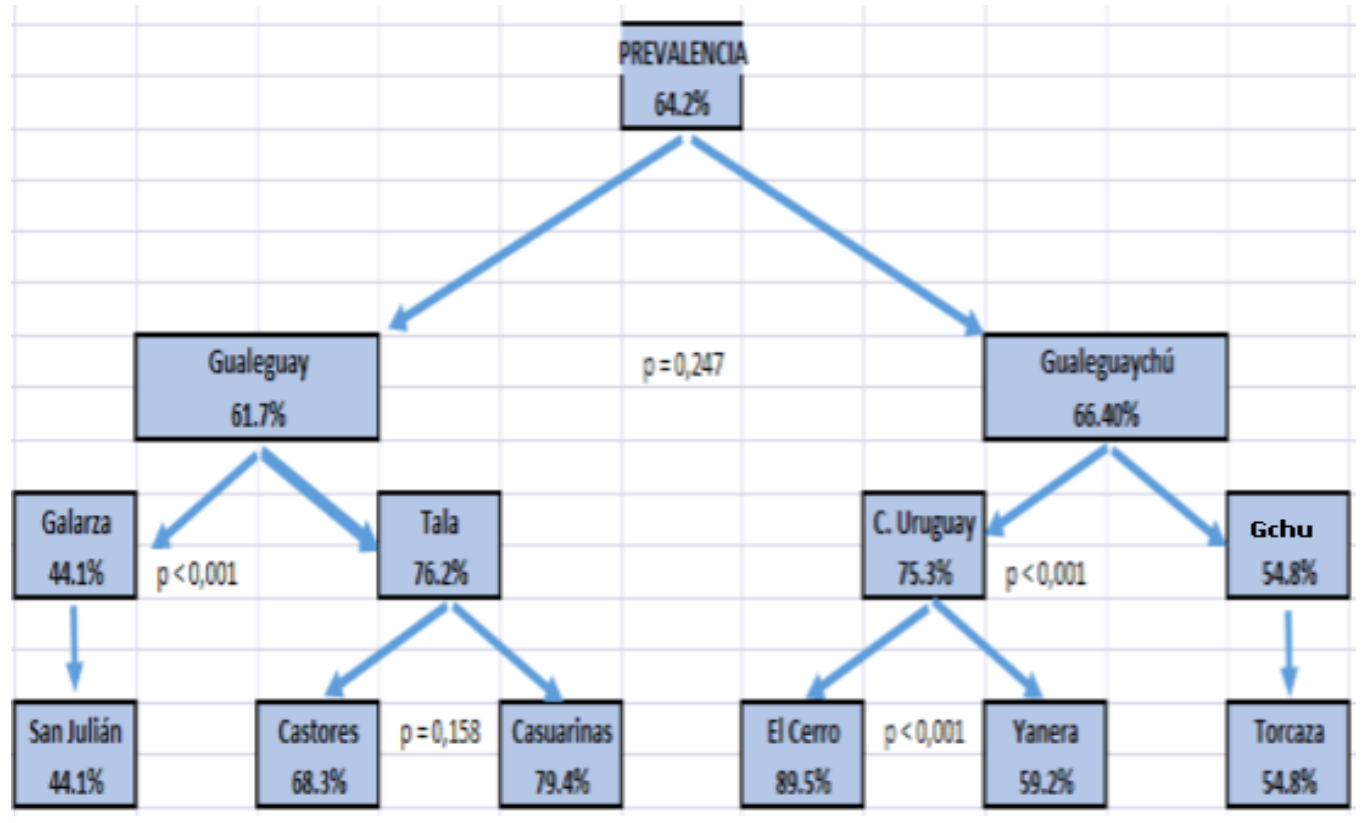

Tabla 2.1. Valores de p para la comparación de prevalencias de F. hepatica en bovinos, entre establecimientos, a través de la prueba de $z$.

\begin{tabular}{lllllll}
\hline Localidad & & & \multicolumn{2}{l}{ San } \\
& Castores & Casuarinas & El Cerro & Julián & Torcaza & Yanera \\
\hline Castores & 1 & 0.193149 & 0.005203 & 0.010713 & 0.147067 & 0.424327 \\
Casuarinas & 0.193149 & 1 & 0.072483 & 0.000000 & 0.000127 & 0.004502 \\
El cerro & 0.005203 & 0.072483 & 1 & 0.000000 & 0.000000 & 0.000009 \\
San Julián & 0.010713 & 0.000000 & 0.000000 & 1 & 0.096937 & 0.041301 \\
Torcaza & 0.147067 & 0.000127 & 0.000000 & 0.096937 & 1 & 0.560360 \\
Yanera & 0.424327 & 0.004502 & 0.000009 & 0.041301 & 0.560360 & 1 \\
\hline
\end{tabular}


Tabla 2.2. Comparación de prevalencias entre períodos de temperatura baja (abril a agosto) y temperatura alta (septiembre a marzo).

\begin{tabular}{ccccc}
\hline & & Negativo & Positivo & TOTAL \\
\hline $\begin{array}{c}\text { Baja temperatura } \\
\text { (mes 4 a 8) }\end{array}$ & $\mathrm{N}$ & 120 & 130 & 250 \\
\cline { 2 - 5 } & $\%$ & $48.00 \%$ & $52.00 \%$ & $100 \%$ \\
\hline $\begin{array}{c}\text { Alta temperatura } \\
\text { (mes 9 a 3) }\end{array}$ & $\mathrm{N}$ & 76 & 221 & 297 \\
\cline { 2 - 5 } & $\%$ & $25.60 \%$ & $74.40 \%$ & $100 \%$ \\
\hline Total & $\mathrm{N}$ & 196 & 351 & 547 \\
\hline
\end{tabular}

Tabla 2.3. Recuento de huevos por gramo (HPG) de F. hepatica por establecimiento.

\begin{tabular}{ccccc} 
Establecimiento & $\begin{array}{c}\text { Promedio } \\
\text { HPG }\end{array}$ & D.E. & Min. & Max. \\
\hline Castores & 3.2 & 1.7 & 1.7 & 5 \\
Casuarinas & 13.0 & 10.8 & 2.3 & 23.9 \\
El Cerro & 16.9 & 6.7 & 8.1 & 24.9 \\
San Julián & 8.9 & 17.8 & 0 & 48.9 \\
Torcaza & 6.8 & 7.1 & 0.3 & 16.5 \\
Yanera & 6.7 & 5.4 & 0.3 & 14.9 \\
\hline
\end{tabular}

D.E.: desvío estándar; Max.: valor máximo; Min.: valor mínimo.

No se encontró asociación estadísticamente significativa entre las variables climáticas $\mathrm{T}^{\circ}$ máxima, $\mathrm{T}^{\circ}$ mínima, $\mathrm{T}^{\circ}$ media, precipitaciones, exceso y déficit hídrico, en relación a la prevalencia y HPG medidos en el mes en curso, a los dos y a los cuatro meses antes. Sin embargo, se halló asociación entre la prevalencia y la temperatura máxima de 2 meses antes $(p=0,041)$. En la tabla 2.5 se muestran las proporciones de tipos de suelos que presenta cada establecimiento, obtenido de la capa tipos_suelos_campos (tabla 2.4) 
En este sentido, se halló correlación significativa entre las variables prevalencia y tipo de suelo franco $(R=0,81 ; p=0,03)$. en la figura 2.10 se muestra la distribución de la textura de suelo franco en la provincia de Entre Ríos.

Tabla 2.5. Atributos de la capa tipos_suelos_campos obtenida por SIG.

\begin{tabular}{llllll} 
Establecimiento & ORDEN_SUE1 & TEXT_BS1 & DRENAJE_S1 & ALCALIN_S1 & Radio(m) \\
\hline Los Castores & Molisoles & Franco arcillo limos & Moderado & No sodico & 1784.56 \\
Los Castores & Inceptisoles & Franca & Pobre & Muy fuerte & 1784.56 \\
Las Casuarinas & Molisoles & Franco arcillo limos & Moderado & No sodico & 974.19 \\
Las Casuarinas & Inceptisoles & Franca & Pobre & Muy fuerte & 974.19 \\
El Cerro & Inceptisoles & Franca & Pobre & Muy fuerte & 1954.40 \\
El Cerro & Vertisoles & Arcillo limosa & Moderado & No sodico & 1954.40 \\
Yanera & Molisoles & Franco arcillo areno & Imperfecto & No sodico & 977.45 \\
La Torcaza & Molisoles & Franco arcillo limos & Moderado & No sodico & 1128.58 \\
La Torcaza & Alfisoles & Franco arcillo limos & Imperfecto & Muy fuerte & 1128.58 \\
San Julián & Molisoles & Franco arcillo limos & Moderado & No sodico & 1945.60 \\
San Julián & Molisoles & Franco arcillo limos & Moderado & No sodico & 1945.60 \\
San Julián & Entisoles & Franco arcillo limos & Pobre & No sodico & 1945.60
\end{tabular}

Referencias: orden_sue1, grupo de suelo principal según Soil Taxonomy; text_bs1, textura del suelo principal; drenaje_s1, drenaje del suelo principal; alcalin_s1, alcalinidad del suelo principal. Radio: valor en metros obtenido a partir del área de la capa de buffers, de acuerdo a la superficie de cada establecimiento.

Tabla 2.6. Proporción porcentual de tipo de suelo de los establecimientos estudiados, calculada mediante SIG (capa tipo_suelos_campos).

\begin{tabular}{ccccl}
\hline Establecimiento & $\begin{array}{c}\text { Franco } \\
\text { arcillo } \\
\text { limoso }\end{array}$ & Franco & $\begin{array}{l}\text { Arcillo } \\
\text { limoso }\end{array}$ & $\begin{array}{l}\text { Franco } \\
\text { arcillo } \\
\text { arenoso }\end{array}$ \\
\hline El Cerro & 0 & $71 \%$ & $29 \%$ & 0 \\
\hline Yanera & 0 & 0 & 0 & $100 \%$ \\
\hline Torcaza & 0 & 0 & $100 \%$ & 0 \\
\hline Casuarinas & $28 \%$ & $72 \%$ & 0 & 0 \\
\hline Castores & $22 \%$ & $78 \%$ & 0 & 0 \\
\hline San Julián & 0 & 0 & $100 \%$ & 0 \\
\hline
\end{tabular}


Figura 2.8. Disposición de textura de suelo franco en Entre Ríos, en relación a los establecimientos estudiados.

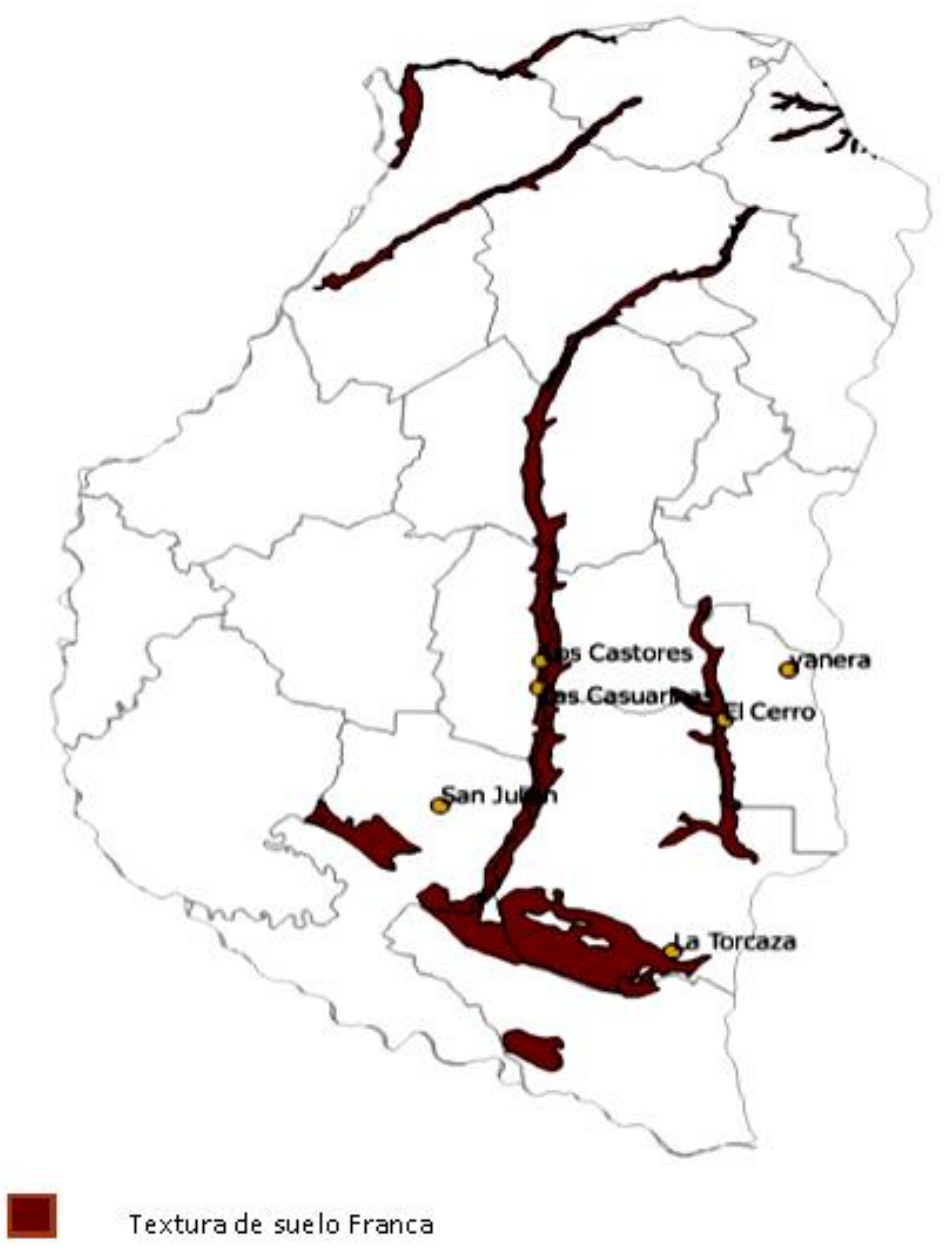

Evaluación de la resistencia antihelmíntica

Tanto TCBZ como closantel mostraron niveles de eficacia satisfactorios (figura 2.11). No obstante, en los cuatro establecimientos se observó resistencia a $A B Z$, a dosis fasciolicida estándar para bovinos (10 mg/kg). 
Figura 2.9. Eficacia de triclabendazol, albendazol y closantel en los establecimientos estudiados.

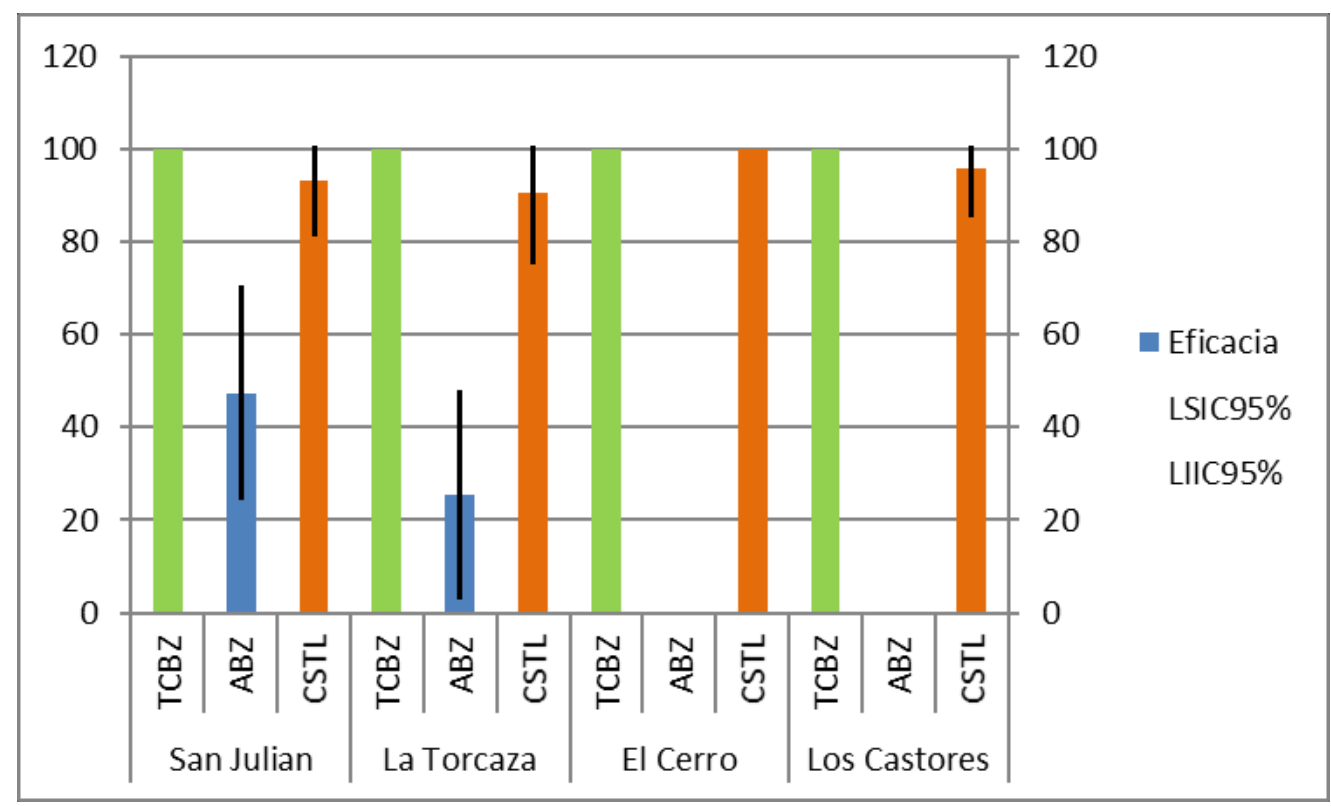

LSIC95\% LIIC95\%: límites superior e inferior, respectivamente, para el intervalo de confianza del95\% (líneas negras).

\subsection{Discusión}

Durante el periodo de estudio (2013-2015), los bovinos mostraron parasitismo por $F$. hepatica en cada muestreo y en todos los establecimientos. Los resultados de prevalencias superaron siempre el $40 \%$, lo que confirma la endemicidad de esta parasitosis en la región.

Las diferencias en la prevalencia observada entre los establecimientos podrían adjudicarse en parte al manejo aplicado, algunos de ellos realizan control farmacológico estratégico mientras que otros no lo realizan o lo hacen solo cuando les es factible operativamente.

También se observó incidencia de la temperatura en la prevalencia, pese a no observarse una estacionalidad marcada. No obstante, en los periodos 
de altas temperaturas (septiembre a marzo) la probabilidad de encontrar alta proporción de animales infestados es casi 3 veces superior a las épocas de baja temperaturas (abril- agosto). Esto debería considerarse al planificar estrategias de control farmacológico y de manejo.

La falta de asociación significativa entre otras variables climáticas y la infestación en el ganado no permitió determinar períodos de mayor riesgo. Pese a ello, la persistencia de excesos hídricos ya sea como producto de precipitaciones o crecidas de cursos de agua, posiblemente influya en la infestación en los animales a lo largo del año, y en el mantenimiento de la elevada tasa de infestación.

La utilización de SIG permitió asociar el tipo de suelo a la prevalencia de esta parasitosis, indicando una tendencia a presentar mayor infestación por F. hepatica en aquellos establecimientos que presentan mayor proporción de textura de suelo franco. En concordancia, los tres establecimientos con mayor proporción de suelo franco (tabla 2.6.), fueron los que presentaron los valores más altos de prevalencia en promedio (figura 2.9.). A su vez, la prevalencia de estos establecimientos fue significativamente mayor $(p<0,05)$, comparada con establecimientos de la misma cuenca con menor proporción de suelo franco (figura 2.9.; tabla 2.1.). Estos suelos se caracterizan por un drenaje pobre, permanecen saturados la mayor parte del tiempo y con exceso de humedad superficial (Arauz, 2011), siendo estas condiciones fundamentales para la presencia de los $\mathrm{HI}$ (Olaechea et al., 2007; Martins et al., 2012). Similares hallazgos fueron mencionados en Bélgica, donde establecimientos con textura de suelos franco presentaron 
mayor presencia de Galba truncatula, respecto a otros tipos de suelo (Charlier et al., 2011). Puede asumirse un mayor riesgo para el desarrollo de la fasciolosis en establecimientos que contengan este tipo de suelos, el cual parece proporcionalmente mayor al sur que al norte de la provincia (figura 2.8). Además, su distribución presenta un patrón vinculado a los principales ríos que dan nombre a las cuencas (figura 2.2y 2.8.).

Sin embargo, la proporción de los diferentes tipos de suelo puede ir modificándose con el transcurso de los años, lo cual puede condicionar el ambiente para el desarrollo de los $\mathrm{HI}$, y así ampliar o reducir la oferta de MTC. La incorporación de nuevas variables podría ampliar este análisis y agregar precisión a las estimaciones.

En cuanto a la eficacia antihelmíntica, detectamos que la resistencia al ABZ es frecuente en los bovinos de la región de estudio, en concordancia con observaciones previas en ovinos de la misma zona (Sanabria et al., 2013). Varias circunstancias pueden haber llevado a esta situación, entre ellas la subdosificación de $A B Z(5 \mathrm{mg} / \mathrm{kg})$, para el tratamiento de nematodos gastrointestinales (Beesley et al., 2017, Sanabria et al., 2013), contribuyendo así a una alta presión de selección de aislamientos de $F$. hepatica resistentes a dicha droga. Además, es llamativa la difusión de este fenómeno en la zona, contando con pocos antecedentes de este tipo a nivel mundial. En Perú, se reportó una situación similar donde se detectó resistencia a TCBZ en cuatro establecimientos analizados (Rojas Moncada et al., 2013). La generalización de este fenómeno a nivel local hace suponer la existencia de otra vía de difusión. Posiblemente, el desplazamiento de 
los $\mathrm{HI}$ infectados con formas larvarias ABZ-resistentes, mediante el ascenso y descenso de los numerosos cursos de agua, pueda ser un factor a analizar. Finalmente, la alta eficacia observada frente a TCBZ, pone de manifiesto que, pese a pertenecer al mismo grupo farmacológico, la halogenación de la molécula de TCBZ implica mecanismos de acción diferentes a los de ABZ.

Se sabe de la afinidad de los bencimidazoles carbamatos a la $\beta$-tubulina microtubular como blanco principal, mientras que se ha postulado que mecanismos de detoxificación celular, como los mediados por glicoproteína $\mathrm{P}$, se encontrarían exacerbados en aislamientos de $F$. hepatica resistentes al TCBZ (Kotze et al., 2014). Los aislamientos obtenidos a partir de estos trabajos permitirán profundizar en el conocimiento de resistencia antihelmíntica en $F$. hepatica, en ensayos subsecuentes. 


\section{Objetivo II}

\section{Análisis molecular de la estructura poblacional de Fasciola hepatica en el sur de la provincia de Entre Ríos}

\subsection{Introducción}

La genética de poblaciones estudia las relaciones entre las predicciones basadas en la herencia mendeliana, y las observaciones empíricas realizadas a través de la medición de genotipos y frecuencias alélicas (Hamilton, 2009). Para realizar estas observaciones, se emplean marcadores genéticos que intentan explicar los fenómenos evolutivos, distribución y características dentro de una población y entre poblaciones. Estas poblaciones, están sujetas a cambios evolutivos en los que subyacen cambios genéticos, y estos están influidos por factores como la selección natural, la deriva y flujo genéticos, la mutación y la recombinación (Cabrero y Camacho, 2002). De acuerdo a la ley de equilibrio de Hardy Weinberg, en una población suficientemente grande, apareada al azar, y no sujeta a variaciones por selección, mutación o migración, las frecuencias génicas permanecen constantes de una generación a otra (Stern, 1943). A partir de esta "hipótesis de nulidad", la incidencia de cambios y movimientos poblacionales producirá desvíos de este equilibrio y, por ende, nuevas variantes genéticas.

Respecto a ello, Sewall Wright (1943), postuló que los organismos están formando poblaciones discretas (modelo de islas) y que se diferencian de las otras poblaciones por mutaciones o deriva genética (frecuencias 
alélicas remanentes luego de sucesivas recombinaciones en una población). De forma opuesta, Wright (1965), planteó el modelo de aislamiento por distancia, mediante el cual se forman poblaciones con distribución continua de acuerdo a la distancia física entre padres e hijos, y la posibilidad de intercambio genético está sujeta a la vecindad poblacional (Planter, 2007).

Para F. hepatica, la diferenciación de poblaciones puede relacionarse con interacciones hospedador-parasito, e incluso con la fijación a nivel poblacional de ciertas características, como la expansión de la resistencia a antiparasitarios (Vilas et al., 2012). Por ejemplo, Elliot et al. (2014), hallaron menor polimorfismo en aislamientos de campo susceptibles a TCBZ, en comparación con otros aislamientos TCBZ - resistentes, empleando marcadores mitocondriales.

Fasciola hepatica alcanza la madurez sexual en los conductos biliares del hospedador definitivo, donde se reproducen por autofecundación, fecundación cruzada e incluso partenogénesis (Ichikawa e Itagaki, 2012); esto, sumado a la multiplicación asexual dentro del HI, facilita un alto flujo de genes, y así, el potencial para promover altos niveles de variabilidad genética dentro de la población, lo que influye en la transferencia de genes relacionados a las diferentes características (Hurtrez-Bousses et al., 2004; Vilas et al., 2012).

Además, la presencia de múltiples hospedadores definitivos existentes podría conducir a procesos de selección de determinadas poblaciones de 
F. hepatica, influidas por los hábitos y comportamiento de las diferentes especies, resultando en una sub-estructuración de la población, y diversidad genética en distintos hospedadores y localidades geográficas (Cwiklinsky et al., 2015).

Para estudiar la estructura genética se han utilizado como marcadores, genes del ADN mitocondrial (ADNmt), como los codificantes para citocromo oxidasa I (COI) y nicotinamida adenina dinucleótido I (NADI), entre otros (Itagaki et al., 2005; Elliot et al., 2014; Amer et al., 2011). Los marcadores ADNmt son los mayormente utilizados en la construcción de mapas filogenéticos, debido a que presentan polimorfismo interespecífico, y evolucionan más rápido que el ADN nuclear (Hebert et al., 2003). Se ha propuesto un sistema de identificación global de especies basado en el Gen COI, denominado "barcode of life", disponible en www.barcodinglife.com (Reyna, 2013). Sin embargo, los marcadores ADNmt tienen algunas limitaciones, debido a la ausencia de recombinación, siendo esto de escasa utilidad para inferir dispersión genética entre subpoblaciones (Vilas et al., 2012). Es entonces necesario, en algunos casos, el empleo de marcadores de mayor polimorfismo. En este sentido, una opción son los marcadores microsatélites o secuencias repetidas en tándem (SRT) (Hurtrez-Boussès et al., 2004; Dar et al., 2011, 2013; Vilas et al., 2012; Cwiklinsky et al., 2015,). Los SRT son secuencias cortas repetidas de bases, situadas al azar en el genoma eucariota (Toth et al., 2000). Por su mayor polimorfismo son valorados para evaluar la diversidad genética y la estructura de poblaciones y subpoblaciones (Dar et al., 2011; Hurtrez-Bousses et al., 2004). Un 
ejemplo de su empleo masivo es su utilización en definición de relaciones parentales en prácticamente cualquier especie (Aykanat et al., 2014; Cosenza et al., 2015; Glazewska et al., 2018).

Teniendo en cuenta lo mencionado, el objetivo del presente trabajo fue caracterizar mediante diferencias genotípicas los aislamientos de $F$. hepatica presentes en los establecimientos, mediante el auxilio de marcadores SRT y ADNmt.

\subsection{Materiales y métodos}

Se recuperaron 104 ejemplares adultos de F. hepática a partir de necropsias realizadas a cuatro bovinos de los establecimientos: San Julián, Los Castores, Las Casuarinas y La Torcaza. Los mismos fueron recolectados de vesícula y vías biliares, se depositaron en recipientes identificados conteniendo solución fisiológica, y fueron trasladados al laboratorio refrigerados.

Una vez en el laboratorio, se lavaron tres veces con solución fisiológica y se preservaron en etanol 70 hasta su utilización.

Para la extracción de ADN se empleó la parte posterior de los ejemplares, se secaron entre papel tipo tissue y se inició su digestión por inmersión del

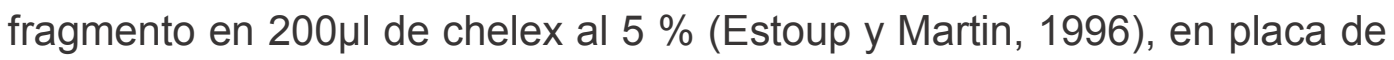
96 pocillos. Posteriormente se le incorporaron $5 \mu$ l de proteinasa K (SigmaAldrich, USA), y se incubó a $56{ }^{\circ} \mathrm{C}$ por 6 horas, con agitaciones periódicas en vortex, y finalmente las muestras fueron incubadas a $95^{\circ} \mathrm{C}$ por 10 minutos. El digesto fue homogeneizado y centrifugado a $10.000 \mathrm{~g}$ por 10 
segundos, y se tomaron $100 \mu \mathrm{l}$ de sobrenadante, para ser diluido en agua ultrapura (proporción 1:10) y almacenado a $-20^{\circ} \mathrm{C}$ para su posterior utilización.

Se emplearon 9 marcadores SRT (Hurtrez-Boussès et al., 2004; Cwiklinsky et al., 2015) (tabla 3.1), para evaluar la diversidad genética de F. hepatica de los establecimientos "San Julián" (departamento Gualeguay) (n=25), "La Torcaza” (departamento Gualeguaychú) (n=23), “Las Casuarinas” (departamento Tala) (n=31), y "Los Castores" (departamento Tala) $(n=25)$. No se pudo obtener ejemplares adultos de los establecimientos "Yanera" y "El Cerro" pertenecientes al departamento de Uruguay.

El ADN extraído se diluyó en una proporción 1:10 en agua ultrapura. Los loci fueron amplificados a partir de $4 \mu$ l de ADN diluído, en $20 \mu l$ de volumen de reacción, conteniendo $2 \mu \mathrm{l}$ de buffer 10x, 1,5 mM de $\mathrm{MgCl} 2$ (Promega, USA) 2 mM dNTPs (Invitrogen/Life Technologies, USA) 5-10 Pmol de cada primer y 1,3 U de Taq polimerasa (Promega, USA). La reacción de PCR se llevó a cabo en un termociclador MPI (Argentina), y consistió en una desnaturalización inicial a $94^{\circ} \mathrm{C}$ por 4 minutos, seguida de 35 ciclos de desnaturalización a $94^{\circ} \mathrm{C}$ por 30 segundos, annealing a temperatura específica para cada primer (tabla 3.1) por 30 segundos, elongación a $72^{\circ} \mathrm{C}$ por 30 segundos, y elongación final de $72^{\circ} \mathrm{C}$ por 10 minutos.

La presencia de productos de PCR del peso molecular esperado fue evidenciada por electroforesis en gel de agarosa al 2,5\%, comparación con 
un ladder de $50 \mathrm{pb}$, empleando SYBRSafe (Invitrogen, USA), y se observaron en transiluminador azul (Safe Imager, Invitrogen, USA).

Posteriormente se genotipificaron el total de las muestras positivas, utilizando $3 \mu \mathrm{l}$ de productos de PCR diluidos (1: 100) con $15 \mu \mathrm{l}$ de Hi-Di Formamide y $0.2 \mu \mathrm{l}$ de GeneScan-500 LIZ Size Standard y se analizaron en un analizador genético ABI Prism 3100 (Applied Biosystems). Los tamaños de alelos se estimaron utilizando el software GeneMapper® v. 4.0 (Applied Biosystems). El tamaño de los microsatelites fue analizado mediante el software GENESCAN (Applied Biosystems, USA). Tanto los procesos de secuenciación como su análisis se realizaron en el laboratorio Maladies Infectieuses et Vecteurs: Écologie, Génétique, Évolution et Contrôle (MIVEGEC) del Intitut de Recherche pour le Devélepppement (IRD) en Montpellier, Francia.

A partir de la información obtenida, se analizaron: números de alelos $(\mathrm{N})$, heterogeneidad observada y esperada ( $\mathrm{Ho} \mathrm{y} \mathrm{He}$ ), coeficiente de endogamia intrapoblacional (Fis) y tasa de autofecundación (S), calculada como $S=(2$ Fis) / (1+Fis) (Hartl y Clark, 1997). Se usó el índice de fijación (Fst) para estimar la diferencia de frecuencias alélicas entre poblaciones, indicados como promedio \pm DS. Los datos fueron analizados utilizado el programa GenoDive versión $2.0 b 23$ (Meirmans y Tinderen, 2004). La frecuencia genotípica se determinó utilizando GENOPOP 4.2.1 (Rousset, 2008, disponible en http//Kimura.univ-montp/russet/genopop.htm) 
Para el análisis filogenético se utilizó el marcador molecular COI del ADNmt, para lo cual se extrajo ADN de 40 adultos de $F$. hepatica (10 por cada establecimiento analizado), utilizando un kit de extracción comercial (Zimo Research. Quick-g DNA Miniprep). La amplificación se realizó en un volumen final de $50 \mu \mathrm{l}$, conteniendo $5 \mu \mathrm{l}$ de ADN molde; 1,25 U de Taq polimerasa (Promega, Madison, USA), $0.2 \mathrm{mM}$ de cada dNTP (Invitrogen/Life Technologies, USA), $2 \mathrm{mM}$ de $\mathrm{MgCl}$, $5 \mu \mathrm{l}$ de buffer, 0,1 $\mu \mathrm{M}$ de los primers Ita 8 (5'-ACGTTGGATCATAAGCGTGT-3'), e Ita 9 (5'CCTCATCCAACATAACCTCT-3') (Ichikawa e Itagaki; 2012). Dieciseis de los amplicones obtenidos (cuatro por establecimiento de origen) fueron purificados con un kit comercial (Zimo Research. DNA Clean \& Concentrator Kit, Zymo Research, USA) y enviadas para su secuenciación a la Unidad de Genómica del Instituto de Biotecnología, INTA Castelar. Las secuencias fueron analizadas y alineadas mediante los programas Chromas 2.1.8 (Technelysium Pty Ldt, Australia), y Clustal Omega (EMBLEBI, Reino Unido). Luego fueron remitidas a la base de datos GenBank ( https://www.ncbi.nlm.nih.gov/genbank/ ), donde se asignaron los números de acceso MF959470-MF959485. A partir de las secuencias obtenidas se generó una secuencia consenso, la cual fue alineada y comparada con las depositadas en la mencionada base de datos, mediante la herramienta BLAST (https://www.ncbi.nlm.nih.gov/Blast.cgi). En base a estas comparaciones se generó un árbol filogenético no enraizado, por comparación con las secuencias de mayor homología con los dos haplotipos encontrados en este estudio. Para su construcción, se 
compararon los métodos de máxima parsimonia, máxima verosimilitud y neighbor joining, utilizando el software MEGA X (Kumar et al., 2018). De esta forma se utilizó el método que presentó mayor robustez.

Tabla 3.1. Características de los loci microsatelites empleados para genotipificación de poblaciones de F. hepatica

\begin{tabular}{|c|c|c|}
\hline Locus & Secuencia del primer $\left(5^{\prime}-3^{\prime}\right)$ & T a \\
\hline \multirow[t]{2}{*}{ Fh_ 2} & F:5'TGTAAAACGACGGCCAGTTGAGAAACTGATTCACCGACTG-3' & $57{ }^{\circ} \mathrm{C}$ \\
\hline & R: 5'- GAGCTTGTGCTCTCGGAACTA-3' & \\
\hline & F:5' -TGTAAAACGACGGCCAGTCATCACCACTGTCTTCGATCA-3' & $57^{\circ} \mathrm{C}$ \\
\hline Fh_5 & R: 5'-CGAAGCATTGATAAGATTTCCA-3' & \\
\hline \multirow[t]{2}{*}{ Fh_6 } & F: 5 '-TGTAAAACGACGGCCAGTACGTCCGTCCGTTAAGTGAG-3 ’ & $55^{\circ} \mathrm{C}$ \\
\hline & R: 5 '-TTTTGAGGTCGACATCCTTCA-3' & \\
\hline \multirow[t]{2}{*}{ Fh_7 } & F: $5^{\prime}$ '-TGTAAAACGACGGCCAGTTGCACTCTAGCATGGTTTGG-3' & $57^{\circ} \mathrm{C}$ \\
\hline & R: 5 '-AAGTCTTCAGTGCCCCTTCC-3' & \\
\hline \multirow[t]{2}{*}{ Fh_10 } & F: $5^{\prime}$ '-TGTAAAACGACGGCCAGTTTTAGTCGCGGAGCTACCAT-3' & $57^{\circ} \mathrm{C}$ \\
\hline & R: 5 '-CCACTTTTCGTCATGCACATT-3' & \\
\hline \multirow[t]{2}{*}{ Fh_12 } & F: 5 '-TGTAAAACGACGGCCAGTCCACGAGAAGTGGAATTCGT-3 & $60^{\circ} \mathrm{C}$ \\
\hline & R: 5 '-GTAGGTCCACTCCCTGTCCA-3' & \\
\hline \multirow[t]{2}{*}{ Fh_15 } & F: 5'-TGTAAAACGACGGCCAGTAATGCGGAAAAGAGCGATTA-3' & $55^{\circ} \mathrm{C}$ \\
\hline & R: 5'-GAAATTGGGAGCAACTGCAT-3' & \\
\hline \multirow[t]{2}{*}{ Fh_25 } & F: 5'-TAGCGGTTTTGACTCTAC-3' & $51^{\circ} \mathrm{C}$ \\
\hline & R: 5'-GATTCGGTTAGGATGTTG-3' & \\
\hline \multirow[t]{2}{*}{ Fh_40 } & F: 5'-TGTAAAACGACGGCCAGTTAAACCGTTGCTTCACGTTG-3' & $57^{\circ} \mathrm{C}$ \\
\hline & R: 5'-CAAAGTGTTTGGCGAGCTG-3' & \\
\hline
\end{tabular}

Ta: Temperatura de annealing; F: primer en sentido anterior; R: primer en sentido reverso.

\subsection{Resultados}

El análisis de los SRT reveló polimorfismo en los 9 loci. El número de promedio de alelos fue $11 \pm 6$ por locus, con un rango de 5 a 26 dependiendo del SRT analizado (Tabla.3.2). Los alelos con mayor frecuencia de cada locus por origen se muestran en la tabla 3.3 y los de los 
genotipos más frecuentes en la tabla 3.4. Todas las poblaciones de $F$. hepatica mostraron alta diversidad, alta $\mathrm{Ho}(0,598 \pm 0,078)$ y $\mathrm{He}(0,722 \pm$ 0,047) (tabla 3.5), relacionada con desviación del equilibrio de Hardy Weinberg (tabla 3.6). El valor promedio del Fis fue bajo $(0,164 \pm 0.07)$, y consecuentemente también el valor de $S(0,28)$. El polimorfismo observado se manifestó de forma homogénea, por lo cual no se hallaron diferencias estadísticamente significativas entre los aislamientos de acuerdo a su origen (Tabla 3.7).

El análisis del marcador COI arrojó secuencias de 423 pb, las cuales presentaron dos haplotipos definidos por una transversión ( $\mathrm{G} \times \mathrm{T})$, en la base 150 (base 219 del gen COI completo) (figura 3.1). De esta forma se designó como haplotipo 1(H1) al que presentó $\mathrm{G}$ y haplotipo $2(\mathrm{H} 2)$ al que presentó T. De las 16 muestras secuenciadas, siete presentaron el haplotipo $\mathrm{H} 1$ y nueve el haplotipo $\mathrm{H} 2$.

Al comparar las secuencias obtenidas con las previamente depositadas en GenBank para el mismo locus, se observó mayor homología con aislamientos de F. hepatica pertenecientes a Brasil (MF696150-52), China (AJ628037/38, KX856337/38), Nigeria (FJ469984, GU112466/71), España (GU112457), Perú (KJ716822/23, KJ852772, KT869168/69), Australia (AB207103), Uruguay (AB207170), Egipto (AB553820/21/25/26), Italia (JF824271/73/84/86), Polonia (KR422383-87), Francia (AJ628039), Irán (KT893722-25), Japón (AB300704), Túnez (JK231551), Argelia (JK231549), Reino Unido (KR422348), y Estados Unidos (JU112482/83). El método de máxima parsimonia mostró mayor robustez a nivel de los 
nodos de bootstrap que los métodos de máxima verosimilitud y neighboor joining, lo cual fundamentó su elección. El modelo filogenético empleado agrupó a las poblaciones del F. hepatica en un clado compartido con secuencias de Uruguay, Perú, Brasil, Reino Unido, Polonia, e Irán (Figura $3.2)$.

Tabla 3.2 números de alelos para cada locus microsatélite analizado de Fasciola hepática de Entre Ríos.

\begin{tabular}{cc}
\hline Locus & $\begin{array}{c}\text { Numero de } \\
\text { alelos }\end{array}$ \\
\hline Fh2 & 11 \\
\hline Fh5 & 17 \\
\hline Fh10 & 11 \\
\hline Fh6 & 26 \\
\hline Fh7 & 7 \\
\hline Fh12 & 10 \\
\hline Fh15 & 6 \\
\hline Fh25 & 5 \\
\hline Fh40 & 10 \\
\hline
\end{tabular}

Tabla 3.3 Frecuencias alélicas observadas por locus y origen, para marcadores microsatélites de F.hepatica.

\begin{tabular}{ccccccc} 
Locus & Alelo & San Julián & Torcaza & Casuarinas & Castores & Total \\
\hline \multirow{2}{*}{ Fh2 } & 183 & 0.74 & 0.47 & 0.41 & 0.45 & 0.52 \\
& 203 & 0.17 & 0.24 & 0.23 & 0.10 & 0.18 \\
\hline \multirow{2}{*}{ Fh5 } & 206 & 0.27 & 0.17 & 0.15 & 0.13 & 0.18 \\
& 209 & 0.21 & 0.24 & 0.19 & 0.17 & 0.20 \\
\hline \multirow{2}{*}{ Fh6 } & 165 & 0.07 & 0.14 & 0.25 & 0.14 & 0.15 \\
& 189 & 0.11 & 0.21 & 0.21 & 0.12 & 0.16 \\
\hline \multirow{2}{*}{ Fh7 } & 163 & 0.15 & 0.30 & 0.27 & 0.32 & 0.26 \\
& 181 & 0.42 & 0.23 & 0.27 & 0.34 & 0.31 \\
\hline \multirow{2}{*}{ Fh10 } & 209 & 0.31 & 0.17 & 0.24 & 0.30 & 0.26 \\
& 215 & 0.17 & 0.20 & 0.23 & 0.17 & 0.19 \\
\hline \multirow{2}{*}{ Fh12 } & 214 & 0.60 & 0.66 & 0.47 & 0.75 & 0.61 \\
\hline \multirow{2}{*}{ Fh15 } & 233 & 0.68 & 0.45 & 0.62 & 0.77 & 0.64 \\
& 235 & 0.09 & 0.26 & 0.20 & 0.06 & 0.15 \\
\hline \multirow{2}{*}{ Fh25 } & 280 & 0.52 & 0.61 & 0.58 & 0.78 & 0.62 \\
\hline \multirow{2}{*}{ Fh40 } & 158 & 0.17 & 0.18 & 0.29 & 0.30 & 0.24 \\
& 160 & 0.52 & 0.43 & 0.31 & 0.59 & 0.46 \\
\hline
\end{tabular}

Total: frecuencia alélica calculada para cada alelo por locus. 
Tabla 3.4 Frecuencias genotípicas más comunes por locus y origen para marcadores microsatélites de F.hepatica.

\begin{tabular}{ccccc} 
Locus & San Julián & Torcaza & Casuarinas & Castores \\
\hline \multirow{2}{*}{ Fh2 } & $183,183(0,51)$ & $183,183(0,33)$ & $183,183(0,22)$ & $183,183(0,13)$ \\
& $203,203(0,14)$ & $203,203(0,1)$ & $203,203(0,13)$ & $203,183(0,08)$ \\
\hline \multirow{2}{*}{ Fh5 } & $203,198(0,06)$ & $203,200(0,05)$ & $198,159(0,05)$ & $206,198(0,02)$ \\
& $209,198(0.06)$ & $209,203(0,05)$ & $209,203(0,05)$ & $209,198(0,05)$ \\
\hline \multirow{2}{*}{ Fh6 } & $253,229(0,01)$ & $189,192(0,04)$ & $165,165(0,03)$ & $165,183(0,02)$ \\
& $192,189(0,01)$ & $229,253(0,01)$ & $189,189(0,03)$ & $189,165(0,01)$ \\
\hline \multirow{2}{*}{ Fh7 } & $181,181(0,33)$ & $181,178(0,27)$ & $181,178(0,54)$ & $181,163(0,23)$ \\
& $181,163(0,26)$ & $163,175(0,46)$ & $178,178(0,26)$ & $181,178(0,19)$ \\
\hline \multirow{2}{*}{ Fh10 } & $215,209(0,09)$ & $209,212(0,04)$ & $215,209(0,09)$ & $209,205(0,03)$ \\
& $209,212(0,03)$ & $215,212(0,04)$ & $229,215(0,09)$ & $209,229(0,03)$ \\
\hline \multirow{2}{*}{ Fh12 } & $214,225(0,57)$ & $214,214(0,57)$ & $225,214(0,30)$ & $214,214(0,57)$ \\
\multirow{2}{*}{ Fh15 } & $214,214(0,33)$ & $214,217(0,09)$ & $214,214(0,17)$ & $225,214(0,23)$ \\
\cline { 3 - 5 } & $233,233(0,80)$ & $233,233(0,23)$ & $233,233(0,80)$ & $233,233(0,53)$ \\
\multirow{2}{*}{ Fh25 } & $283,229(0,13)$ & $233,235(0.09)$ & $233,229(0,13)$ & $233,229(0,39)$ \\
\hline \multirow{2}{*}{ Fh40 } & $280,278(0,16)$ & $280,280(0,44)$ & $280,280(0,44)$ & $280,280(0,54)$ \\
& $160,160(0,17)$ & $160,158(0,18)$ & $160,156(0.06)$ & $160,158(0,30)$ \\
& $160,158(0,04)$ & $162,143(0.12)$ & $160,160(0,08)$ & $160,160(0.16)$ \\
\hline
\end{tabular}

Tabla 3.5 Índices de diversidad genética promedio para todos los aislamientos de F. hepatica, estimados en base al análisis de marcadores microsatélites.

\begin{tabular}{ccccc}
\hline Estadistico & Valor & D.E. & $\begin{array}{c}\text { LIIC } \\
\mathbf{9 5 \%}\end{array}$ & LSIC 95\% \\
\hline $\mathbf{N}^{\circ}$ de alelos & 11.44 & 2.16 & 8.00 & 15.88 \\
\hline Ho & 0.59 & 0.07 & 0.45 & 0.74 \\
\hline He & 0.71 & 0.04 & 0.62 & 0.80 \\
\hline Fis & 0.16 & 0.07 & 0.03 & 0.31 \\
\hline
\end{tabular}

Ho: heterocigosis observada; He: heterocigosis esperada; Fis: coeficiente de endogamia, D.E. desvió estándar. LIIC 95\%, LSIC 95\%: límite inferior y superior, respectivamente, del intervalo de confianza del $95 \%$. 
Tabla 3.6. Índices de diversidad genética de F. hepatica por establecimiento de origen de los aislamientos, mediante el análisis de marcadores microsatélites.

\begin{tabular}{cccc} 
Población & Ho & He & Fis \\
\hline San Julian & 0.58 & 0.69 & 0.16 \\
Torcaza & 0.62 & 0.75 & 0.17 \\
Casuarinas & 0.56 & 0.76 & 0.26 \\
Castores & 0.63 & 0.66 & 0.05 \\
\hline
\end{tabular}

Ho: heterogenicidad observada; He: heterogenicidad esperada; Fis: coeficiente de endogamia

Tabla 3.7. Índice de fijación (Fst) entre los aislamientos de F.hepatica, calculado de acuerdo al establecimiento de origen marcadores microsatélites.

\begin{tabular}{ccccc} 
& $\begin{array}{c}\text { San } \\
\text { Julián }\end{array}$ & Torcaza & Casuarina & Castores \\
\hline San Julian & 0 & 0.016 & 0.012 & 0.012 \\
Torcaza & 0.016 & 0 & -0.002 & 0.015 \\
Casuarina & 0.012 & -0.002 & 0 & 0.017 \\
Castores & 0.012 & 0.016 & 0.018 & 0 \\
\hline
\end{tabular}

Figura 3.1. Secuencia correspondiente a segmento parcial del ADN mitocondrial codificante para citocromo oxidasa I, obtenida de los aislamientos de Fasciola hepatica del sur de Entre Ríos. Se observa en la base 150 (K) una transversión (GxT), originando dos haplotipos locales (H1 y H2).

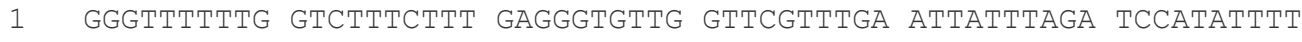

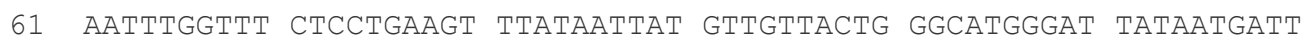

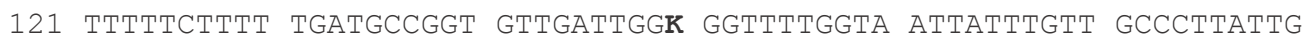

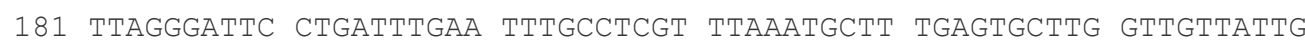

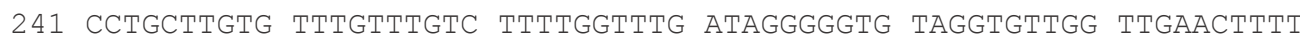

301 TATCCGCCTC TTTCTAGgtT GgAtTATTCT AgGTGgGgGg TTGATTTTTT GATGTTTTCT

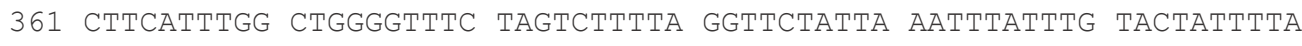
$421 \mathrm{GAG}$ 
Figura 3.2. Relaciones filogenéticas entre aislamientos de Fasciola hepatica de establecimientos del sur de Entre Ríos, y los aislamientos de mayor homología reportados en GenBank ( $N=50)$, mediante análisis del segmento parcial COI del ADN mitocondrial. El análisis fue realizado por el método de máxima parsimonia El porcentaje de réplicas en el cual las secuencias asociadas agruparon juntas (luego de 1000 bootstrap) se observa junto a los nodos. Los haplotipos hallados en el presente estudio correspondes a "haplotipo 1" y "haplotipo 2".

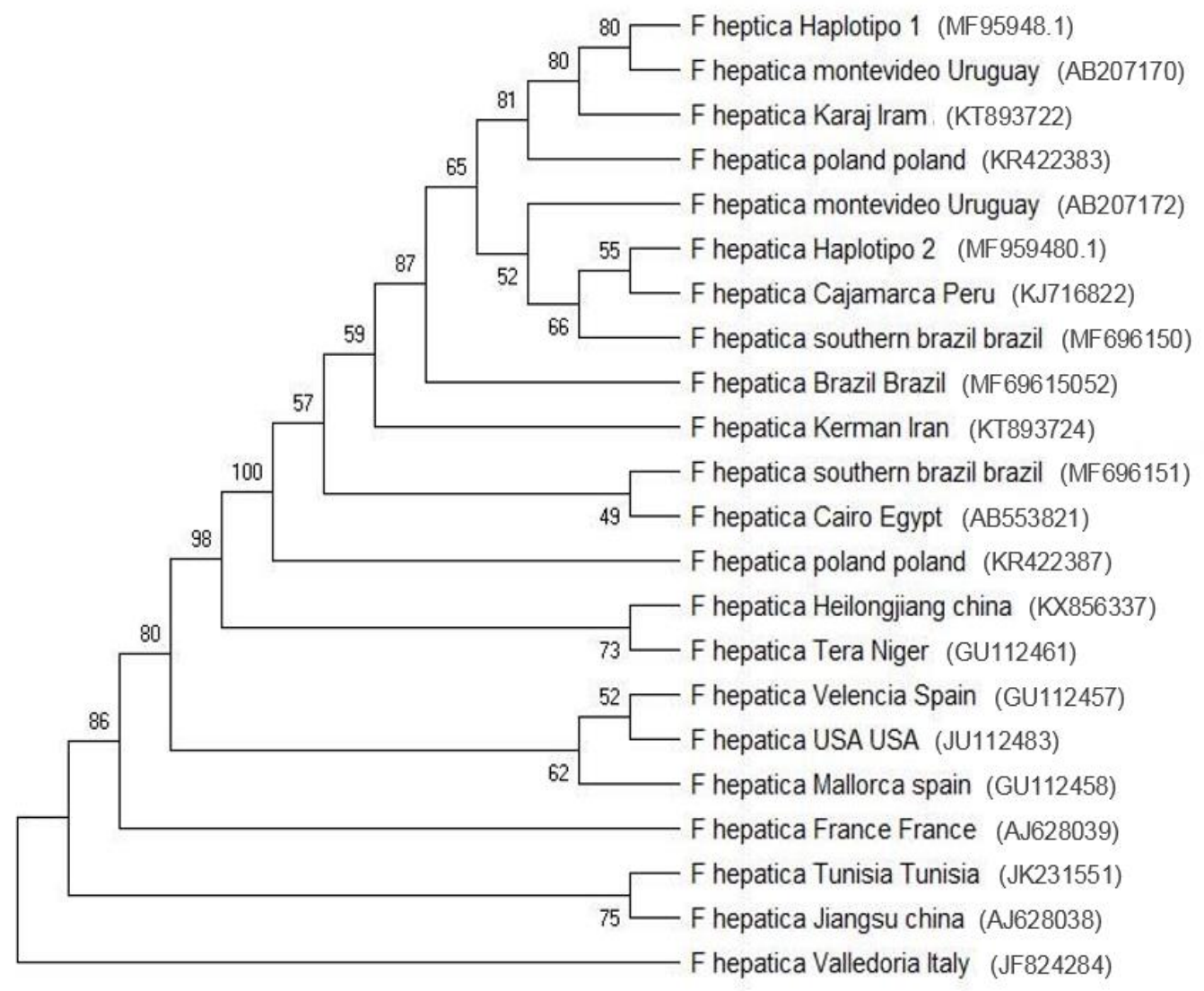

Entre parentesis número de acceso de GenBank 


\subsection{Discusión}

El estudio de poblaciones mediante marcadores SRT en 104 adultos de $F$ hepatica extraídos de cuatro bovinos de los establecimientos del sur de Entre Ríos, mostraron diversidad en frecuencias alélicas, indicando predominancia de heterocigosis. Los alelos 183 (locus Fh2), 233 (Fh15) y 280 (Fh 25) fueron los de mayor predominancia. El tamaño de estos alelos coincide con lo descripto previamente por Hurtrez-Boussès et al, (2004), y Cwiklinsky et al, (2015). Aunque estos alelos no se encuentran vinculados a ningún atributo fenotípico o genotípico conocido, caracterizan a la población de F. hepatica en la zona de estudio. Sin embargo, debe considerarse que su representatividad es parcial, ya que solo se pudieron obtener ejemplares de $F$. hepatica de un bovino en cada establecimiento.

El coeficiente de endogamia (Fis) en las poblaciones en estudio fue bajo por consiguiente su tasa de autofecundación (S) también. Esto, sumado a la elevada variabilidad alélica y heterogeneidad, indican que la reproducción de $F$. hepatica en la región estudiada es mayormente sexual por cruzamiento, coincidiendo con lo reportado por otros autores (HutrezBousses et al., 2004; Walker et al., 2010; Elliot et al., 2014; Cwiklinski et al., 2015). Pese a la diversidad alélica hallada para estos marcadores, el Fst para la comparación entre poblaciones arrojó, en todos los casos, valores cercanos a cero (tabla 3.7), indicando que, en la actualidad, existe un bajo o nulo efecto de mecanismos de selección específicos, ya sea por expansión (Fst cercano a 1), u opuestamente, deficiencia o concentración de alelos (cuello de botella, Fst cercano a -1). Por consiguiente, existiría 
una baja diferenciación genética entre las poblaciones (Beesley,et al, 2017)

Una población es una entidad genéticamente abierta, pudiendo intercambiar información con otras poblaciones (flujo genético) como fue descripto en párrafos anteriores (Eguiarte, et al. 2007). En este caso, las poblaciones mostraron desvío del equilibrio de Hardy-Weinberg, lo que indicaría que no permanecen aisladas, sino con un flujo genético constante entre ellas.

Existen actualmente pocos estudios de variabilidad genética poblacional de F. hepatica, por su diferentes hospedadores o zona geográfica, (Farjallah, et al. 2013), siendo el presente, al menos uno de los primeros estudios de estas características en nuestro país. Si bien, no se estableció diferenciación entre las poblaciones estudiadas, estas en su conjunto podrían ser comparadas con ejemplares de otras regiones, pudiendo evaluar si existe relación en ciertas características, como la resistencia a antiparasitarios. En relación a ello, en todos los establecimientos estudiados se observó resistencia a dosis estándar de albendazol y susceptibilidad a triclabendazol y closantel, mediante test de reducción del recuento de huevos (Pruzzo et al., 2015).

Indicadores de endogamia por autofecundación (Fsi y S), podrían tener relación con fijación de alelos recesivos, y expansión poblacional de la resistencia a antihelmínticos. Contrariamente, en este estudio se observó predominio global de heterocigosis, no obstante, pueden verse algunas frecuencias genotípicas homocigotas en elevada proporción, 
particularmente en el locus Fh 15 (tabla 3.4). Aunque no puede tomarse per se cómo indicador, la repetición de algunas frecuencias alélicas homocigotas y su relación con fenotipos resistentes sería interesante de ser explorado en forma más exhaustiva.

Al momento no se han elucidado exactamente las vías y genes que gobiernan la resistencia a los principales fasciolicidas, como albendazol y triclabendazol (Virkel et al., 2009; Scarcella et al., 2012; Savage et al, 2013; Fuchs et al., 2013). Este tipo de análisis podrían ser auxiliares en este sentido, a fin de identificar características poblacionales y su relación con genotipos resistentes o susceptibles, en conjunto con otros marcadores moleculares.

La escala del presente trabajo posiblemente dificulte visualizar características poblacionales de este tipo. De esta forma el empleo de SRT sería más útil para la comparación de poblaciones geográficamente más distantes entre sí.

La presencia de los dos haplotipos hallados para COI no arrojó variación atribuible a aislamientos de cada establecimiento, pero contextualiza una tipificación local para este marcador.

Tal como sería esperable, dichos haplotipos fueron similares a otros aislamientos del cono sur de América. No obstante, también se observó similitud con otros aislamientos europeos.

En este sentido, generalmente se sostuvo que las fasciolosis fue introducida con la colonización europea en América, más precisamente en 
Uruguay (Mas-Coma et al., 2001; Bargues et al., 2017), pero recientes hallazgos paleoparasitologicos locales en fósiles animales con más de 2000 años de antigüedad suponen que este trematodo podría haber llegado antes a América (Beltrame et al., 2017). En efecto, Sey (1991), propuso que rumiantes parasitados por trematodos podría haber migrado desde Eurasia hacia América a través del canal de Bering, y posteriormente al surgimiento del estrecho de Panamá (hace 3 millones de años), haber arribado a América del Sur. Un análisis filogenético comparado con otras regiones podría mejorar el conocimiento actual en este sentido. 


\section{Objetivo III A.}

\section{Identificación molecular de lymneidos del sur de Entre Ríos.}

\subsection{Introducción}

Los lymneidos actúan como hospedadores intermediarios de más de 70 especies de trematodos. Ejemplo de ello son las familias Notocotylidae y Echinostomatidae, siendo más estricta la especificidad hospedadorparásito en el caso de F. hepatica (Lounnas et al., 2016).

Los lymneidos están ampliamente distribuidos en el mundo y, al menos 20 especies han sido descriptas como potenciales hospedadores de $F$. hepatica (Correa et al., 2010).

La correcta identificación de los hospedadores intermediarios contribuye, en parte, a determinar áreas de riesgo epidemiológico de fasciolosis, definir su dinámica de transmisión y profundizar en el conocimiento de la relación parasito-hospedador (Stanley et al., 2014). Sin embargo, las especies son muy similares en su apariencia y establecer límites morfológicos entre ellas es difícil (Pointier et al., 2006; Stanley, 2013). Especies morfológicamente similares pueden ser muy eficientes transmisores de la fasciolosis (Sanabria et al., 2012), o estar presentes en regiones enzoóticas sin ser transmisoras (Bargues et al., 2012).

La identificación por medio de la morfología de su conchilla se ha utilizado por varios años y aún se continúa empleando (Prepelitchi, 2009). Debido a la gran diversidad en su forma determinada por la plasticidad fenotípica, es que varias especies hoy se consideran sinónimo (Hurtrez-Bousses et al., 2005; Pontier et al., 2008; Lounnas et al., 2017; Alda et al., 2018). 
La identificación también puede realizarse utilizando el aparato reproductor (próstata, pene), pero en muchas especies da lugar a identificaciones erróneas (Pointer et al., 2008). Sin embargo, estudios inmunológicos, electroforesis enzimática y técnicas de biología molecular han demostrado extensiva homoplastia en las características anatómicas (Hurtrez-Boussez et al., 2005; Wullschleger y Jokela, 2002).

Las diferencias entre los criterios de identificación morfológicos de la conchilla y anatómicos explican en cierta medida porque la sistemática de los lymneidos ha sido controversial (Remigio y Blair, 1997). De esta forma se han clasificado 1143 especies utilizando únicamente criterios morfológicos de su conchilla, pero actualmente se acepta que el número de especies de lymneidos podría ser menor a 100 (Pointier et al., 2008).

Recientemente se han unificado criterios por la utilización de análisis filogenético de supermatrix (Correa et al. 2010), donde se utilizan tres marcadores moleculares que amplifican secuencias de ADN nuclear, como espacios de transcripción interna ribosomal 1 y 2 (ITS1 e ITS2), para la subunidad 16s ribosomal (16s) y COI y NADI del ADNmt. Estos genes presentan, por un lado, variabilidad suficiente para permitir discriminar especies, pero por su proximidad a regiones funcionales del genoma, también presentan estabilidad, permitiendo trazabilidad especie-específica. Por esto han sido usados en una gran cantidad de estudios filogenéticos de lymneidos (Bargues et al., 2007; Correa et al., 2010; Pujadas et al 2015; Lounnas et al., 2016). Además, se han utilizado marcadores SRT para caracterizar la estructura poblacional de lymneidos, lo que arroja patrones 
específicos de amplificación para cada grupo y especie (Hurtrez-Bousses et al., 2010; Lounnas et al., 2016, Alda et al., 2018) (Figura 4.2). En base a estos criterios se elaboró una PCR multiplex, que permite discriminar tres especies criticas (G. cubensis, G. schirazensis y G. truncatula) utilizando SRT. La exactitud de este método fue testeada por comparación con identificaciones de especie basadas en secuencias de ADN mitocondrial y nuclear (Alda et al., 2018).

Muchos de los nombres de géneros de lymneidos no se acordaron aún y se asignaron en base a similitudes fenotípicas, más que a estudios evolutivos o filogenéticos. Correa et al. (2010), reorganizaron a las especies en tres grandes clases de lymneidos: americanos, euroasiáticos e indopacíficos. Dentro del grupo americano hay dos subgrupos: sudamericanos y norteamericanos. En el primero se han utilizado al menos tres nombres de géneros que se consideran sinónimos: Fossaria (Westerlund, 1885), Galba (Schrank, 1803) y Lymnaea (Lamark, 1799). Para unificar criterios, el Código Internacional de Nomenclatura Zoológica (ICNZ), sugiere la utilización del nombre Galba como género de las especies dentro del subgrupo sudamericano (Correa et al., 2010).

Incluso hoy, hay especies que se consideran co-específicas o sinónimo, tal es el caso de las recientemente descriptas G. neotropica y G. meridenses, consideradas como sinónimo de G. cubensis y G. cousini respectivamente, debido a que los marcadores moleculares y su morfología no permiten diferenciarlos claramente (Pointer et al., 2004; Bargues et al., 2011; Correa et al., 2011; Lounnas et al., 2016, 2017; Alda et al., 2018). 
El objetivo de este capítulo es la identificación de los hospedadores intermediarios presentes en los establecimientos de estudio, en el sur de la provincia de Entre Ríos, a fin de verificar las especies presentes, y si esto tiene implicancias en la epidemiología local de la fasciolosis.

\subsection{Materiales y métodos}

\subsubsection{Colecta y procesamiento del hospedador intermediario}

Los muestreos de caracoles se realizaron en forma simultánea con la toma de muestra de los HD en los diferentes establecimientos durante el periodo de marzo de 2013 a septiembre de 2015.

Los muestreos se llevaron a cabo en los bordes de los arroyos, lagunas, bañados o acúmulos de agua que se encuentran próximos a los establecimientos. La búsqueda fue realizada por dos a tres personas en cada visita, por aproximadamente 3 horas. Los sitios de búsqueda fueron georreferenciados con GPS, fijándose puntos de referencia para las sucesivas búsquedas. De esta forma, se pudieron recolectar lymneidos en los establecimientos La Torcaza (departamento de Gualeguaychú), San Julián (departamento de Gualeguay), y Los Castores (departamento de Tala). Se llevó a cabo la recolección por el método de captura por remoción (Ravinovich, 1980). De acuerdo a este, se recolectan caracoles a mano por una sola persona durante 30 minutos y se colocaron en un recipiente de plástico, con agua del mismo lugar. Este tipo de muestreo permite luego la estimación de un índice de abundancia (ver capitulo siguiente). Las

muestras se rotularon con nombre del establecimiento y fecha, y en esas 
condiciones se trasladaron hasta el laboratorio del CEDIVE para su posterior procesamiento.

Figura 4.1. Toma de muestras de lymneidos en los diferentes establecimientos de las cuencas de los ríos Gualeguay y Gualeguaychú.
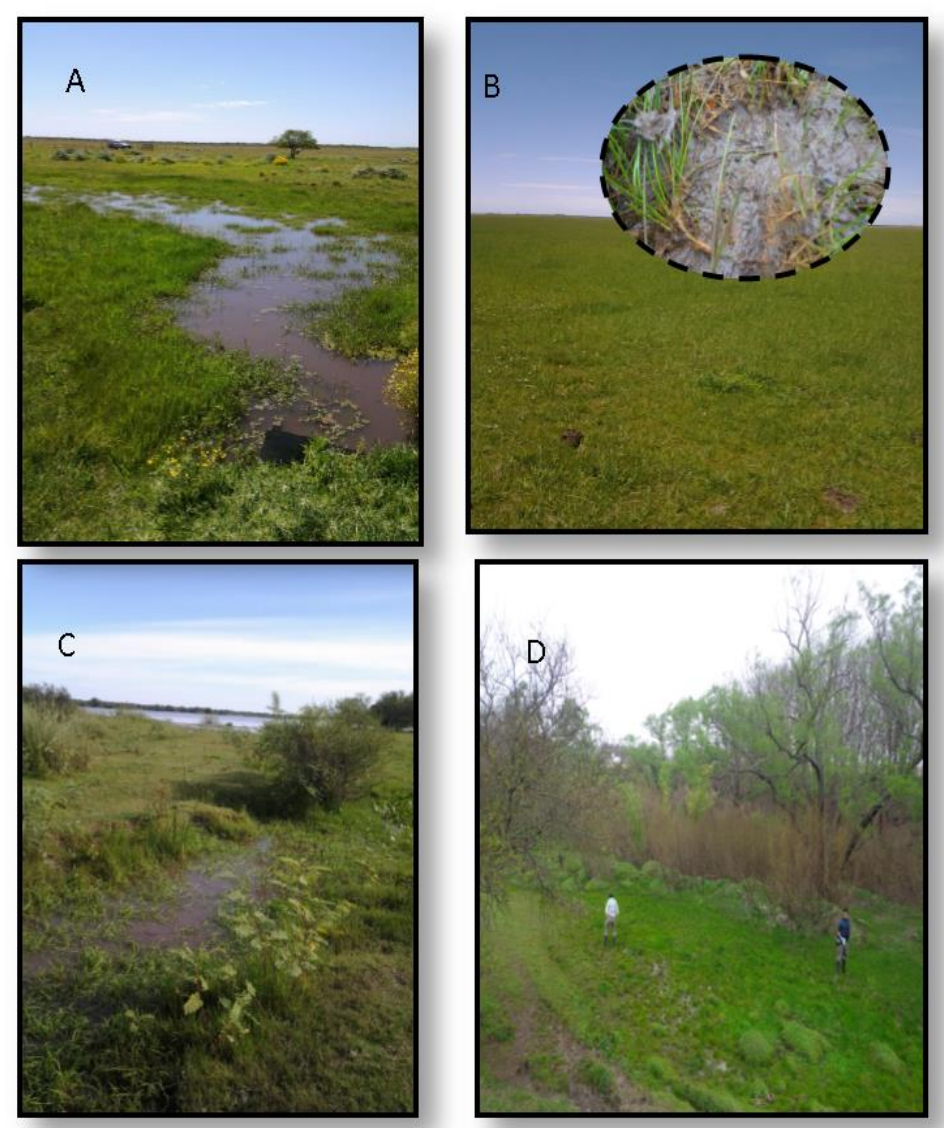

A y B: arroyo no permanente y bañado en el establecimiento "La Torcaza" (departamento de Gualeguaychú). C: arroyo no permanente en el establecimiento "Los castores" (departamento de Tala). D: margen de arroyo Clé, en el establecimiento "San Julián” (departamento de Gualeguay).

Para realizar la identificación molecular se procesaron 15 caracoles por cada origen. De cada espécimen se tomó la parte distal del pie, y se conservaron identificados por establecimiento, en etanol $96^{\circ}$. Para la 
extracción de ADN, se realizaron 5 lavajes con agua destilada. Luego se procedió a la digestión individual de cada espécimen, como fue descripto para los ejemplares de F. hepatica. El material digerido se almacenó a $20^{\circ} \mathrm{C}$ para su posterior utilización.

Para la amplificación del ADN, se utilizó una reacción de PCR multiplex, que incluye marcadores SRT microsatélites que permiten discriminar entre especies de lymneidos sudamericanas que son morfológicamente similares: Galba cubensis, G. schirasensis y G. truncatula. Cada primer amplifica un locus específico de una especie, como fue descripto para $G$. truncatula (Trouvé, et al. 2000), G. cubensis (Lounnas et al., 2016) y G. schirazensis (Lounnas et al., 2017) (Tabla 4.1).

Tabla 4.1 Primers usados en multiplex PCR-detección de especies del género Galba.

\begin{tabular}{|c|c|c|c|c|c|}
\hline $\begin{array}{l}\text { Especie } \\
\text { y primer }\end{array}$ & $\begin{array}{l}\text { Secuencia } \\
\left(5^{\prime}-3^{\prime}\right)\end{array}$ & $\begin{array}{c}\text { Numero de } \\
\text { acceso } \\
\text { GenBank }\end{array}$ & $\begin{array}{c}\text { Tamaño } \\
\text { producto } \\
\text { PCR }\end{array}$ & $\begin{array}{c}\text { Concentración } \\
\text { Primers }(\mu \mathrm{M})\end{array}$ & Referencia \\
\hline $\begin{array}{c}\text { Galba } \\
\text { cubensis } \\
\text { (Lc34) }\end{array}$ & $\begin{array}{l}\text { F:GTCACT } \\
\text { ACTGCTTG } \\
\text { TCTCAGC } \\
\text { R:AAAAGA } \\
\text { CTTTAACC } \\
\text { CTTACCAC } \\
\text { CC } \\
\end{array}$ & AF226985 & 190 & 2 & $\begin{array}{l}\text { Lounnas et } \\
\text { al. (2016) }\end{array}$ \\
\hline $\begin{array}{c}\text { Galba } \\
\text { schirazeinsis } \\
\text { (Ls23) }\end{array}$ & $\begin{array}{l}\text { F:AARGAC } \\
\text { CCAGTGG } \\
\text { GGAAG } \\
\text { R:TGGGGA } \\
\text { AGGTTCAA } \\
\text { TTGTTT }\end{array}$ & KT285822 & 235 & 8 & $\begin{array}{l}\text { Lounnas et } \\
\text { al. (2017) }\end{array}$ \\
\hline $\begin{array}{c}\text { Galba } \\
\text { truncatula } \\
\text { (Lt37) }\end{array}$ & $\begin{array}{l}\text { F:GTCCAG } \\
\text { TCTTTGTA } \\
\text { TGTC } \\
\text { R:GTTAAG } \\
\text { TACCCAAC } \\
\text { TTCTTC }\end{array}$ & KT324723 & 120 & 10 & $\begin{array}{l}\text { Trouvé et al. } \\
(2000)\end{array}$ \\
\hline
\end{tabular}


EI ADN extraído de cada individuo fue amplificado en un volumen final de 10 $\mu$ l conteniendo: $3 \mu$ de agua ultrapura, $5 \mu$ de Taq PCR mastermix Kit (Quiagen), $1 \mu$ le primer mix, a las concentraciones especificadas en la tabla 4.1, y 1 ul de ADN en un vial de 0,2 ml. La reacción de PCR se llevó a cabo mediante una desnaturalización inicial a $95^{\circ} \mathrm{C}$ por 15 minutos, seguido por 35 ciclos de desnaturalización a $94^{\circ} \mathrm{C}$ por 30 segundos, annealing a $52^{\circ} \mathrm{C}$ por 90 segundos y extensión a $52^{\circ} \mathrm{C}$ por 1 minuto, seguida por una extensión final a $60^{\circ} \mathrm{C}$ por $30 \mathrm{~min}$. Los productos de la amplificación fueron sometidos a electroforesis durante 2 horas a 100v en gel de agarosa al 5\% teñido con EZ Vision (VWR Chemicals, USA).

En paralelo al método anterior, sobre las mismas muestras de ADN extraído, se amplificó el segmento ITS 2 en cinco ejemplares de cada origen, utilizando los primers descriptos por Almeida-Artigas et al. (2000): ITS2 F: 5' TGTGTCGATGAAGAACGCAG 3', e ITS2 R: 5' TTCTATGCTTAAATTCAGGGG 3'. La amplificación fue desarrollada en un volumen final de $50 \mu \mathrm{l}$, conteniendo 35,5 $\mu \mathrm{l}$ de agua ultrapura, $5 \mu \mathrm{l}$ de Buffer, $2 \mu \mathrm{l}$ de cloruro de magnesio, $0,5 \mu \mathrm{l}$ de taq polimerasa (Invitrogen, USA), 0,5 $\mu l$ de cada uno de los primers, y $5 \mu$ de ADN. Se utilizó como control ADN previamente extraído y amplificado de G. cubensis. La reacción de PCR incluyó una desnaturalización inicial a $95^{\circ} \mathrm{C}$ por 3 minutos, seguido de 35 ciclos de desnaturalización a $95^{\circ} \mathrm{C}$ por 30 segundos, annealing a $50^{\circ} \mathrm{C}$ por 1 minuto, extensión a $72^{\circ} \mathrm{C}$ por 1 minuto, y una extensión final a $72^{\circ} \mathrm{C}$ por 3 minutos. Los productos de la amplificación fueron revelados por electroforesis en gel de agarosa al $1 \%$ con el agregado de SYBRSafe 
(Invitrogen, USA), y purificados posteriormente con el kit Quick-g DNA Miniprep (Zimo Research, USA), y enviadas para su secuenciación a la Unidad Genómica del Instituto de Biotecnología - INTA Castelar. Las secuencias obtenidas fueron procesadas y alineadas utilizando los programas Chromas 2.1.8 (Technelysium Pty Ldt, Australia) y Clustal Omega (EMBL-EBI, Reino Unido), y luego sometidas a comparación con secuencias reportadas en GenBank para el grupo Lymnaea/Galba/Fossaria. Una vez alineadas y corroboradas, las secuencias fueron reportadas a GenBank.

\subsection{Resultados}

Los marcadores SRT indicaron compatibilidad de las 45 muestras analizadas con patrones correspondientes a G. cubensis (Figura 4.2).

Fig. 4.2. Electroforesis en gel de agarosa de los productos del multiplex PCR de diferentes especies del género Galba.

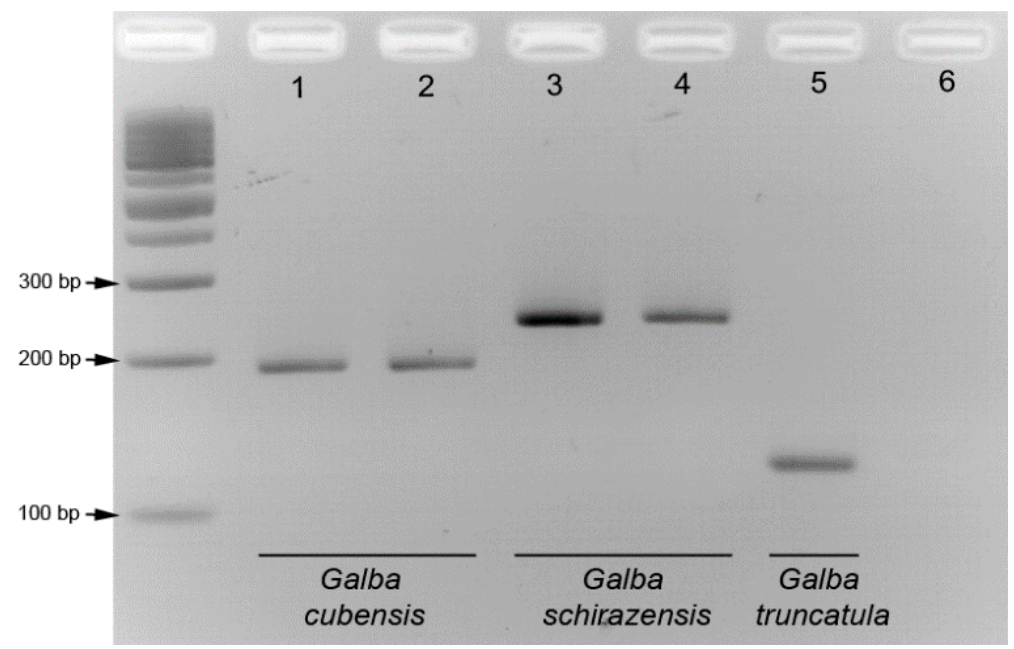

Se obtuvieron 15 amplificación del segmento ITS 2, 5 por cada origen, las cuales arrojaron amplicones de aproximadamente 400 pb (figura 4.3). Las 
secuencias obtenidas fueron idénticas entre sí. Tras la edición y alineado de las secuencias, se obtuvo una secuencia representativa de de 365 pb (figura 4.4). Esta secuencia presentó un $100 \%$ de identidad con el segmento ITS2 reportado para un aislamiento de G. cubensis de Argentina (KT781173) y G. cubensis de Venezuela (KT781218) (Alda et al., 2015). También se observó $100 \%$ de identidad con secuencias de G. neotropica (AM412225) (Bargues et al., 2007). Las secuencias obtenidas fueron reportadas en GenBank bajo los números de acceso KP897135-44 y KP897150-54.

Figura 4.3. Electroforesis en gel agarosa de las amplificaciones de los segmentos ITS2 de lymneidos del sur de Entre Ríos.

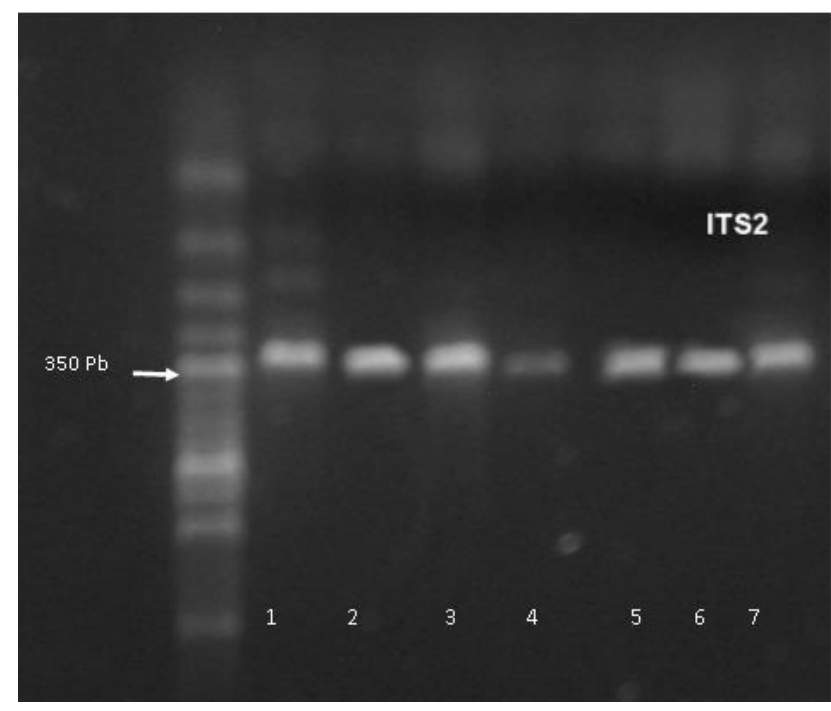

Calles 1 y 2: establecimiento San Julián (departamento Gualeguay). Calles 3 y 4 : establecimiento Los castores (departamento Tala). Calles 5, 6 y 7: establecimiento La Torcaza (departamento Gualeguaychú). 
Figura 4.4. Secuencia consenso (365 pb), correspondiente al segmento parcial 5.8S, segmento completo ITS2 y segmento parcial $28 S$ de ADN ribosómico de los aislamientos de Galba cubensis (Syn. G. neotropica) del sur de Entre Ríos.

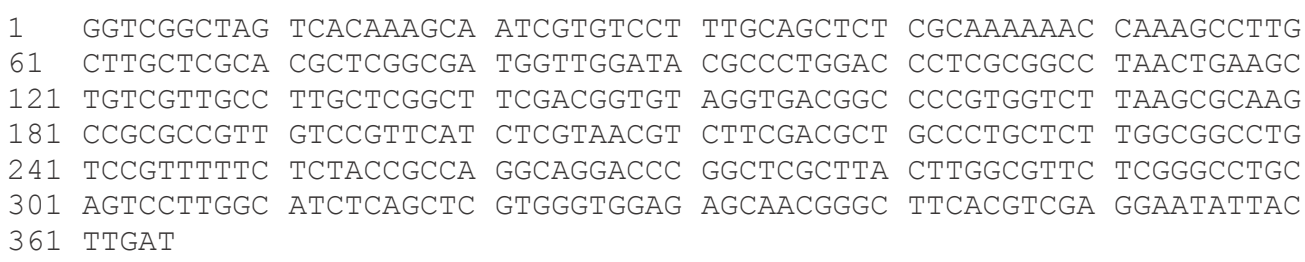

\subsection{Discusión}

En base la técnica multiplex PCR la única especie identificada en la zona de estudio fue G. cubensis. De la misma forma, para el segmento ITS2 observo 100\% de identidad con G cubensis (KT781173, KT781218) reportadas en GenBank, no encontrándose diferencias entre los establecimientos estudiados, ni mutaciones que sugieran divergencia de especies o subespecies.

En el segmento ITS2 no solo se observó homología con reportes previos de G. cubensis, sino que también se observó $100 \%$ de identidad con secuencias de G. neotropica (AM412225). Esto pone de manifiesto lo mencionado anteriormente respecto a similitudes interespecíficas, y a la simplificación del clado en un menor número de géneros y especies.

La relativa cercanía entre los establecimientos, la gran capacidad de dispersión de esta especie, y su capacidad autofecundante podrían explicar la falta de variación (Meunier et al., 2004; Bargues et al., 2011; Lounnas et al., 2016; Alda et al., 2018). Estas características hacen posible que unos 
pocos individuos, pueden colonizar nuevos lugares formando grandes poblaciones en relativamente corto tiempo (Bargues, et al. 2011).

Si bien G. cubensis presenta una amplia distribución en toda América (Correa et al., 2010; Burgarrella et al., 2015), el presente estudio no descarta que coexistan otras especies no halladas durante los muestreos, en menor proporción (Bargues et al., 2011; Medeiros et al., 2014). En este sentido, debe tenerse en cuenta que en tres de los establecimientos no se pudo hallar caracoles en los dos años de evaluación.

Existen informes de identificación de la coexistencia de G. cubensis y G. viator (Stanley et al., 2013), lo cual podría producir cambios proporcionales de una u otra especie, incluso de forma cíclica, de acuerdo a las condiciones ambientales, y modificando de alguna forma la infestación del HD. Sin embargo, poco se sabe sobre la capacidad de especies de Galba para mantenerse en equilibrio, e incluso reemplazar otras especies del mismo género en el tiempo (Alda et al., 2018). 


\section{Objetivo III B}

\section{Abundancia y estructura poblacional de lymneidos}

\subsection{Introducción}

Se ha observado que, en regiones de clima templado-cálido, algunos lymneidos presentan una dinámica poblacional anual y cíclica, con mayor abundancia y predomino de caracoles de tamaño grande en los meses más fríos y secos, y con descenso de la abundancia en los meses más calurosos y lluviosos (Kleiman, 2004). Por otro lado, en otros trabajos no se ha encontrado un patrón estacional en la abundancia y estructura poblacional (Cañete et al. 2004; Coelho y Lima, 2008).

La presencia, la abundancia y la estructura poblacional de los lymneidos están sujetas a las fluctuaciones ambientales (Gerard, 2001). Entre estas interrelaciones, la temperatura y las precipitaciones son las variables que más influyen sobre la densidad y variabilidad poblacional (Ollerenshaw, 1971; Torgerson y Claxton, 1999). Se ha informado que la temperatura influye directamente en la biología de los organismos poiquilotermos, afectando la tasa de reproducción, y la edad de maduración sexual, entre otros procesos biológicos. La humedad también juega un rol importante en la presencia de los $\mathrm{HI}$, ya que estos requieren de suelos saturados de agua (Venturini, 1990).

Cuando las condiciones ambientales son idóneas y prolongadas en el tiempo, estas especies mantienen una alta tasa de crecimiento y reproducción, pero cuando están sujetas a ciclos favorables y 
desfavorables, se observa una dinámica de tipo "crash - boom", con crecimiento y reproducción abundantes cuando las condiciones son favorables y una disminución abrupta cuando dejan de serlo (Prepelitchi, 2009). La rápida recuperación de la población de lymneidos se debe a que son especies hermafroditas, pudiendo reproducirse por autofecundación o fecundación cruzada (Dillon, 2000). Se ha visto incluso que los especímenes criados aisladamente producen más huevos que criados de a pares (Gutiérrez et al., 2000).

La supervivencia de los caracoles luego de su estivación dependerá de la resistencia que presenten a las condiciones ambientales adversas (tiempo durante el cual fueron sometidos) y de su tamaño (Thaddeus y Bernard, 1999).

Los lymneidos suelen estivar enterrándose en el barro o retraídos en su conchilla, permaneciendo sobre la vegetación, barro, troncos, etc. Se ha observado que los lymneidos de mayor tamaño son más resistentes a las condiciones adversas que los más pequeños.

El tamaño aproximado en el cual los lymneidos comienzan a poner huevos es de $4 \mathrm{~mm}$, presentando una alta tasa de reproducción (Kleiman et al., 2007). Un solo espécimen puede llegar a poner 2.300 huevos durante su vida reproductiva, que es de aproximadamente 98 días (Gutiérrez et al., 2002). 
Por lo expuesto, resulta fundamental determinar cómo se comporta la población de los lymneidos para comprender la epidemiologia de la fasciolosis (Beesley et al., 2017).

Por ello, el objetivo de este capítulo fue determinar la abundancia y estructura poblacional de los lymneidos en aquellos establecimientos donde se hallaron especímenes en la mayoría de los muestreos realizados.

\subsection{Materiales y métodos}

Se trabajó con dos de los tres establecimientos en donde se encontraron caracoles en los diferentes muestreos realizados: "San Julián" y "La Torcaza", el primero correspondiente a la cuenca de río Gualeguay y el segundo al rio Gualeguaychú. No se trabajó con los lymneidos capturados en "Las Casuarinas" debido a la escasez de ejemplares hallados en forma esporádica. Durante el periodo de estudio se colectaron un total de 865 lymneidos. Para poder determinar un índice de abundancia poblacional (AHI), se utilizó el método de captura por unidad de esfuerzo (Prepelitchi, 2009), definiéndose como el número de ejemplares capturados durante 30 minutos por una sola persona. Los caracoles recolectados por esta metodología fueron colocados en envases de plásticos junto con agua y barro del sitio de colecta, se rotularon con los datos fecha y establecimiento, y fueron trasladados al laboratorio.

Para estudiar la estructura y dinámica poblacional se realizó la medición de todos los ejemplares recolectados, mediante análisis digital de imágenes (Raffo et al., 2010). Para ello, se colocaron los caracoles sobre un film 
transparente respetando una separación mínima entre ellos, junto con una porción de papel milimetrado para la posterior calibración espacial. Luego este montaje fue llevado a un escáner (Epson ${ }^{\odot}$ Stylus TX235W).

Se configuro la imagen de salida en tamaño de hoja A4, escala de grises 8 bit de 300 pixeles por pulgadas, formato .jpg, y se obtuvo una imagen de valores de pixeles entre 0 (negro) y 255 (blanco). Para realizar el análisis de la imagen se utilizó el programa UTHSCSA Image Tool 3.02 (Bio-soft Net), el cual permite discriminar la morfología y tamaño en base a los pixeles que ocupa el objeto. Una vez cargadas las imágenes escaneadas, se calibro la dimensión espacial de la imagen, mediante selección de la distancia sobre el papel milimetrado, y se incorporó la referencia en milímetros.

Se individualizaron los objetos seleccionando la zona más oscura (silueta de los caracoles) y se estableció el punto de corte en el rango de valores de pixeles entre 0 y 90 (Figura 5.1). Luego, el programa entrega una tabla con las medidas de dichos atributos, los cuales fueron exportados a una hoja de cálculo. De acuerdo a Kleiman et al. (2007), los lymneidos mayores a $4 \mathrm{~mm}$ se consideraron maduros sexualmente.

Se realizó la comparación del índice de abundancia (cantidad de caracoles capturados por la misma persona en $30 \mathrm{~min}$ ) entre los diferentes meses de muestreo, independientemente del año, mediante la prueba no paramétrica de Kruskal-Wallis con un nivel de significancia del $95 \%$, utilizando la prueba de Dunn como post hoc. 
Para analizar la relación entre la abundancia poblacional, y el tamaño de los caracoles y las variables climáticas $\left(\mathrm{T}^{\circ}\right.$, máxima, mínima, media, precipitaciones, exceso y déficit hídrico), se realizó correlación no paramétrica de Spearman entre el primer parámetro y los demás, con un nivel de significancia del 95\%. Las variables climáticas incluidas en el modelo de correlación fueron temperatura media $\mathrm{T}^{\circ} \mathrm{M}$, máxima $\left(\mathrm{T}^{\circ} \mathrm{máx}\right.$ ), mínima $\left(\mathrm{T}^{\circ} \mathrm{min}\right)$ y precipitación mensual $(\mathrm{Pm})$. Dichos parámetros fueron registrados durante el mes de muestreo (M0), dos (M-2), y cuatro (M-4) meses antes de cada visita a los campos.

Fig. 5.1. Análisis digital de imágenes para estimar la longitud de caracoles mediante el software Image Tool 3.02
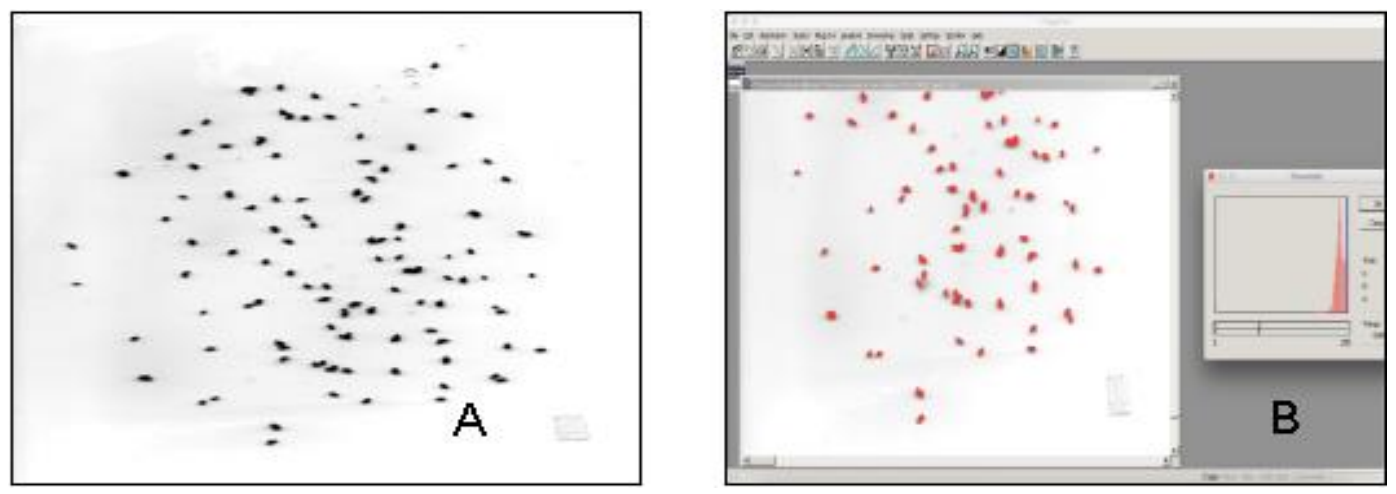

A) imagen blanco y negro obtenida por el escáner. B) Individualización manual de objetos de la imagen por nivel de pixel.

\subsection{Resultados}

Abundancia poblacional

En la figura 5. 2. se observa la abundancia de lymneidos en los diferentes meses en los que fueron capturados. 
En este sentido, se hallaron diferencias significativas entre los diferentes muestreos, observándose mayor abundancia en los muestreos de finales de invierno y principio de primavera (agosto, septiembre y octubre), y menos en los muestreos de fines de verano (marzo, abril y mayo) $(p<0,001)$.

Fig 5.2 Abundancia de hospedadores intermediarios (AHI) por mes y año de los establecimientos San Julián (Gualeguay) y La Torcaza (Gualeguaychú).

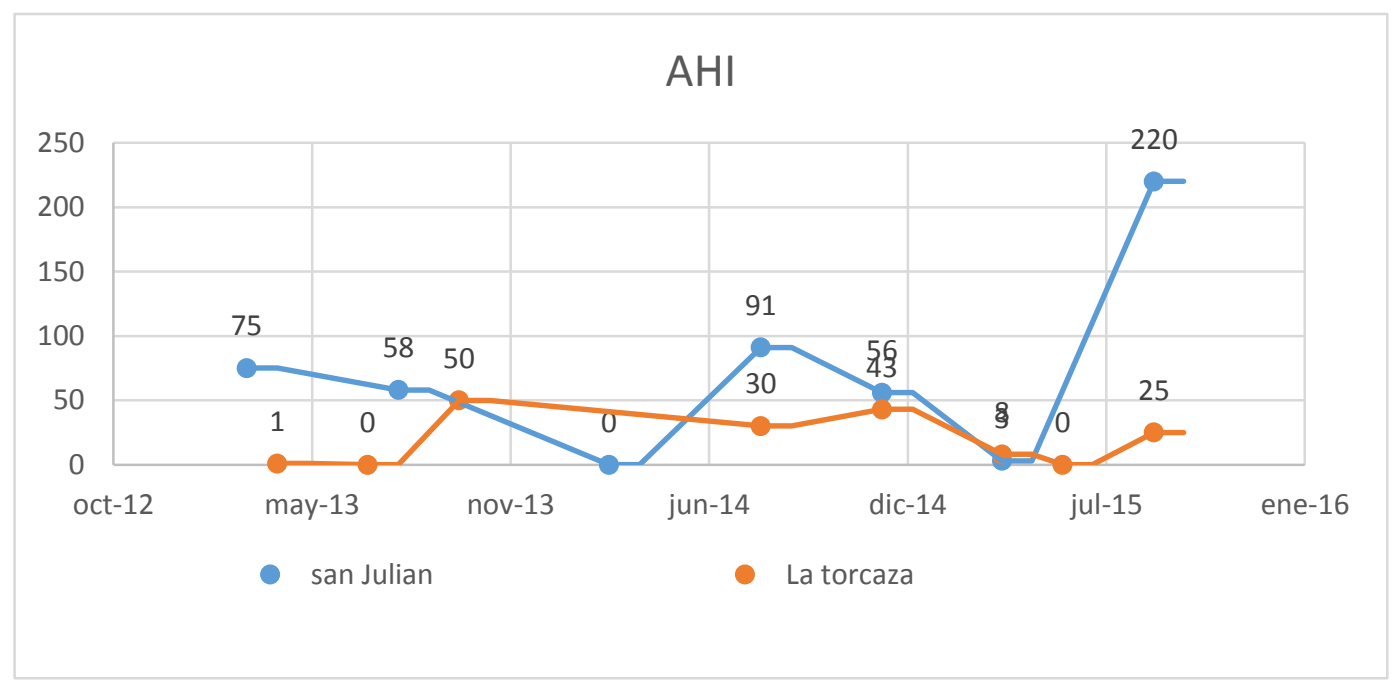

Esta densidad poblacional, se correlacionó negativamente con la temperatura media y máxima de los dos meses anteriores al muestreo $(R=-$ $0,35, p<0,001$ y $R=-0,23, p<0,001$, respectivamente). No se encontraron asociación entre el $\mathrm{AHI}$ y el resto de las variables climáticas analizadas, ni con los HPG y prevalencia en los bovinos.

\section{Estructura poblacional}

Los ejemplares de $G$. cubensis capturados midieron en promedio $4,48 \mathrm{~mm}$ (Rango: $0,57-8,67 \mathrm{~mm}$ ). Se encontraron diferencias significativas en los tamaños de los mismos entre los diferentes muestreos y entre los diferentes 
meses $(p<0,001)$, siendo en los meses de verano (diciembre a marzo) donde mayor proporción de lymneidos grandes (mayores a $6 \mathrm{~mm}$ ) se hallaron (Promedio: 6,88; DS 0,65) (figura 5.3), y en los meses de fines de invierno, principios de primavera donde mayor proporción de caracoles pequeños (<4mm) (promedio: 2,63; DS: 1,25) y medianos (entre 4 y $6 \mathrm{~mm}$ ) se encontraron.

\subsection{Discusión}

En el establecimiento San Julián, perteneciente a la cuenca del río Gualeguay y al departamento del mismo nombre, los lymneidos fueron hallados en los márgenes del arroyo Clé. Estos se encontraron en pequeños depósitos de agua, o en zonas de barro húmedo, coincidiendo con lo descripto en la bibliografía, ya que G. cubensis es anfibio y habita preferentemente en este tipo de ambientes (Prepelitchi, 2009). De los muestreos realizados, solo en uno (marzo de 2014) no se capturaron lymneidos, debido a una crecida y desborde del arroyo. Aunque esto constituye en parte un medio hostil para la mayoría de las especies de lymneidos (Gerard 2001), es también un vehículo hacia los potreros inundados, y una vía de dispersión, lo cual puede dificultar su hallazgo. La dispersión de los caracoles permite la colonización y formación de poblaciones temporarias y focos secundarios en zonas aledañas (Olaechea, et al. 2001).

Los lymneidos del área del establecimiento La Torcaza, perteneciente a la cuenca del río Gualeguaychú y al departamento homónimo, se encontraron 
Figura 5.3. Distribución del tamaño de Galba cubensis durante el estudio.
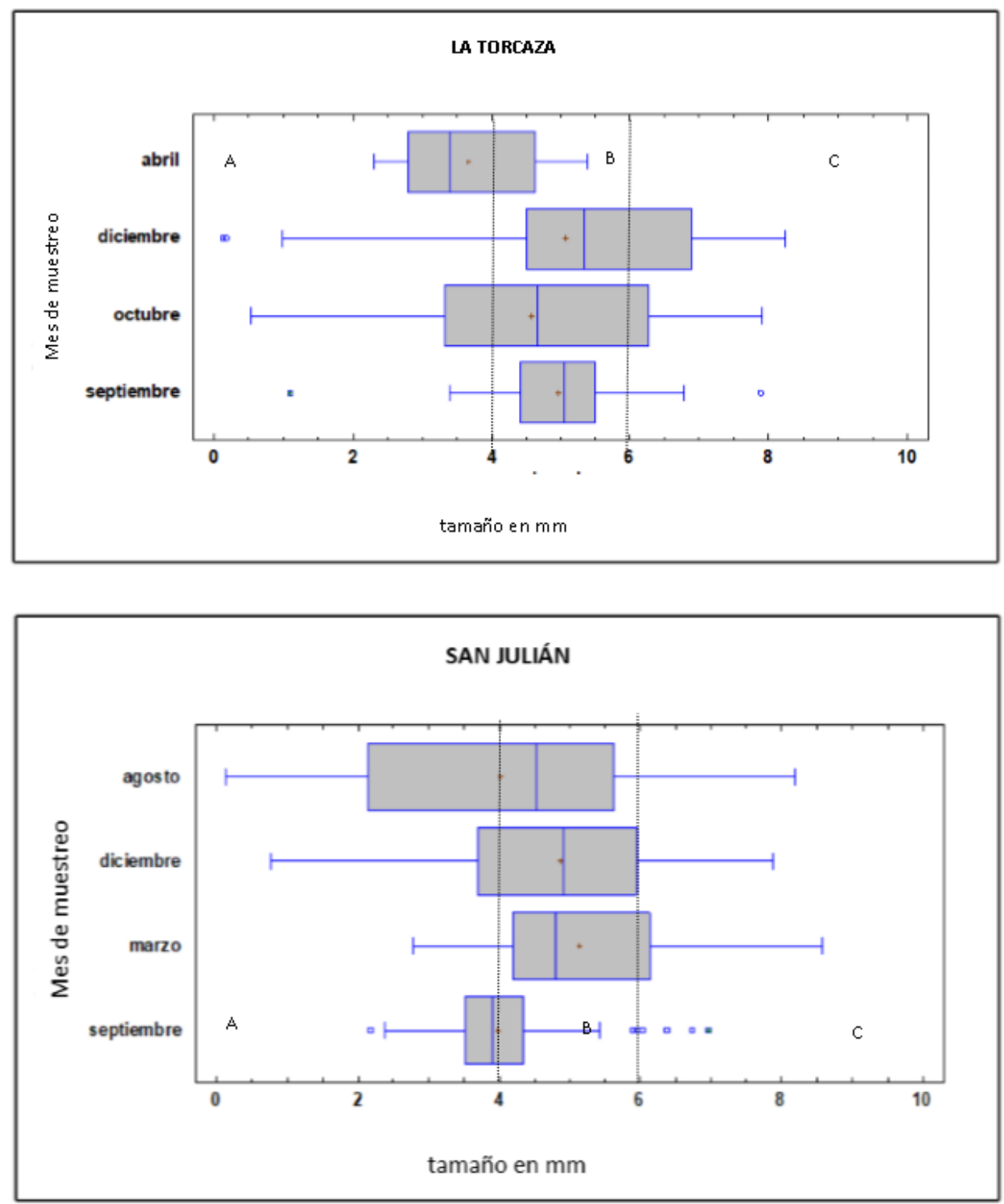

Las líneas punteadas verticales representan las distintas categorías de tamaños: A: chicos (<4mm); B: medianos $\left(>4\right.$ y <6mm) C: grandes $(>6 \mathrm{~mm}) ;{ }^{*}=$ promedio, Línea vertical.

en un bañado. Durante el primer semestre de 2014 no se pudieron realizar muestreos debido a que la crecida del rio Uruguay inundó dicha zona, imposibilitando el acceso al campo. En los dos establecimientos, los meses 
de mayor abundancia fueron los meses de agosto, septiembre y octubre, donde los registros de temperatura media fueron entre 14,5 a $15,5^{\circ} \mathrm{C}$. También se observó la mayor cantidad de caracoles pequeños y medianos, indicando una alta tasa de reproducción. En los meses de diciembre a marzo- abril se observó la disminución de esta cohorte y el aumento de los de tamaño grande, siendo estos últimos, los más resistentes a los ambientes adversos (Torgenson y Claxton, 1999). En este trabajo, los coeficientes de correlación entre la $\mathrm{AHI}$ y la $\mathrm{T}^{\circ}$ media y máxima de dos meses anteriores al muestreo determinaron una asociación discreta, a pesar de ello, no debería desestimarse el rol de la temperatura en la dinámica poblacional, ya que otros autores han observado asociaciones negativas en este sentido (Prepelitchi, 2009). Otros en cambio destacaron la importancia de la temperatura en el crecimiento y desarrollo del HI (Aguiar, 2010; Olaechea et al., 2007; Venturini,1990). Prepelitchi (2009), mencionó que el patrón de abundancia de $P$. columella estaría relacionado con la presencia y la abundancia de otros caracoles que integran la comunidad de gasterópodos, como los de los géneros Ampullaria, Physa, Drepanotrema y Biomphalaria, potenciales competidores por sustrato y recursos. Esta variable no puede ser extrapolada directamente a $G$. cubensis, ya que, por su naturaleza anfibia, no prefieren el mismo ambiente que los mencionados géneros (Rumi et al., 2003).

Si bien no se halló una relación estadísticamente significativa entre la abundancia y estructura poblacional de los caracoles con la prevalencia en los bovinos, en los periodos de mayor abundancia poblacional la oferta 
permanente de huevos de F. hepatica en el ambiente podría producir incrementos en la tasa de infestación del HI, aportando mayor disponibilidad de MTC al ambiente. 


\section{Objetivo V}

\section{Evaluación de la susceptibilidad de los lymneidos a la infestación por} Fasciola hepatica.

\subsection{Introducción}

La presencia de $F$. hepatica en una región depende fundamentalmente de la presencia de su hospedador intermediario que, como fue mencionado para la zona de estudio, sería G. cubensis. En ellos se produce una multiplicación asexual del parásito, donde un solo miracidio puede llegar a producir más de 1000 MTC (Sanabria et al., 2012). Los parásitos son capaces de un rápido cambio evolutivo en relación a sus hospedadores, debido a su corto ciclo de vida, al corto tiempo entre generaciones y a su alta fecundidad, dando como resultado una rápida adaptación al genotipo del hospedador local, como también a las condiciones ambientales (Holmes, 1983).

Se ha observado que la producción de cercarias es diferente según la especie de lymneidos (Sanabria et al., 2012), y que la capacidad de infección de $F$. hepatica en su hospedador intermediario difiere según su origen geográfico. Experimentalmente, se observaron variaciones en la producción de MTC en relación a la especie del hospedador intermediario (Vignoles et al., 2015). Además, se ha estudiado la capacidad infectante en términos de producción de MTC, en base a infestaciones de $\mathrm{HI}$ con aislamientos alopátricos y simpátricos. En este sentido, las combinaciones alopátricas parecen tener mejor tasa de infectividad en lymneidos (Gasnier 
et al., 2000; Sanabria et al., 2013). Para ello, diferentes factores bióticos y abióticos influyen en el desarrollo de $F$. hepatica dentro del $\mathrm{HI}$, y por consiguiente en el número de generaciones de redias producidas y en la emisión de cercarias (Rondelaud et al., 2013; Vignoles et al., 2015).

Teniendo en cuenta lo enunciado, el objetivo de este capítulo fue determinar la susceptibilidad diferencial de las especies o poblaciones de lymneidos estudiados pertenecientes a distintos establecimientos, frente al desafío experimental con aislamientos de $F$. hepatica del mismo origen.

\subsection{Materiales y métodos}

Se trabajó con caracoles obtenidos de los establecimientos San Julián (Gualeguay), La Torcaza (Gualeguaychú), y Los Castores (Tala). Los lymneidos capturados fueron analizados para determinar la presencia de estadios larvarios de F. hepatica. Para ello, los caracoles capturados fueron observados a trasluz bajo lupa estereoscópica (30X) (Figura 6.1). Al 50\% de los ejemplares se le realizo el método de aplastamiento (Prepelitchi, 2009), que consiste en romper la conchilla con un objeto romo, y observar posteriormente con lupa estereoscópica, la presencia de formas larvarias, permitiendo así mayor precisión.

Los caracoles que no fueron sacrificados para la identificación de formas larvarias fueron criados separadamente según su origen para luego ser sometidos experimentalmente a infecciones con miracidios de $F$. hepatica del mimo origen. 
Para ello, se formaron grupos de 10 ejemplares en recipientes de 500ml. Allí se mantuvieron 3 a 4 días con agua del lugar donde fueron capturados, así como también, con barro y vegetación del lugar de origen. Se alimentaron con hojas de lechuga seca (Rondelaud et al. 2013), y suplemento de Arthrospira spp. (Espirulina) deshidratada, dos veces por semana (Prepelitchi et al., 2014) (figura 6.2). El agua se reemplazó dos veces por semana para mantener la oxigenación (Rondelaud et al., 2007).

Se obtuvieron huevos de F. hepatica de vesícula biliar, en necropsias de cuatro animales de los establecimientos estudiados. Luego de su obtención, los huevos fueron lavados con solución fisiológica $0,9 \%$ varias veces e incubados por 20 días a $25^{\circ} \mathrm{C}$ en oscuridad.

Cien lymneidos de cada establecimiento, mayores a $4 \mathrm{~mm}$ fueron expuestos individualmente a 2 miracidios de un aislamiento de $F$. hepatica del mismo origen. Para ello fueron alojados en placas de 24 pocillos junto a los miracidios recién eclosionados, donde permanecieron 4 h (Figura 6.3), para luego ser trasladados a los recipientes de cría. Entre los 20 y 30 días post infestación los caracoles que sobrevivieron se examinaron una vez por semana bajo lupa estereoscópica con el fin de determinar si presentaban formas larvarias de F. hepatica (Figura 6.1). Los caracoles positivos a la presencia de redias o cercarias fueron colocados individualmente en placas de Petri de $35 \mathrm{~mm}$ y alimentados con Espirulina, con recambios diarios de alimento y agua. Con igual frecuencia se realizó conteo y remoción de MTC en cada placa de Petri, aplicándose este proceso hasta la muerte de caracol. 
Para evaluar la susceptibilidad a la infestación, se tuvo en cuenta el número de caracoles sobrevivientes al día 30 post infestación, el período prepatente y la producción de MTC. Los resultados, se compararon mediante prueba de Kruskall Wallis, con un nivel de significación del 95\%.

Figura 6.1. Infestación de Fasciola hepatica en Galba cubensis.
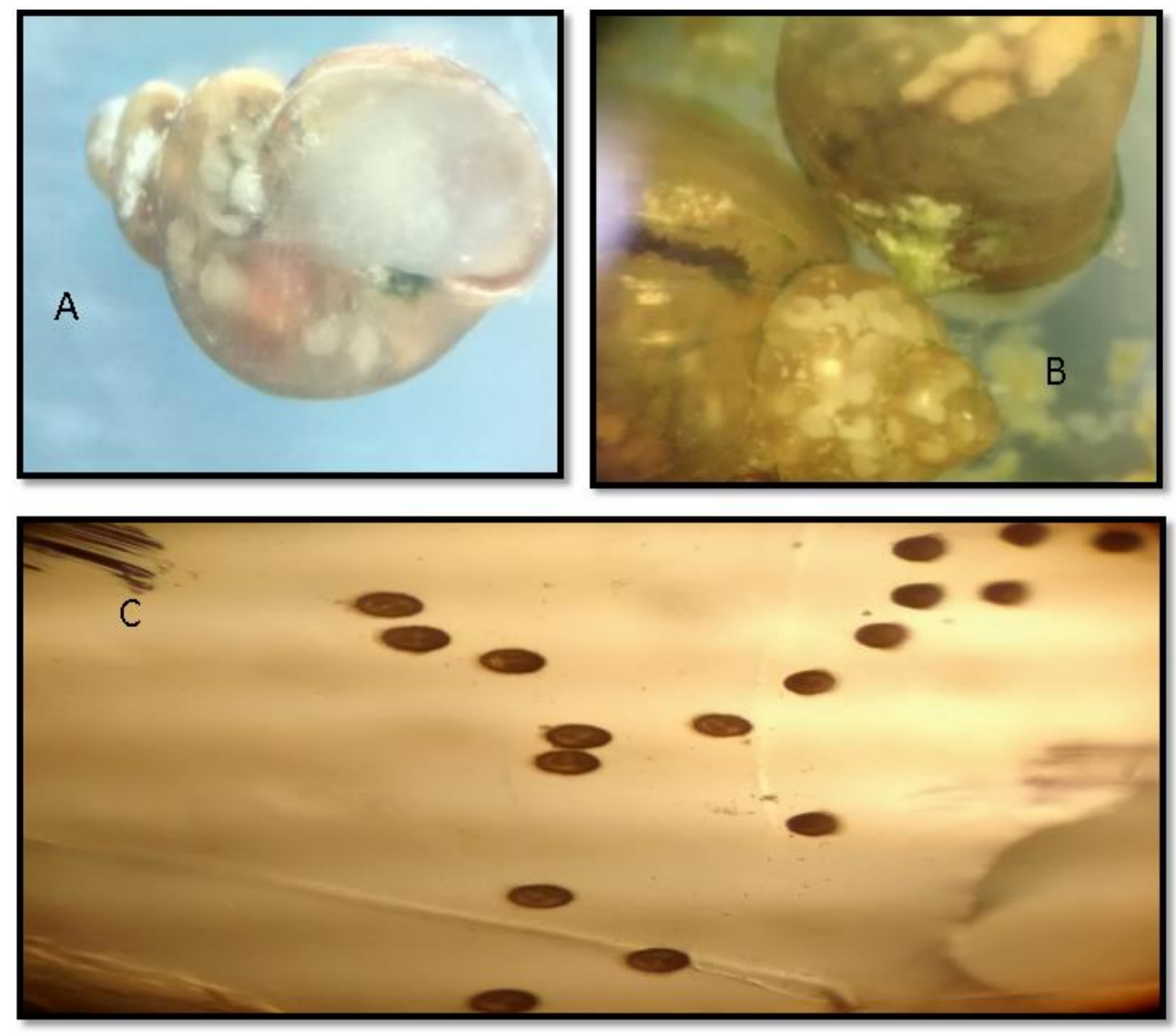

A y B: estadios larvarios observados a trasluz por lupa estereoscópica, en el interior de G. cubensis 30X. C: metacercarias observadas en placa de Petri a los 42 días post-infestación, 35X. 
Fig.6.2 Cría de lymneidos en laboratorio.

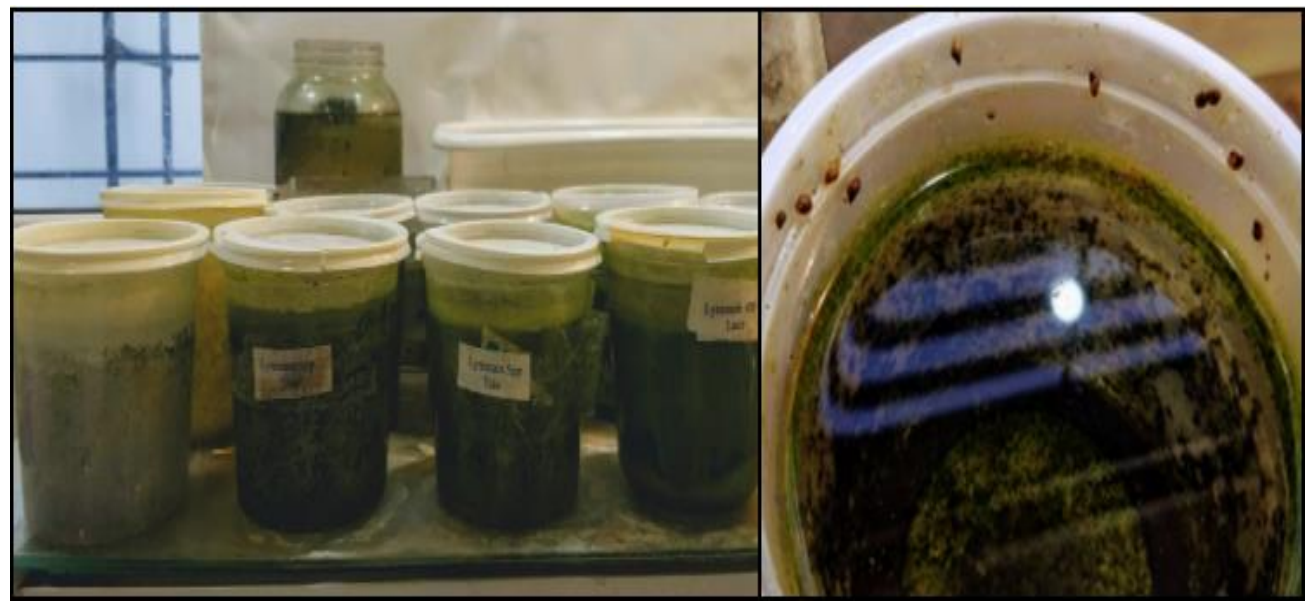

Fig 6.3 Placa de 24 pocillos donde son colocados los caracoles de manera individual para la infestación con F. hepatica.
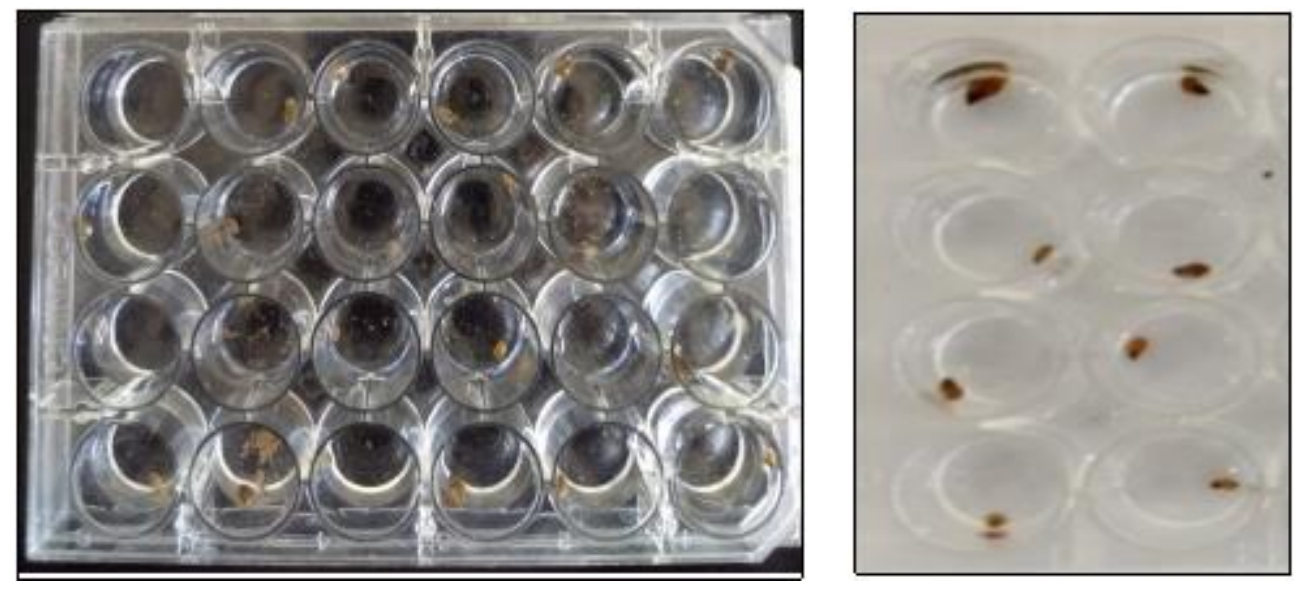

\subsection{Resultados}

No se observaron infestaciones naturales por $F$. hepatica en los caracoles observados a trasluz, ni en aquellos que fueron aplastados. 
En la tabla 6.1 se muestran los resúmenes de los resultados de la producción de MTC, periodo de prepatencia, y numero de caracoles sobrevivientes al día 30 post infestación.

La supervivencia de los lymneidos a los 30 días no mostro diferencias significativas de acuerdo al origen $(p=0,42)$. Tampoco se hallaron diferencias estadísticamente significativas entre el número de MTC producidas y su origen $(p=0,88)$, ni entre este y el periodo de prepatencia $(p=0,90)$.

Tabla 6.1. Parámetros obtenidos de la infestación experimental por Fasciola hepatica de Galba cubensis, de acuerdo al establecimiento de origen.

\begin{tabular}{lccc}
\hline Origen & Torcaza & Los Castores & San Julián \\
\hline \hline$N^{\circ}$ de caracoles expuestos. & 100 & 100 & 100 \\
Sobrevivientes al día 30. & 65 & 67 & 78 \\
Caracoles infectados. & 60 & 52 & 53 \\
Periodo Prepatente promedio (DS) & & & \\
en días. & $48,5(6,4)$ & $48,8(10,0)$ & $46,8(8,2)$ \\
Promedio de metacercarias & & & $166,1(56,5)$ \\
producidas (DS) por caracol. & $186,4(90,2)$ & $168,0(95,5)$ & \\
\end{tabular}

\subsection{Discusión}

La ausencia de diferenciación en la producción de MTC podría estar explicada por la adaptación que presenta F. hepatica a la especie de HI local, así como también a las condiciones ambientales locales (Gasnier et al., 2000). 
Se han reportado diferencias en la producción de MTC en lymneidos según el origen geográfico de los aislamientos de F. hepatica (Rondelaud et al., 2013). Aunque las poblaciones estudiadas pertenecen a diferentes localidades, la distancia que las separan podría no ser suficientemente amplia como para producir cambios adaptativos locales (Rondelaud et al., 2013). Esto además concordaría con que la única especie identificada en el sur de la provincia de Entre Ríos es G. cubensis. La falta de diferencias entre aislamientos pone de manifiesto una adaptación local parásito-HI. Con esto en mente, la infestación de caracoles con aislamientos alopátricos de $F$. hepatica podría mejorar la sensibilidad, en función de encontrar poblaciones más o menos sensibles al desafío experimental. 


\section{Conclusiones}

Los hallazgos del presente estudio ponen de manifiesto que la fasciolosis ocurre de forma endémica en el sur de la provincia de Entre Ríos, estando presente, al menos, en cada evento de muestreo realizado. Se hallaron tasas de prevalencia moderadas a elevadas en el hospedador definitivo, y no se hallaron infestaciones naturales en el hospedador intermediario. Otros estudios epidemiológicos indicaron que no existe una relación directa entre la prevalencia en el ganado y en los lymneidos (Amato et al., 1986), ya que las MTC no son necesariamente ingeridas inmediatamente después de formarse, y pueden permanecer infectivas durante varios meses en el ambiente. De esta forma el ganado puede infectarse, incluso aunque el caracol no esté presente (Roberts y Sahordono, 1996).

La prevalencia en los bovinos fue siempre superior al $40 \%$ en los diferentes muestreos. Estos niveles, en general, no reflejan una infestación inmediata en bovinos, sino que la longevidad de estos trematodes y un daño crónico, y relativamente de bajo impacto clínico en esta especie, permite la acumulación de cargas en el tiempo. Solo el efecto de la desparasitación tendería a reducir las cargas parasitarias, pero teniendo en cuenta que se halló una gran dispersión de la resistencia a albendazol, muchos de los tratamientos implementados reducirían escasa o nulamente las poblaciones de Fasciola. Bajo este escenario regional de resistencia a albendazol, solo triclabendazol, salicilanilidas (closantel, nitroxinyl) y eventualmente bencenosulfonamidas (clorsulon, no evaluado en el presente estudio), podrían ser útiles para el control de la fasciolosis en esta 
región. El empleo de bencimidazoles metilcarbamatos debería estar sujeto a una previa evaluación de eficacia en cada establecimiento.

Del punto de vista epidemiológico, existió una asociación significativa entre suelos de pobre drenaje y la prevalencia de $F$. hepatica, lo cual permitió delimitar regiones donde se puede mantener la infestación por aptitud para el desarrollo del HI (figura 2.10). Además, se observó mayor probabilidad de hallazgo de animales positivos $(\mathrm{OR}=2,86)$ en los periodos de mayor temperatura, por lo cual en los meses de septiembre a marzo sería el momento para implementar estrategias de manejo y control farmacológico que reduzcan la incidencia. Respecto a la prevalencia, ésta se relacionó significativamente con la temperatura máxima de dos meses antes de la fecha de muestreos. Esto indicaría posiblemente una relación entre la duración del período prepatente y el momento de infestación, sugiriendo que, incluso antes del inicio del período de mayor riesgo (septiembre) sería conveniente la implementación de estrategias de tratamiento y manejo.

Los análisis filogenéticos y moleculares de F. hepatica evidenciaron diversidad genética, lo cual estaría relacionado a procesos de recombinación vinculados principalmente a fecundación cruzada entre individuos. No se encontraron diferencias genéticas en $F$. hepatica entre las poblaciones estudiadas, indicando cruzamiento aleatorio y alto flujo genético entre estas. En este estudio se observó resistencia generalizada a $A B Z$, fenómeno que se asoció, en estudios previos, a la predominancia homocigota en nematodes (Diawara et al., 2013). No obstante, no está claro aún el mecanismo por el cual se produce resistencia a este fármaco 
en F. hepatica. En nematodes, predominan mutaciones puntuales en el sitio activo, que consisten en el caso de ABZ, en la sustitución de tirosina por fenilalanina en del codón 200 del isotipo 1 de $\beta$-tubulina, (Kwa et al., 1994), aunque otras mutaciones fueron demostradas con posterioridad (Sylvestre y Cabaret, 2002; Ghisi et al., 2007). Sin embargo, Chambers et al. (2010), hallaron una mayor afinidad de $\mathrm{ABZ}$ por el isotipo 2 de $\beta$-tubulina en $F$. hepatica, y aun no está claro el protagonismo de mecanismos inespecíficos en la resistencia a $A B Z$, como la sobre-expresión de la detoxificación mediada por citocromo P450 o glicoproteina-P (Kotze et al., 2014). Esta incertidumbre hace difícil suponer si la resistencia local a $A B Z$ se presenta por fijación de genes (lo cual parece menos probable para este estudio), o bien mediante posibles mecanismos inespecíficos, en respuesta a, por ejemplo, subdosificaciones (dosis nematodicida de $A B Z$ de $5 \mathrm{mg} / \mathrm{kg}$ vs. fasciolicida de $10 \mathrm{mg} / \mathrm{kg}$ ), e incluso combinaciones de varios mecanismos. Estudios de mayor profundad son necesarios en este aspecto.

Respecto al $\mathrm{HI}$, no se hallaron caracoles infectados naturalmente por $F$. hepatica. Algunos trabajos mencionaron prevalencias de hasta $88,4 \%$ (Malone et al., 1984), pero en nuestro país se registraron infecciones del 2,1\% en P. collumela en Corrientes (Prepelitchi, 2009), similar a lo encontrado en G. truncatula en la provincia de Mendoza (Rubel et al., 2005)

Los estudios moleculares evidenciaron la presencia de una sola especie, identificada como G. cubensis de acuerdo a la nomenclatura vigente, que sería, al menos, la especie predomínate en la región. Su adaptación al 
medio, el equilibrio HI-parásito y la posibilidad de desplazamiento por las crecientes y reducciones frecuentes en los cursos de agua locales podrían contribuir a vehiculizar linajes de F. hepatica ABZ-resistentes. Esto podría explicar, al menos parcialmente, la amplia dispersión del fenómeno de resistencia a esta droga.

Los análisis de estructura poblacional revelaron una mayor abundancia entre fines de invierno y principios de primavera, pero un mayor tamaño promedio durante el verano y principios de otoño. Esto indica una expansión poblacional primaveral favorecida por las condiciones ambientales de temperaturas moderadas y humedad, que luego tiende a reducirse en número en favor de los ejemplares sobrevivientes que adquieren mayor tamaño. Estos mismos ejemplares, por sus características, tienen mayor posibilidad de resultar infectados, originando el pie de infección ambiental de otoño y la reserva biológica para la siguiente expansión poblacional primaveral.

A nivel experimental, G. cubensis mostro eficiencia como hospedador de $F$. hepatica, ya que $83 \%$ de los caracoles sobrevivientes al día 30 resultaron infectados. No obstante, la producción de MTC fue casi diez veces menor que infestaciones reportadas para esta especie con aislamientos europeos de F. hepatica (Sanabria et al., 2013). Esto, sumado a la relativamente baja mortalidad luego de la infestación, podría manifestar una adaptación o "equilibrio" parásito-hospedador a nivel local.

Aunque solo en algunos establecimientos pudieron hallarse lymneidos, no pudo establecerse diferencias de susceptibilidad a $F$. hepatica entre 
diferentes aislamientos, ni indicadores moleculares relacionados a esta característica, lo cual indica nuevamente cierta homogeneidad poblacional local.

Finalmente, las observaciones realizadas en estos trabajos contribuyen a explicar la dinámica de infestación de la fasciolosis en el sur de Entre Ríos, donde la predominancia de infestación en los bovinos ocurre a fines de invierno y principios de primavera, asociada a ambientes con suelos de bajo drenaje. Bajo estas condiciones, es necesario implementar medidas de control estacional que contribuyan a reducir la incidencia regional de esta parasitosis. Es importante además la evaluación de los fármacos a nivel predial a fin de evitar fallas en los tratamientos. 


\section{Bibliografía}

Andrews SJ. 1999. The life cycle of Fasciola hepatica. En: Fasciolosis, J. P. Dalton (Ed). London, UK, CABI International, 544.

Aguilar M. 2010. Situación de Fasciola hepatica al sur del paralelo $48^{\circ}$. Tesis de Magister Scientiae. Facultad de Cs. Agrarias, Universidad Nacional de Mar del Plata, 78.

Alda P, Lounnas M, Vázquez AA, Ayaqui R, Calvopiña M, Celi-Erazo M, Dillon RT, Jarne P, Loker ES, Muñiz Pareja FC, Muzzio-Aroca J, Nárvaez AO, Noya O, Robles LM, Rodríguez-Hidalgo R, Uribe N, David P, Pointier JP, Hurtrez-Boussès S. 2018. A new multiplex PCR assay to distinguish among three cryptic Galba species, intermediate hosts of Fasciola hepatica. Vet Parasitol. 251:101-105.

Amato SDB, Deepened HEB, Gomez DC, Freire NM. 1986. Da Serra. Epidemiology of Fasciola hepatica infection in the Paraiba River Valley, Sao Paulo, Brazil. Vet Parasitol, 22 (3-4).275-284.

Amer S, Dar Y, Ichikawa M, Fukuda Y, Tada C, Itagui T, Nakai. 2011. Identification of Fasciola species isolated from Egypt based on sequence analysis of genomic (ITS1 and ITS2) and mitochondrial (NDI and COI) gene markers. Parasitol Int, 60(1):5-12.

Aguirre D, Cafrune M, Salatín A, Abeyá A. 2005. Fasciolosis clínica en cabras de Metán (Salta, Argentina). Revista FAVE - Ciencias Veterinarias $4(1-2)$. 
Aykanat T, Johnston SE, Cotter D, Cross TF, Poole R, Prodőhl PA, Reed T, Roga G, Mc Ginnity P. 2014. Primmer CR. Molecular pedigree reconstruction and estimation of evolutionary parameters in a wild Atlantic salmon river system with incomplete sampling: a power analysis. BMC Evol Biol. 14(1):68.

Bargues M, Mas-Coma S. 1997. Phylogenetic analysis of Lymnaeid snails based on 18S rDNA sequences. Mol Biol Evol. 14(5):569-577.

Bargues M. Artigas P, Mera y Sierra R, Pointier JP, Mas-Coma S. 2007. Characterisation of Lymnaea cubensis, L. viatrix and L. neotropica $\mathrm{n}$. sp., the main vectors of Fasciola hepatica in Latin America, by analysis of their ribosomal and mitochondrial DNA. Ann Trop Med Parasitol. 101(7): 621641.

Bargues MD, Artigas P, Khoubbane M, Mas-Coma S. 2011. DNA sequence characterization and phylogeography of Lymnaea cousini and related species, vectors of fascioliasis in northern Andean countries, with description of L. meridensis n. sp. (Gastropoda: Lymnaeidae). Parasit Vectors. 4:132.

Bargues M, Gayo V, Sanchis J, Artigas P, Khoubbane M, et al. 2017. DNA multigene characterization of Fasciola hepatica and Lymnaea neotropica and its fascioliasis transmission capacity in Uruguay, with historical correlation, human report review and infection risk analysis. PLoS Negl Trop Dis. 11(2): e0005352. 
Beesley NJ, Williams DJL, Paterson S, Hodgkinson, J. 2017. Fasciola hepatica demonstrates high levels of genetic diversity, a lack of population structure and high gene flow: possible implications for drug resistance. Int $\mathrm{J}$ Parasitol. 47(1):11-20.

Beltrame M, Tietze E, Pérez A, Bellusci A, Sardella, N. 2017. Ancient parasites from endemic deer from "CUEVA PARQUE DIANA" archeological site, Patagonia, Argentina. Parasitol Res. 116:1523-1531.

Boray J C. 1964. Studies on the ecology of Lymnaea tomentosa the intermediate host of Fasciola hepatica. History, geographical distribution and environment. Australian J Zool. 12:217-230.

Boyce W, Courtney C, Loggins P. 1987. Resistance to experimental infection with Fasciola hepatica in exotic and domestic breeds of sheep. Int J Parasitol. 17:1233-1237.

Burgarella C, Gayral P, Ballenghien M, Bernard A, David P, Jarne P, Correa A, Hurtrez-Bousses S, Escobar J, Galtier N, Glemin S. 2015. Molecular evolution of freshwater snails with contrasting mating systems. Mol Biol Evol. 32(9):2403-2416.

Cabrero J, Camacho J. Fundamentos de genética de poblaciones. En: Soler Cruz M. Evolución: la base de la biología. España. Proyecto Sur; 2002. p. 83-126.

Cañete R, Yong M, Sánchez J, Wong L, Gutiérrez A. 2004. Population dynamics of intermediate snails hosts of Fasciola hepatica and some 
environmental factors in San Juan y Martinez municipality, Cuba. Mem Inst Oswaldo Cruz. 98(3):257-262.

Cosenza M, Reale S, Lupo T, Vitale F, Caracappa S. 2015. Allele frequencies of microsatellite loci for genetic characterization of a Sicilian bovine population. Genet Mol Res. 14(1):691-9.

Cardozo H, Paiva N, Acosta D, Armentano J. 1991. Importancia de Fasciola hepatica sobre la ganancia de peso y su porcentaje de preñez al segundo entore en ganado de carne infestado naturalmente. Veterinaria. 27(111):410.

Carvalho O, Cardoso P, Lira P, Rumi A, Roche A, Berne E, Müller G, Caldeira R. 2004. The use of the polymerase chain reaction and restriction fragment length polymorphism technique associated with the classical morphology for characterization of Lymnaea columella, L. viatrix, and $L$. diaphana (Mollusca: Lymnaeidae). Mem Inst Oswaldo Cruz. 99(5):503-507.

Chambers E, Ryan LA, Hoey EM, Trudgett A, McFerran NV, Fairweather I, Timson DJ. 2010. Liver fluke $\beta$-tubulin isotype 2 binds albendazole and is thus a probable target of this drug. Parasitol Res. 107(5):1257-64.

Charlier J, Caroliene B, Caron Y, Counotte M, Ducheyne E, Guy H, Vercruysse J. 2011. Towards assessing fine-scale indicators for the spatial transmission risk of Fasciola hepatica in cattle. Geospat Health 5(2):239245. 
Ghisi M, Kaminsky R, Maser P. 2007. Phenotyping and genotyping of Haemonchus contortus isolates reveal a new putative candidate mutation for benzimidazole resistance in nematodes. Vet Parasitol 144(3-4):313-320.

Coelho LHL, Guimarães MP, Lima WS. 2008. Influence of shell size of Lymnaea columella on infectivity and development of Fasciola hepatica. J Helminthol. 82:77-80.

Coles GC, Stafford KA. 2001. Activity of oxyclozanide, nitroxynil, clorsulon and albendazole against adult triclabendazole-resistant Fasciola hepatica. Vet Rec. 148(23):723-724.

Correa AC, Escobar JS, Durand P, Renaud F, David P, Jarne P. 2010. Bridging gaps in the molecular phylogeny of the Lymnaeidae (Gastropoda: Pulmonata), vectors of Fascioliasis. BMC Evol Biol. 10:381.

Correa AC, Escobar JS, Noya O, Velásquez LE, González-Ramírez C, Hurtrez-Boussès S, Pointier JP. 2011. Morphological and molecular characterization of Neotropic Lymnaeidae (Gastropoda: Lymnaeoidea), vectors of fasciolosis. Infect Genet Evol. 11(8):1978-1988.

Cringoli G, Rinaldi L, Veneziano V, Genchi CA. 2006. Dual anthelmintic treatment strategic scheme for the control of fasciolosis in dairy sheep farms. Parasitol Res. 99(6):700-705.

Cruz R. 2014. Sistemas de información geográfica nivel 1. Centro de Capacitación de Ciencias Geográficas. Disponible en: www.ing.gob.ar. 
Cwiklinski K, Allen K, LaCourse J, Williams D, Paterson S, Hodgkinson J. 2015. Characterization of a novel panel of polymorphic microsatellite loci for the liver fluke, Fasciola hepatica, using a next generation sequencing approach. Infect Genet Evol. 32:298-304.

Dar Y, Amer S, Courtioux B, Dreyfuss G. 2011. Microsatellite analysis of Fasciola spp. in Egypt. Parasitol Res. 109(6):1741-1744.

Dar Y, Lounnas M, Djuikwo Teukeng FF, Mouzet R, Courtioux B, HurtrezBousses S, Vignoles P, Dreyfuss G, Rondelaud D. 2013. Variations in local adaptation of allopatric Fasciola hepatica to French Galba truncatula in relation to parasite origin. Parasitol Res. 112(7):2543-2549.

Diawara A, Schwenkenbecher JM, Kaplan RM, Prichard RK. 2013. Molecular and biological diagnostic tests for monitoring benzimidazole resistance in human soil-transmitted helminths. Am J Trop Med Hyg. 88(6):1052-1061.

Dillon RT. The ecology of freshwater molluscs. Cambridge: Cambridge University Press; 2000.

Dreyfuss G, Vignoles P, Rondelaud D. 2012. Local adaptation of the trematode Fasciola hepatica to the snail Galba truncatula. Parasite. 19:71275.

Dreyfuss G, Vignoles P, Rondelaud D. 2016. Current decline in the number and size of Galba truncatula and Omphiscola glabra populations, intermediate hosts of Fasciola hepatica, on the acidic soils of Central France. Parasite. 23:46. 
Dutra LH, Molento MB, Naumann CRC, Biondo AW, Fortes FS, Savio D, Malone JB, 2010. Mapping risk of bovine fasciolosis in the south of Brazil using geographic information systems. Vet Parasitol. 169:76-81.

Elliott T, Muller A, Brockwell Y, Murphy N, Grillo E, Toet MH, Anderson G, Sangster E, Spithill T. 2012. Evidence for high genetic diversity of NAD1 and COX1 mitochondrial haplotypes among triclabendazole resistant and susceptible populations and field isolates of Fasciola hepatica (liver fluke) in Australia. Vet Parasitol. 200:90-96.

Engler P, Rodríguez M, Cancio R, Handloser M, Vera ML. 2008. Zonas AgroEconómicas Homogéneas de Entre Ríos. Descripción ambiental, socioeconómica y productiva. Estudios socioeconómicos de la sustentabilidad de los sistemas de producción y recursos naturales. INTA ISSN N $61851-6955$.

Estoup A, Martin O. Marqueurs microsatellites: isolement à l'aide de sondes non-radioactives, caractérisation et mise au point .1996. Disponible en: http://www.inapg.inra.fr/dsa/microsat/microsat.htm.

Hope-Cawdery MJ, Strickland KL, Conway A, Crowe PJ. 1977. Production effects of liver fluke in cattle I. The effects of infection on liveweight gain, feed intake and food conversion efficiency in beef cattle. British Veterinary Journal. 133(2):145-159.

Fairweather I, Lawrence T, Threadgold y Robert, EB Hanna. 1999. Development of Fasciola hepatica in mammalian host. J P Dalton (Ed). London. CABI International, p 47-111. 
Fairweather I, Boray J. 1999. Fasciolicides: efficacy, actions, resistance and its management. Vet J. 158(2):81-112.

Flynn RJ, Mulcahy G, Welsh M, Cassidy JP, Corbett D, Milligan C, Andersen P, Strain S, McNair J. 2009. Co-Infection of Cattle with Fasciola hepatica and Mycobacterium bovis - Immunological Consequences. Transbound Emerg Dis. 56(6-7):269-297.

Fox NJ, White PCL, Mc Clean CJ, Marion G, Evans A, Hutchings MR. 2011. Predicting impacts of climate change on Fasciola hepatica risk. PLoS One. 6(1):e16126.

Gasnier N, Delaud D, Abrous M, Carreras F, Boulard FC, Diez-Baños P, Cabaret J. 2000. Allopatric combination of Fasciola hepatica and Lymnaea truncatula is more efficient than sympatric ones. International Journal for Parasitology 30(5):573-578.

Gayo V, Mera-Sierra R. 2010. Latin America controls liver fluke (Fasciola hepatica) in livestock and humans. Disponible en: www.naweb.iaea.org/nafa/aph/stories/2010-fasciola-project.html.

Gérard C. 2001. Consequences of a drought on freshwater gastropods and trematode communities. Hydrobiologia. 459(1-3):9-18.

Głażewska I, Gralak B, Naczk AM, Prusak B. 2018. Genetic diversity and population structure of Polish Arabian horses assessed through breeding and microsatellite data. Anim Sci J. 89(5):735-742. 
Gonzalez-Lanza, Manga-Gonzalez P, Del Pozo-Carnero P, HidalgoArgüello R. 1989. Dynamics of elimination of the eggs of Fasciola hepatica (Trematoda, Digenea) in the faeces of cattle in the Porma Basin, Spain. Vet Parastol. 34(1-2):35-43.

Gutiérrez A, Yong M, Wong L, Sanchez J. 2002. The effect of isolation on reproduction and growth of Pseudosuccinea columella (Pulmonata: Lymnaeidae): a snail conditioned water experiment. Mem Inst Oswaldo Cruz, 97(6):869-870.

Hanna, REB, Moffett D, Forster FI, Trudgett AG, Brennan GP, Fairweather I. 2016. Fasciola hepatica: a light and electron microscope study of the ovary and of the development of oocytes within eggs in the uterus provides an insight in to reproductive strategy. Vet Parasitol 221:93-103.

Hartl D, Clark A. Principles of Population Genetics. Harris RE y Charleston WAG, ed. Fourth ed. Massachusett: Oxford University Press; 2007.

Harris RE, Charleston WAG. 1977. The response of the freshwater gasteropods Lymnaea tomentosa and L. columella to desiccation. J Zool. 183:41-46.

Harris RE, Charleston WAG. 1977 An examination of the marsh microhabitats of Lymnaea tomentosa and L. columella (Mollusca: Gastropoda) by path analysis. N Z J Zool. 4:395-399.

Hebert PD, Ratnasingham S, DeWaardm JR. 2003. Barcoding animal life: cytochrome c oxidase subunit 1 divergences among closely related species. Proc Biol Sci. 270(Suppl 1):S96-S99. 
Holmes JC. 1983. Evolutionary relationships between parasitic helminths and their hosts in Futuyma DJ, Slatkin M, editors. Coevolution. Sunderland, Massachusetts: Sinauer Assoc. Inc. p,161-85.

Hurtrez-Boussès S, Meunier C, Durand Patrick, Renaud François. 2001. Dynamics of host-parasite interactions: the example of population biology of the liver fluke (Fasciola hepatica) Microbes and Infection. 3:841-849.

Hurtrez-Boussès S, Durand P, Jabbour-Zahab R, Guégan J, Meunier C Bargues M, Mas-Coma S, Renaud F. 2004. Isolation and characterization of microsatellite markers in the liver fluke (Fasciola hepatica). Molecular Ecology Notes. 4:689-690.

Hurtrez-Boussès S, Pendin A, Bernabé C, Rondelaud D, Durand C, Meunier C, Hurtrez-Boussès JE, Renaud F. 2005. Comparison between shell morphology and genetic diversity in two sympatric lymnaeid snails, vectors of fasciolosis. Canad J Zool. 83(12):1643-1648.

Itagaki T, Kikawa M, Sakaguchi K, Terasaki T, Shibahara T, Fukuda K. 2005. Genetic characterization of parthenogenic Fasciola sp. in Japan on the basis of the sequences of ribosomal and mitochondrial DNA. Parasitology. 135(Pt 5):679-685.

Khademi N, et al. 2016. Identifying HIV distribution pattern based on clustering test using GIS software, Kermanshah, Iran. HIV \& AIDS Review. 215(4):147-152. 
Kelley JM, Elliott TP, Beddoe T, Anderson G, Skuce P, Spithill TW. 2016. Current threat of triclabendazole resistance in Fasciola hepatica. Trends Parasitol. 32(6):458-469.

Kleiman F, Pietrokovsky S, Paraense LW, Wisnivesky-Colli C. 2004. Southernmost finding of Lymnaea viatrix Orbigny, 1835 (Pulmonata: Lymnaeidae), intermediate host of Fasciola hepatica (Linnaeus, 1758) (Trematoda: Digenea), in urban and rural areas of Patagonia, Argentina. Mem Inst Oswaldo Cruz. 99(1):23-24.

Kleiman F, Pietrokovsky S, Prepelitchi L, Carbajo A, Wisnivesky-Colli, C. 2007. Dynamics of Fasciola hepatica transmission in the Andean Patagonian valleys, Argentina. Vet Parasitol. 145:274-286.

Kotze A, Hunt P, Skuce P, von Samson-Himmelstjerna G, Martin R, Sager H, Krücken J, Hodgkinson J, Lespine A, Jex A, Gilleard J, Beech R, Wolstenholme A, Demeler J, Robertson A, Charvet C, Neveu C, Kaminsky R, Rufener L, Alberich M, Menez C, Prichard R. 2014. Recent advances in candidate-gene and whole-genome approaches to the discovery of anthelmintic resistance markers and the description of drug/receptor interactions. Int J Parasitol Drugs Drug Resist. 4(3):164-184.

Kumar S, Stecher G, Li M, Knyaz C, Tamura, K. 2018. MEGA X: Molecular Evolutionary Genetics Analysis across Computing Platforms. Mol Biol Evol. 35(6):1547-1549. 
Kwa MSG, Veenstra JG, Roos MH. 1994. Benzimidazole resistance in Haemonchus contortus is correlated with a conserved mutation at amino acid 200 in beta-tubulin isotype 1. Mol Biochem Parasitol. 63(2):299-303. Lounnas M, Vázquez AA, Alda P, Sartori K, Pointier JP, David P, HurtrezBoussès S. 2017. Isolation, characterization and population-genetic analysis of microsatellite loci in the freshwater snail Galba cubensis (Lymnaeidae). J Mollus Stud. 83:63-68.

Lounnas M, Correa AC, Alda P, et al. 2018. Population structure and genetic diversity in the invasive freshwater snail Galba schirazensis (Lymnaeidae). Can J Zool. 96:425-435.

Malone JB, Craig T. Cattle Liver Flukes: Risk Assessment and Control. En: D Bechtol, J Pollreisz, editors. Compendium on Continuing Education for the practicing veterinarian. Texas; 1999. p.754.

Malone JB. Enfermedades del sistema hepatobiliar. En: Bradford P. Smith, editor. Medicina Interna de Grandes Animales. Cuarta edición. España: Elsevier; 2010. p. 905-910.

Martins IVF, Avelar BR, Pereira MJS, Fonseca AH. 2012. Application of a geographical information system approach for risk analysis of fascioliasis in southern Espírito Santo State, Brazil. Geospat Health. 6(3): S87-S93.

Marcos LA, Terashima A, Leguia G, Canales M, Espinoza JR, Gotuzzo E. 2007. La infección por Fasciola hepatica en el Perú: una enfermedad emergente. Rev gastroenterol Perú. 27(4):389-396. 
Mas-Coma S, Funatsu I, Bargues M. 2001. Fasciola hepatica and lymnaeid snails occurring at very high altitude in South America. Parasitology. 123 Suppl: S115-27.

Meirmans PG, Van Tienderen PH. 2004. Genotype and Genodive: two programs for the analysis of genetic diversity of asexual organisms. Molecular Ecology Notes. 4:792-794.

Mera y Sierra R, Artigas P, Cuervo P, Deis E, Sidoti L, Mas-Coma S, Bargues M. 2009. Fascioliasis transmission by Lymnaea neotropica confirmed by nuclear rDNA and mtDNA sequencing in Argentina. Vet Parasitol. 166(1-2):73-79.

Mera y Sierra R, Agramunt VH, Cuervo P, Mas-Coma S. 2011. Human fascioliasis in Argentina: retrospective overview, critical analysis and baseline for future research. Parasit Vectors. 4:104.

Meunier C, Tirard C, Hurtrez-Boussès S, Durand P, Bargues MD, MasComa S, Pointier JP, Jourdane J, Renaud F. 2011. Lack of molluscan host diversity and the transmission of an emerging parasitic disease in Bolivia. Mol Ecol 10(5):1333-1340.

Meunier C, Hurtrez-Boussès S, Jabbour-Zahab R, Durand P, Rondelaud D, Renaud, F. 2004. Field and experimental evidence of preferential selfing in the freshwater mollusk Lymnaea truncatula (Gastropoda, Pulmonata). Heredity. 92(4):316-322.

Mooney L, Good B, Hanrahan JP, Mulcahy G, de Waal T. 2009. The comparative efficacy of four anthelmintics against a natural 
acquired Fasciola hepatica infection in hill sheep flock in the west of Ireland. Vet Parasitol. 164(2-4):201-205.

Nicot A, Dubois MP, Debain C, David P, Jarne P. 2008. Characterization of 15 microsatellite loci in the pulmonate snail Pseudosuccinea columella (Mollusca, Gastropoda). Molecular Ecology Resources. 8:1281-1284.

Odening K. Samnaliev T. 1987. A New amphistome cercaria from Lymnaea truncatula in Europe. Ann Parasitol Hum Comp. 62(2):117-121.

Olaechea F. Fasciola hepatica. En: Víctor H Suarez, Fermín Olaechea, Jorge Romero, ed. Enfermedades parasitarias de los ovinos y otros rumiantes del cono sur de América. Argentina: INTA; 2007. p.159-168.

Olaechea F, Lovera V, Larroza M, Raffo F, Cabrera R. 2011. Resistance of Fasciola hepatica against triclabendazole in cattle in Patagonia (Argentina). Vet Parasitol. 178(3-4):364-366.

Olaechea F, Gayo V, Cardozo H, Acosta D. Epidemiologia y Control de Fasciola hepatica. En: C Feil y A Nari, ed. Enfermedades parasitarias de importancia clínica y productiva en rumiantes. Fundamentos epidemiológicos para su diagnóstico y control. Argentina: Editorial Hemisferio Sur; 2013. p.301-320.

Ollerenshaw CB. 1971. The influence of climate on the life cycle of Fasciola hepatica in Britain with some observation on the relationship between climate and the incidence of fasciolasis in the Netherlands. En: Facts and reflections, Symposium Proceedings (3 june 1971), Parasitology Department of the central Diergeneeskunding Institut, Lelystad, pp.41-63. 
Ortiz P, Scarcella S, Cerna C, Rosales C, Cabrera M, Guzmán M, Lamenza P, Solana H. 2013. Resistance of Fasciola hepatica against triclabendazole in cattle in Cajamarca (Peru): a clinical trial and in vivo efficacy test in sheep. Vet Parasitol. 195(1-2):118-121.

Overend DJ, Bowen FL. 1995. Resistance of Fasciola hepatica to triclabendazole. Aust Vet J 72:275-276.

Pleasance J, Wiedosari E, Raadsma H, Meeusen E, Piedrafita D. 2011. Resistance to liver fluke infection in the natural sheep host is correlated with a type-1 cytokine response. Parasite Immunol 33(9):495-505.

Pointier JP, Cazzaniga, N, Gonzalez-Salas C, Guti Interrez A, Arenas J, Bargues M, Mas-Coma S. 2006. Anatomical studies of sibling species within neotropical lymnaeidos, snail intermediate hosts of fascioliasis. Mem Inst Oswaldo Cruz. 101(4):431-435.

Pointier JP, David P, Koene J. Basommatophora gastropods. En: Cordoba, Aguilar y Leonard, ed. The Evolution of Primary Sexual Characters in Animals. New York: Oxford University Press; 2010. p.173-196.

Prepelitchi L, Kleiman F, Pietrokovsky SM, Moriena RA, Racioppi O, Alvarez J, Wisnivesky-Colli C. 2009. First report of Lymnaea columella Say, 1817 (Pulmonata: Lymnaeidae) naturally infected with Fasciola hepatica (Linnaeus, 1758) (Trematoda: Digenea) in Argentina. Mem Inst Oswaldo Cruz. 98(7):889-91.

Prepelitchi, L. 2009. Eco epidemiología de Fasciola hepatica (Trematoda, Digenea) en el norte de la provincia de Corrientes destacando aspectos 
ecológicos de Lymnaea columella (Pulmonata, Lymnaeidae) y su rol como hospedador intermediario. [Tesis doctoral]. Buenos Aires: Facultad de Ciencias Exactas y Naturales de la Universidad de Buenos Aires; 2009.

Prepelitchi I, Pujadas J, Wisnivesky-Colli C. 2015. The effect of spirulina (Arthrospira platensis) (Oscillatoriales: Cyanobacteria) on the experimental breeding of Pseudosuccinea columella (Basommatophora: Lymnaeidae). Rev Biol Trop. 63(2):479-489.

Pruzzo C, Sanabria R, Medus D, Reyna G, Romero J. Fasciola hepatica: spread of albendazole resistance in Central Eastern Argentina. En: XXV Conferencia de la World Association for the Advancement of the Veterinary Parasitology. Liverpool; 2015.

Raffo F, Larroza M, Olaechea F. Propuesta y evaluación de una metodología de análisis digital de imagen para estimar la longitud de los caracoles Lymnaea viatrix. En: XVIII Reunión Científico-Técnica de la Asociación Argentina de Laboratorios de Diagnóstico. Corrientes; 2010.

Recalde-Reyes D, Padilla Sanabria L, Giraldo Giraldo MI, Toro Segovia LJ, González MM, Castaño Osorio JC. 2012-2013. Prevalencia de Fasciola hepatica, en humanos y bovinos en el departamento del Quindío-Colombia. Infectio. 18(4):153-157.

Remegio E, Blair D. 1997. Molecular systematics of the freshwater snail (Pulmonata: Basommatophora) utilizing mitochondrial ribosomal DNA sequences. J Moll Stud. 63:173-185. 
Rodríguez-Morales A, Orrego-Acevedo C, Zambrano-Muñoz Y, GarcíaFolleco FJ, Herrera-Geraldo AC, Lozada-Riascos C. Mapping malaria in municipalities of the Coffee Triangle region of Colombia using Geographic Information Systems (GIS) J Infect Public Health. 8:603-611.

Rojas Moncada J, Palomino Lozano G, Calderón Silva T, Terán Saucedo J. 2013. Diagnóstico de resistencia antihelmíntica de Fasciola hepatica a los antiparasitarios de uso más común en bovinos de cuatro Distritos de Cajamarca, Perú. Disponible en: https://www.engormix.com/ganaderiacarne/articulos/diagnostico-resistencia-antihelmintica-fasciola-t30162.htm.

Rojo Vazquez FA, Ferre Perez. Parasitosis hepática. En: Cordero del Capillo M, Rojo Vazquez FA, coord. Parasitología Veterinaria. Primera edición. España: McGraw Hill-Interamericana; 1999. 260-282.

Rondelaud D, Titi A, Vignoles P, Mekroud A, Dreyfuss G. 2014. Adaptation of Lymnaea fuscus and Radix balthica to Fasciola hepatica through the experimental infection of several successive snail generations. Parasit Vectors. 7:296.

Rondelaud D, Fousi M, Vignoles P, Moncef M, Dreyfuss G. 2007. Optimization of metacercaria production for three digenean species by the use of Petri dishes for raising lettuce-fed Galba truncatula. Parasitol Res. 100:861-865.

Rousset, F,2008. GENEPOP'007:a complete reimplementation of the GENEPOP 802 software for Windows and Linux. Mol. Ecol. Resour. 8, 103106. 803 
Rose H, Rinaldi L, Bosco A, Mavrot F, de Waal T, Skuce P, Charlier J, Torgerson PR, Hertzberg H, Hendrickx G, Vercruysse J, Morgan ER. 2015. Widespread anthelmintic resistance in European farmed ruminants: a systematic review. Vet Rec. 176(21):546.

Ross JG. 1970. The Stormont "wet-day" forecasting system for fascioliasis. Br Vet J. 126:401-408.

Rubel D, Prepelitchi L, Kliman F, Carnevale S, Wisnivesky-Colli C. 2005. Estudio del foco en un caso de fasciolosis humana en Neuquén. Medicina 65:207-212.

Sanabria R, Ceballos L, Moreno L, Romero J, Lanusse C, Alvarez L. 2013. Identification of a field isolate of Fasciola hepatica resistant to albendazole and susceptible to triclabendazole. Vet Parasitol. 193(1-3):105-10.

Sanabria R, Mouzet R, Courtioux B, Vignoles P, Rondelaud D, Dreyfuss G, Cabaret J, Romero J. 2012. Intermediate snail hosts of French Fasciola hepatica: Lymnaea neotropica and Lymnaea viatrix are better hosts than local Galba truncatula. Parasitol Res. 111(5)2011-2016.

SEY O. 1991. CRC Handbook of the Zoology of Amphistomes. CRC press Inc. Boca Ratón, Florida.

Shaw N, McGuire S. 2017. Understanding the use of geographical information systems (GIS) in health informatics research: A review. J Innov Health Inform. 24(2):940. 
Silvestre A, Cabaret J. 2002. Mutation in position 167 of isotype 1 betatubulin gene of Trichostrongylid nematodes: role in benzimidazole resistance? Mol Biochem Parasitol. 120(2):297-300.

Spithill TW, Dalton JP. 1998. Progress in development of liver fluke vaccines, Parasitol Today. 14(6):224-227.

Stanley CJ, Goodacre S, Wade C, Stothard JR. 2014.The population genetic structure of Biomphalaria choanomphala in Lake Victoria, East Africa: implications for schistosomiasis transmission. Parasit Vectors. $7: 524$

Thaddeus K, Graczy K, Bernard F. Development of Fasciola hepatica in intermediate host. En: JP Dalton, ed. London; 1999. p.31-43.

Thrusfield, M. (1990) Epidemiología Veterinaria. Editorial ACRIBIA, S.A. Zaragoza, España. 339p

Torgerson P, Claxton J. Epidemiology and control. En: JP Dalton, ed. London; 1999. p.544.

Toth G, Gaspari Z, Jurka J. 2000. Microsatellites in different eukaryotic genomes: survey and analysis. Genome Res 10(7):967-981.

Trouvé S, Degen L, Meunier C, Tirard C, Hurtrez-Boussès S, Durand P, Guégan JF, Goudet J, Renaud F. 2009. Microsatellites in the hermaphroditic snail, Lymnaea truncatula, intermediate host of the liver fluke, Fasciola hepatica. Mol Ecol.9(10):1662-1664. 
Venturini L. 1990. El ciclo de Fasciola hepatica Linneo 1758 en Lymnaea viatrix d'Orbigny 1835: su duración y las formas juveniles presentes con temperatura de verano. Vet Arg. 7(62): 84-90.

Vercruysse J, Holdsworth P, Letonja T, Barth D, Conder G, Hamamoto K, Okano K. 2001. International harmonisation of Anthelmintic Efficacy Guidelines. Vet Parasitol. 96(3):171-193.

Vidigal T, Spatz L, Kissinger J, Redondo R, Pires E, Simpson A, Carvalho O. 2004. Analysis of the First and Second Internal Transcribed Spacer Sequences of the Ribosomal DNA in Biomphalaria tenagophila Complex (Mollusca: Planorbidae). Mem Inst Oswaldo Cruz. 99:153-158.

Vignoles P, Novobilský A, Höglund J, Kašný Ma, Pankrác J, Dreyfuss G, Pointier J, Rondelaud D. 2014. Lymnaea cubensis, an experimental intermediate host for Fascioloides magna. Fol Parasitol 61(2):185-188.

Vignoles P, Dreyfuss G, Rondelaud D. 2015. Fasciola hepatica: comparative metacercaria productions in experimentally-infected Galba truncatula and Pseudosuccinea columella. Parasite. 22:15.

Vignoles P, Rondelaud D, Dreyfuss G. 2016. Aptitude of Lymnaea palustris and L. stagnalis to Fasciola hepatica larval development through the infection of several successive generations of 4-mm-high snails. Parasitol Res. 115(6):2263-8.

Vilas R, Vazquez-Prieto S, Paniagua E. 2012. Contrasting patterns of population genetic structure of Fasciola hepatica from cattle and sheep: 
implications for the evolution of anthelmintic resistance. Infect Genet Evol. 12(1):45-52.

Wullschleger EB, Jokela J. 2002. Morphological plasticity and divergence in life history traits between two closely related freshwater snails, Lymnaea ovata and Lymnaea peregra. J Moll Stud. 68(1):1-5. 